\title{
Evaluation of gem-diacetates as alternative reagents for enzymatic regio- and stereoselective acylation of alcohols
}

\author{
Dominik Koszelewski, ${ }^{*}$ Anna Brodzka, Arleta Madej, Damian Trzepizur and Ryszard Ostaszewski* \\ Institute of Organic Chemistry Polish Academy of Sciences, Kasprzaka 44/52, o1-224 Warszawa, Poland \\ dominik.koszelewski@icho.edu.pl \\ ryszard.ostaszewski@icho.edu.pl
}

\section{Table of contents:}

1. The standard curve for compound za (Fig Si)

2. The studies on acylation of compound $3 n$ (Scheme $S_{1}$ )

3. ${ }^{1} \mathrm{H}$ NMR and $\left.{ }^{13} \mathrm{C}{ }^{1} \mathrm{H}\right\}$ NMR spectra (Fig $\left.\mathrm{S}_{2}-\mathrm{S}_{51}\right)$

4. GC and HPLC traces (Fig $\mathrm{S}_{52}$-S66) 
1. The standard curve for compound $3 a$

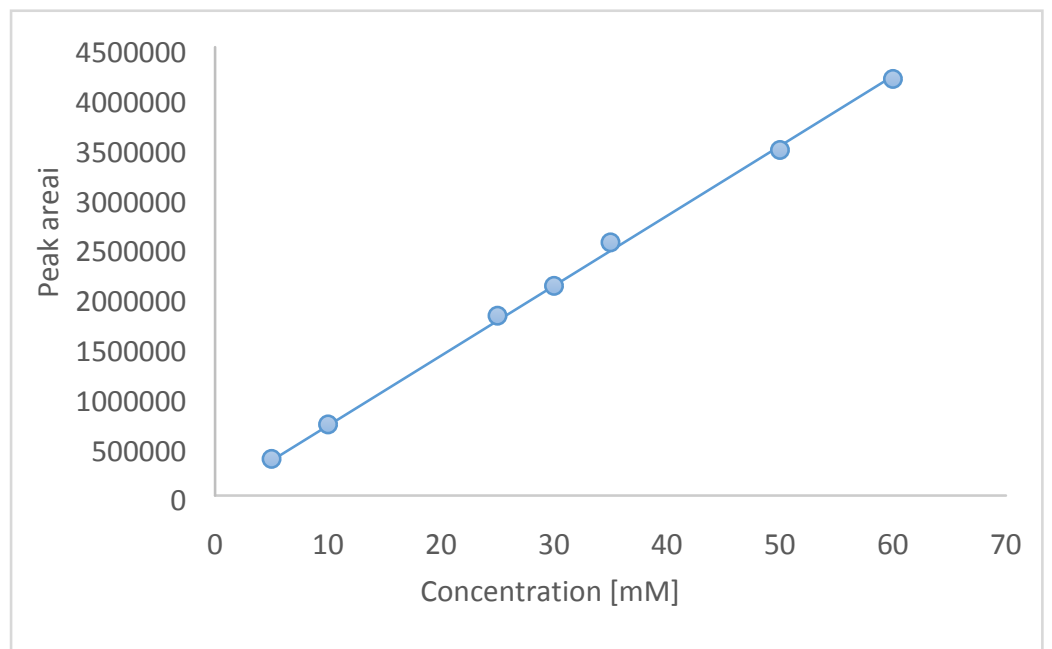

Fig S1. The standard curve for compound za

2. The studies on acylation of compound $3 n$

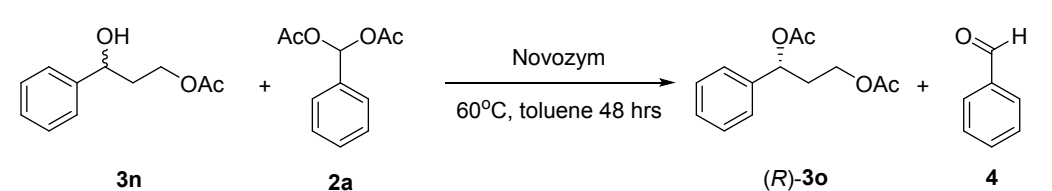

Scheme S1. Enzymatic acylation of 3n with acylal 2a. Reaction conditions: compound 3n (1 mmol), benzylidene 1,1-diacetate (2a) (1.5 equiv.), and Novozym 435 (20 $\mathrm{mg})$ in toluene $(2 \mathrm{~mL})$ at $60^{\circ} \mathrm{C}$ for $48 \mathrm{hrs}, 200 \mathrm{rpm}$.

3. ${ }^{1} \mathrm{H} N M R$ and ${ }^{13} \mathrm{C}\left\{{ }^{1} \mathrm{H}\right\}$ NMR spectra 


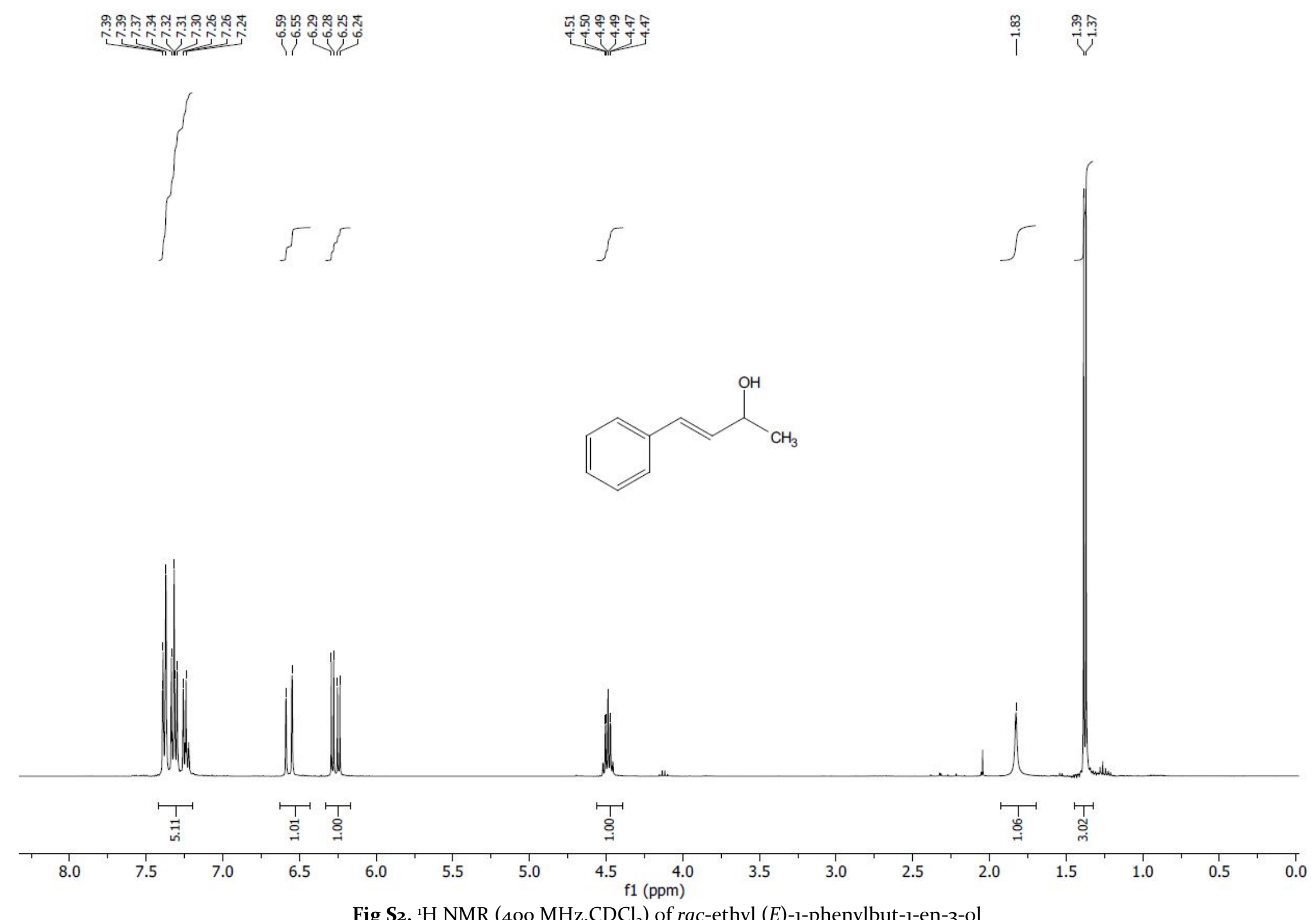

Fig S2. ${ }^{1} \mathrm{H}$ NMR ( $400 \mathrm{MHz}, \mathrm{CDCl}_{3}$ ) of rac-ethyl $(E)$-1-phenylbut-1-en-3-ol 


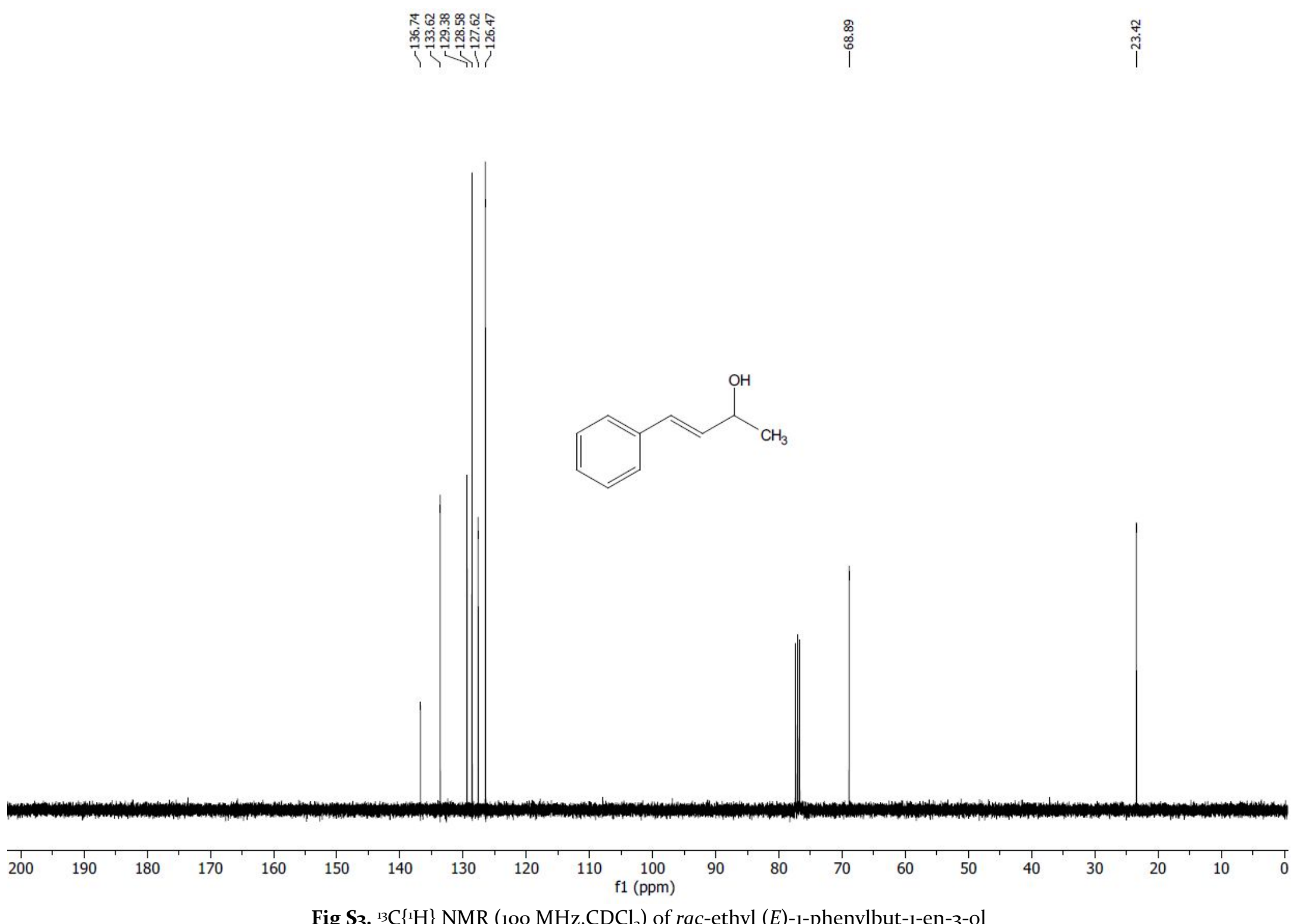




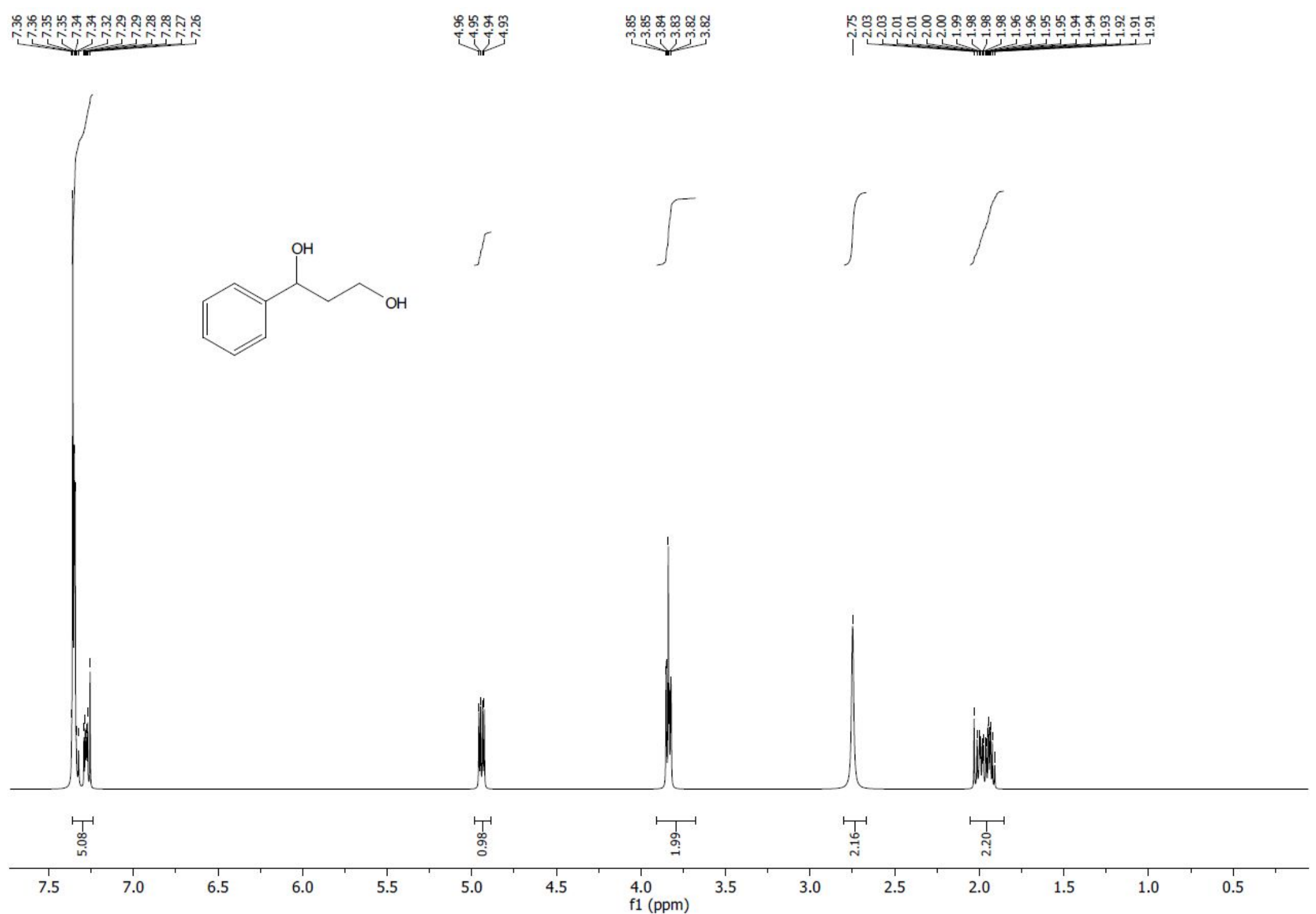

Fig S4. ${ }^{1} \mathrm{H}$ NMR (40o MHz,CDCl 3 ) of rac-1-phenyl-1,3-propanediol 


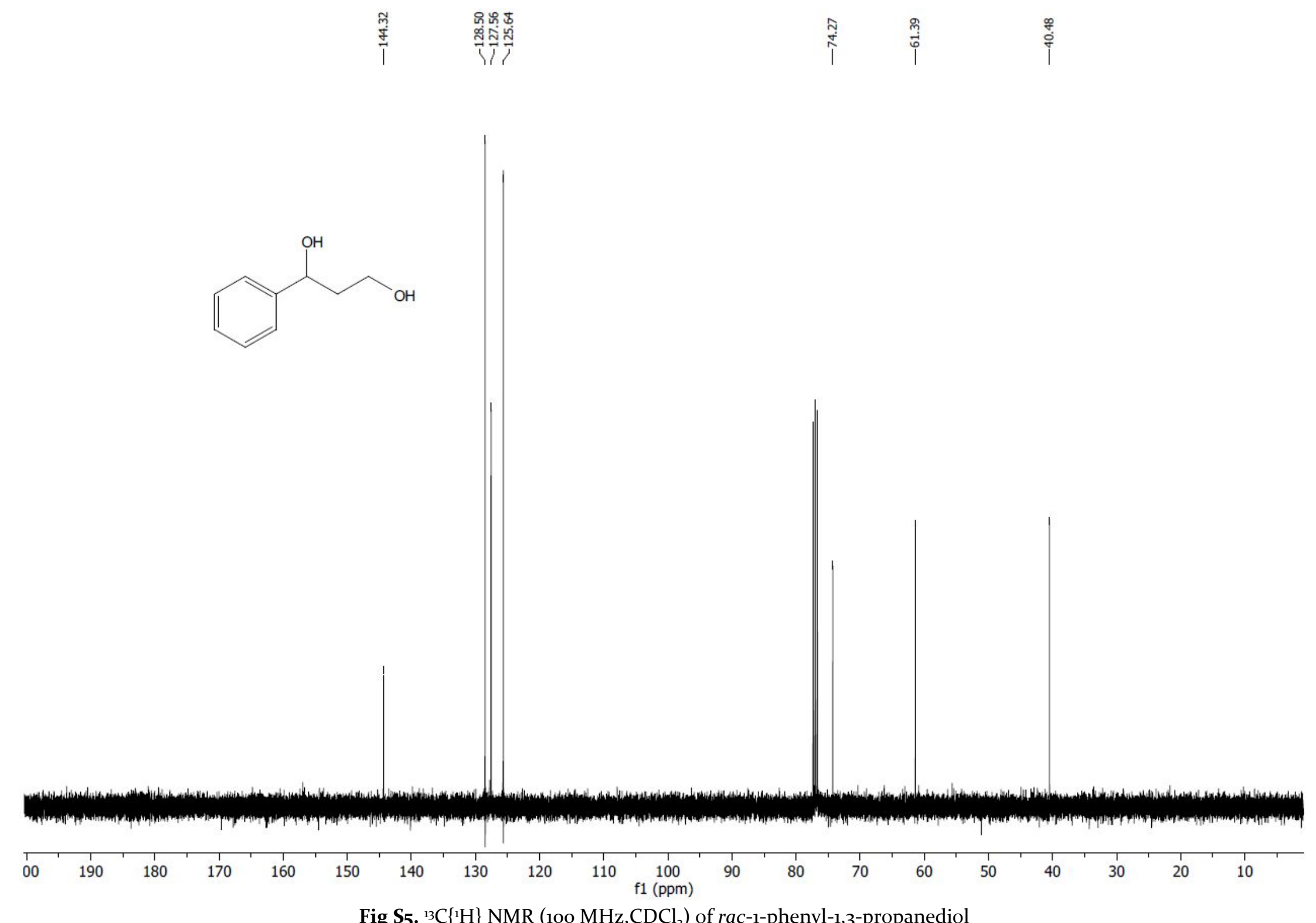




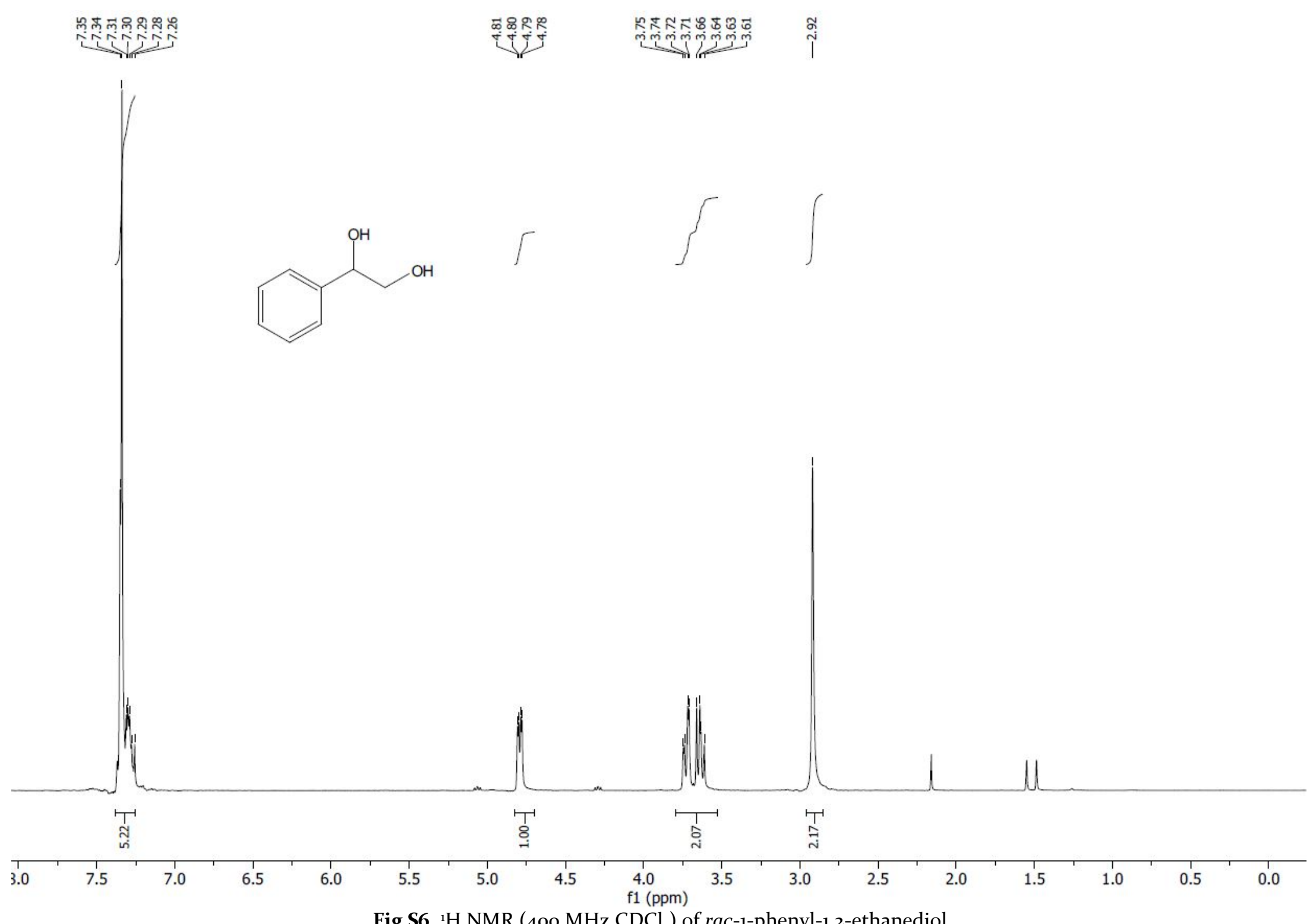

Fig S6. ${ }^{1} \mathrm{H}$ NMR ( $400 \mathrm{MHz}, \mathrm{CDCl}_{3}$ ) of rac-1-phenyl-1,2-ethanediol 


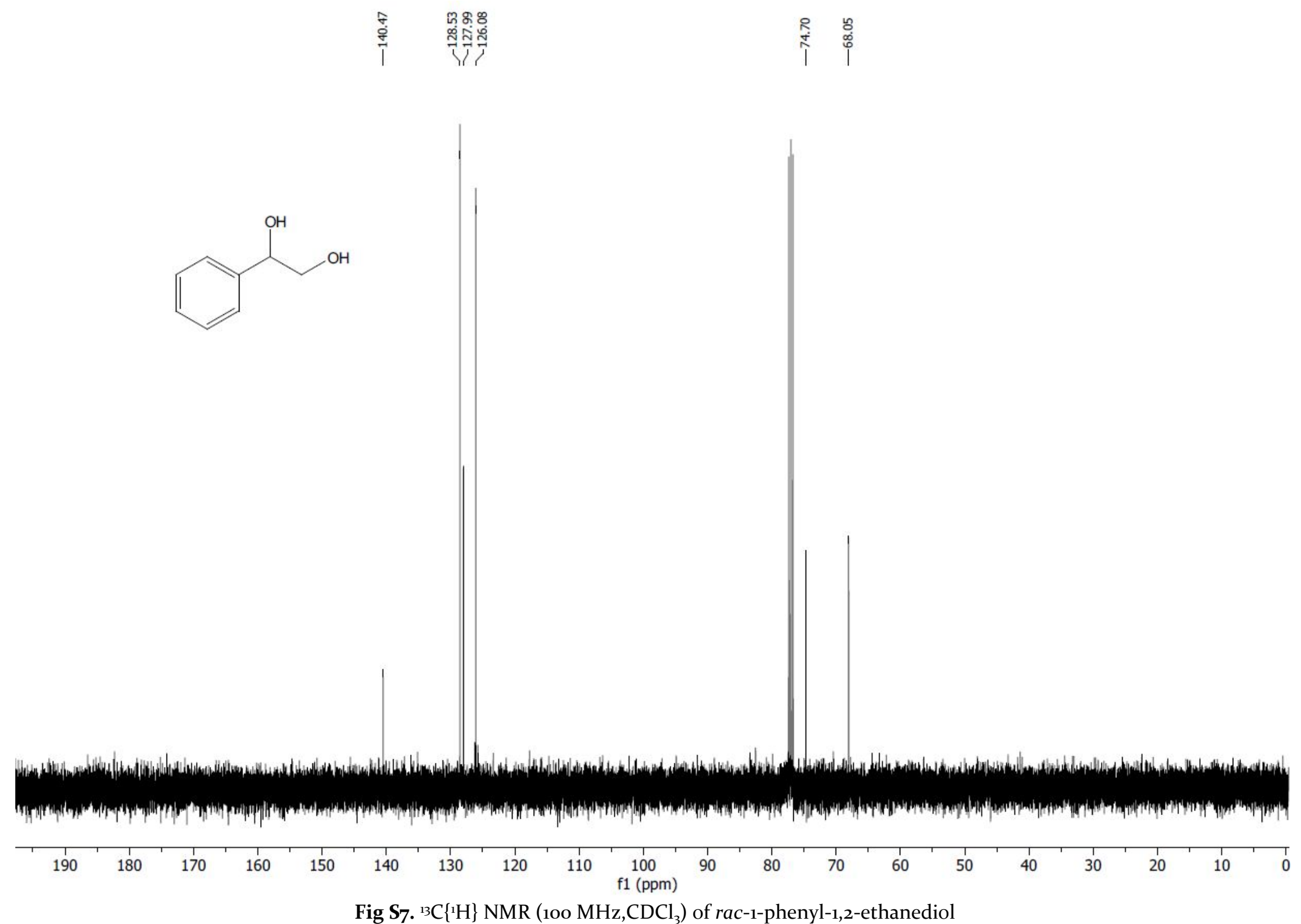

Fig S7. ${ }^{13} \mathrm{C}\left\{{ }^{1} \mathrm{H}\right\}$ NMR (10o MHz,CDCl ) of rac-1-phenyl-1,2-ethanediol 


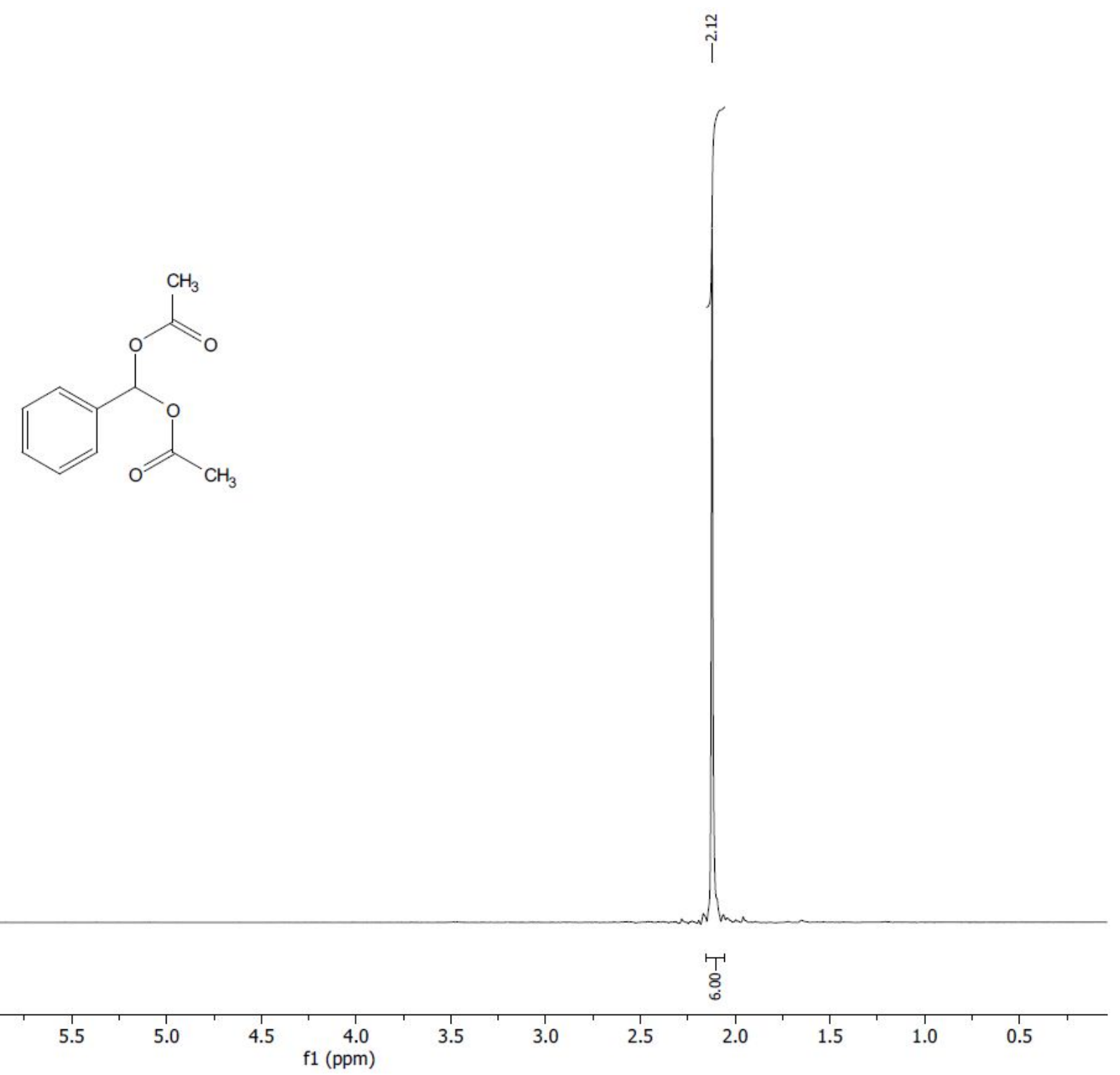

$\iint$

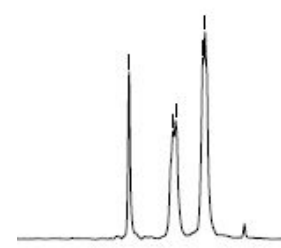

Fig S8. ${ }^{1} \mathrm{H} \mathrm{NMR}\left(400 \mathrm{MHz}, \mathrm{CDCl}_{3}\right.$ ) of benzylidene 1,1-diacetate (2a) 


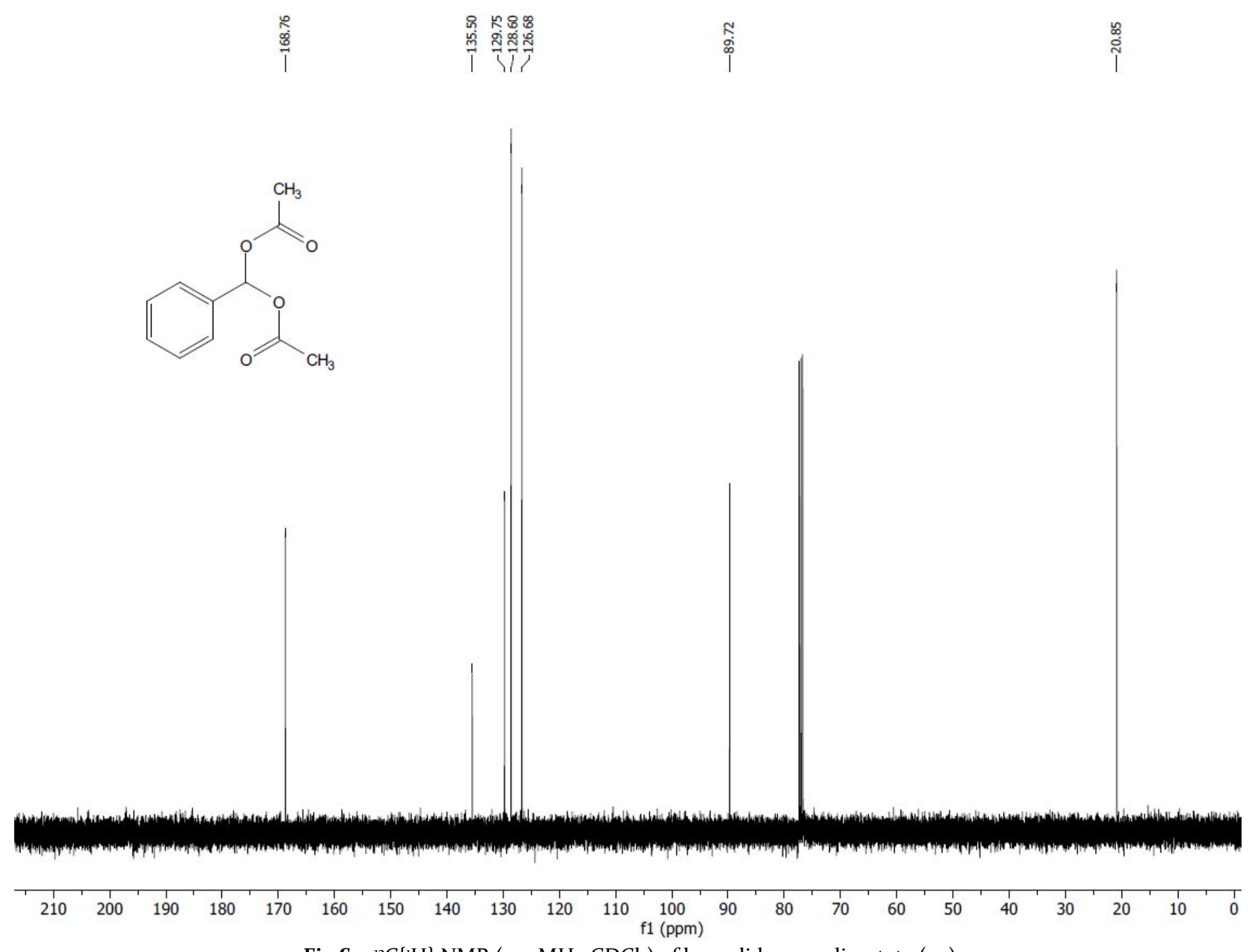

Fig S9. ${ }^{33}\left\{{ }^{1} \mathrm{H}\right\}$ NMR (10o $\left.\mathrm{MHz}, \mathrm{CDCl}_{3}\right)$ of benzylidene 1,1-diacetate (2a) 

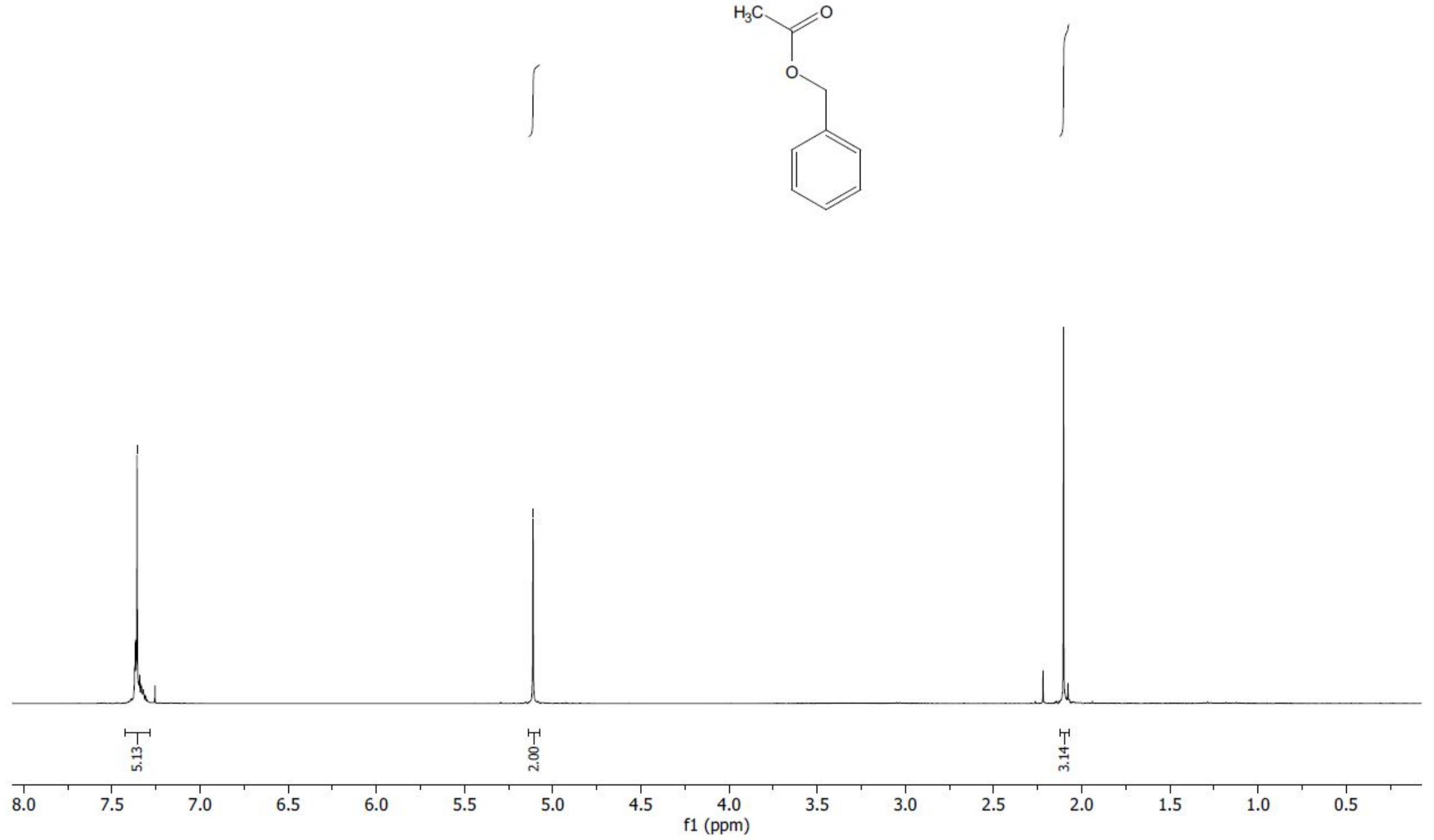

Fig S1o. ${ }^{1} \mathrm{H}$ NMR (400 MHz, $\mathrm{CDCl}_{3}$ ) of benzyl acetate (3a) 


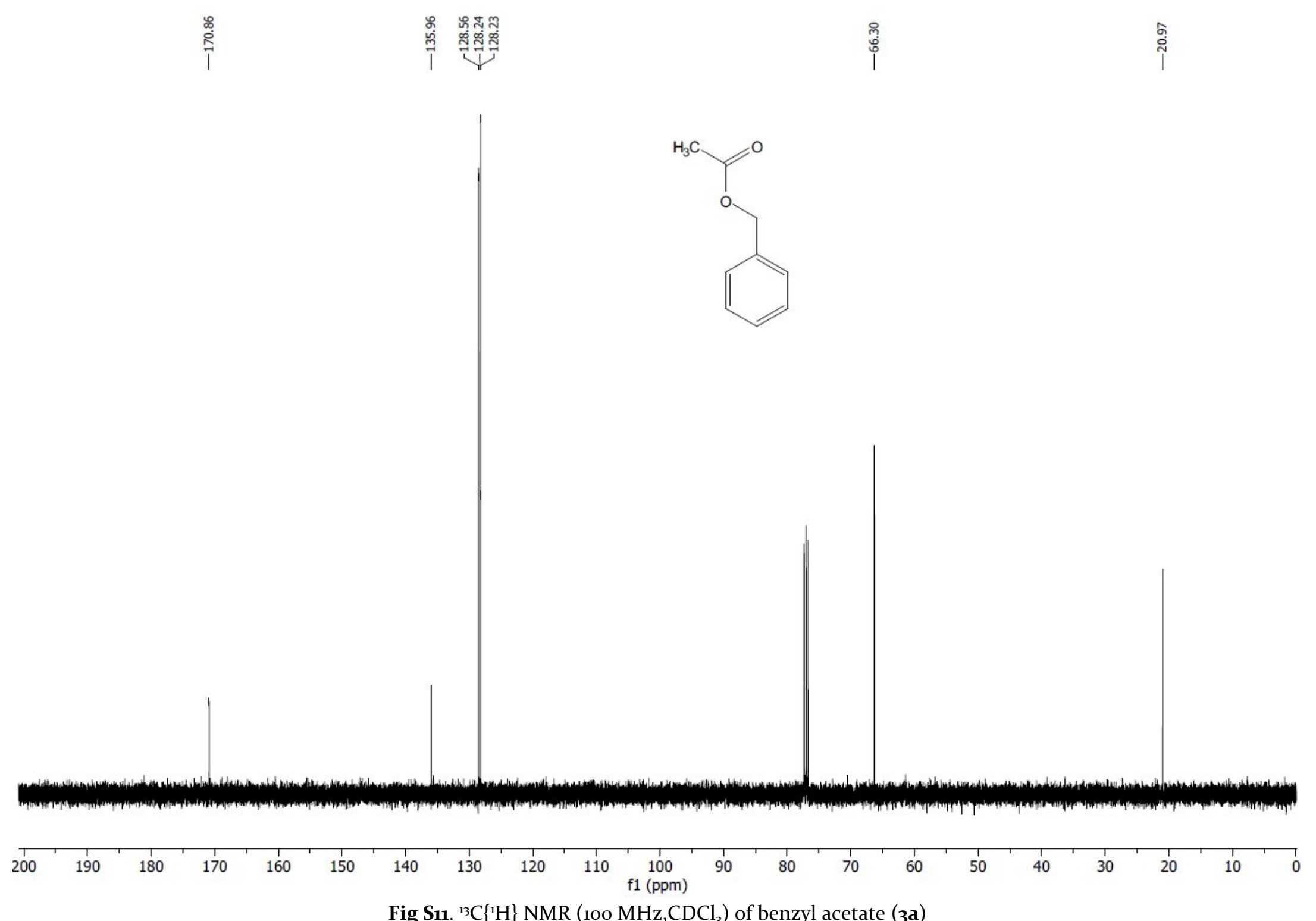




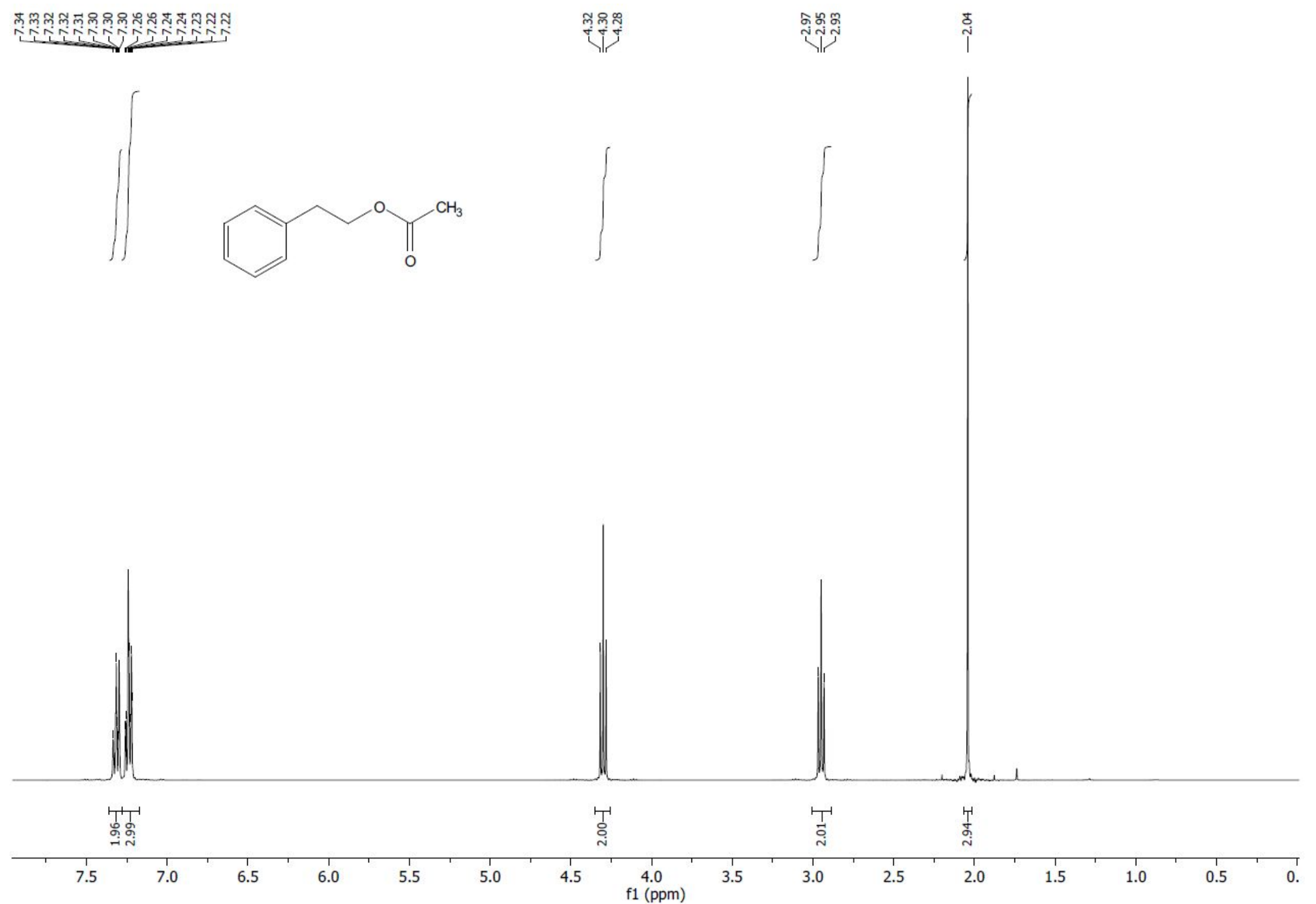

Fig S12. ${ }^{1} \mathrm{H}$ NMR (40o $\mathrm{MHz}, \mathrm{CDCl}_{3}$ ) of 2-phenylethyl acetate (3b) 


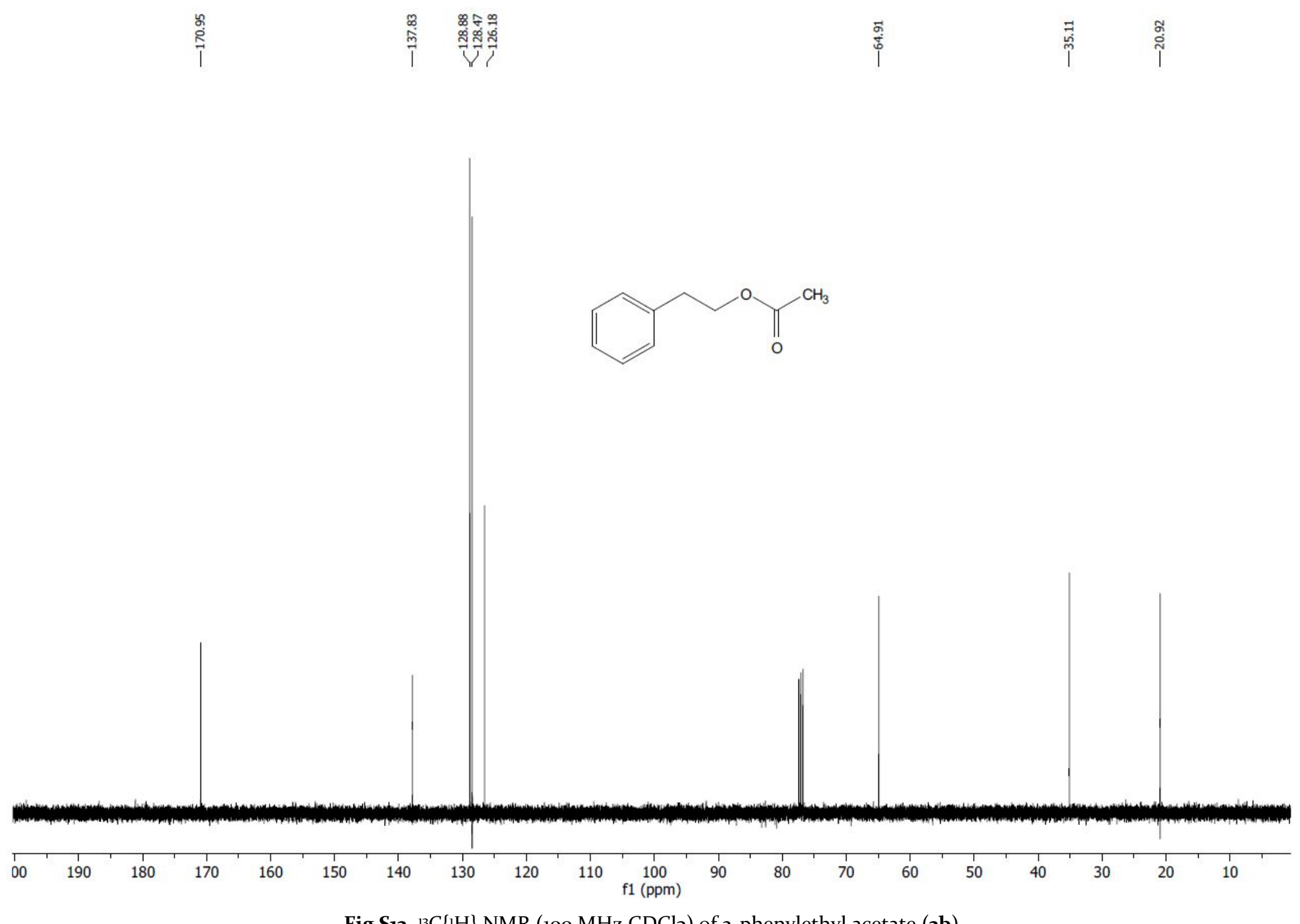

Fig S13. ${ }^{13} \mathrm{C}\left\{{ }^{1} \mathrm{H}\right\}$ NMR (100 MHz, $\left.\mathrm{CDCl}_{3}\right)$ of 2-phenylethyl acetate (3b) 


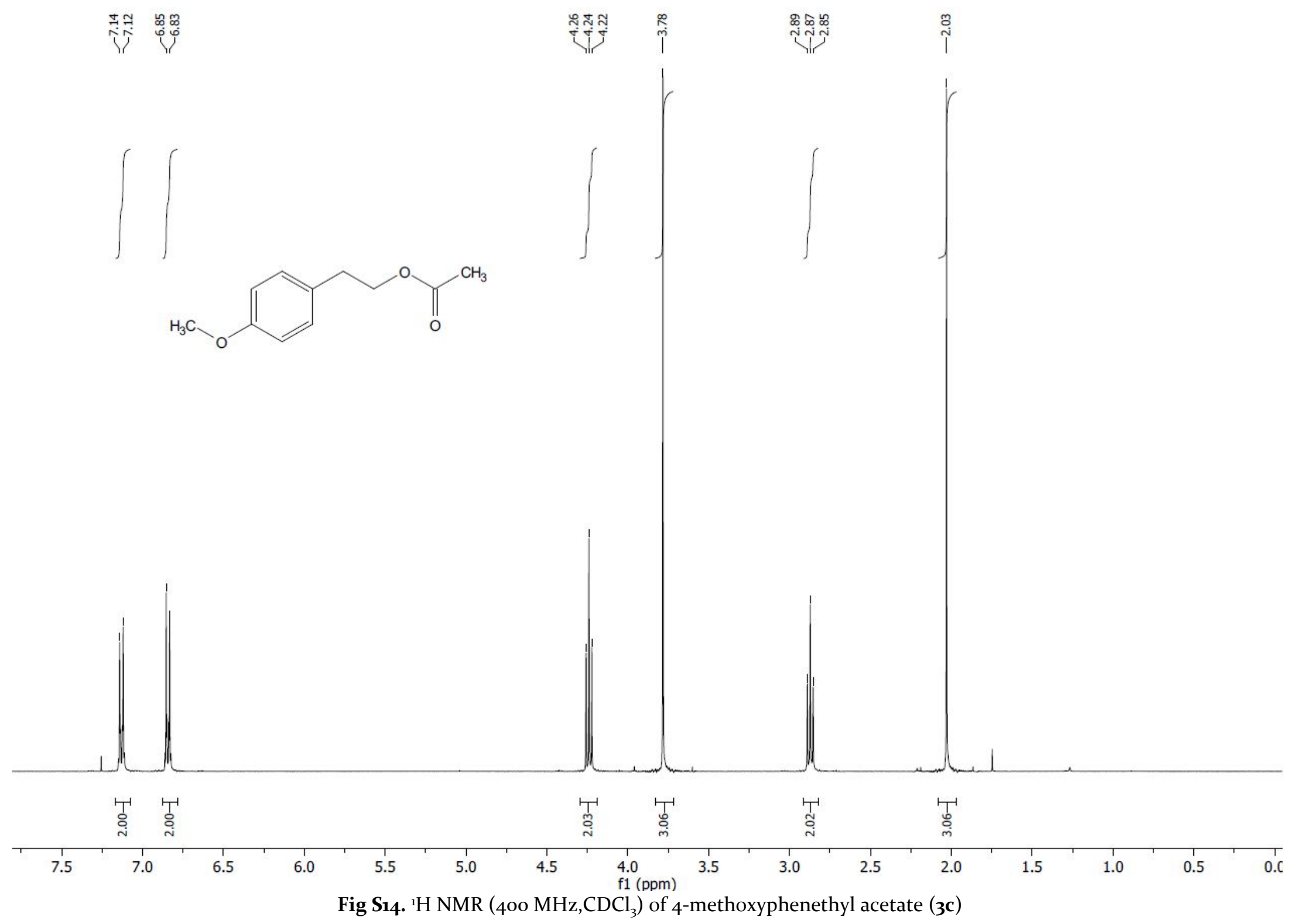




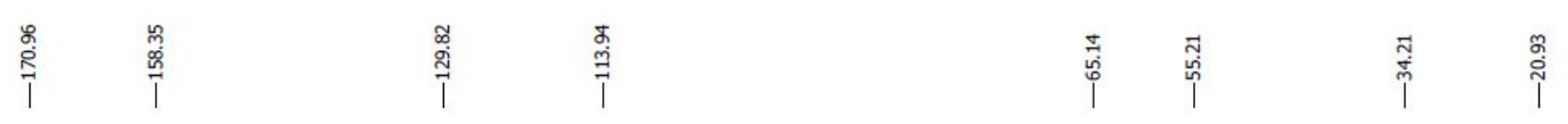

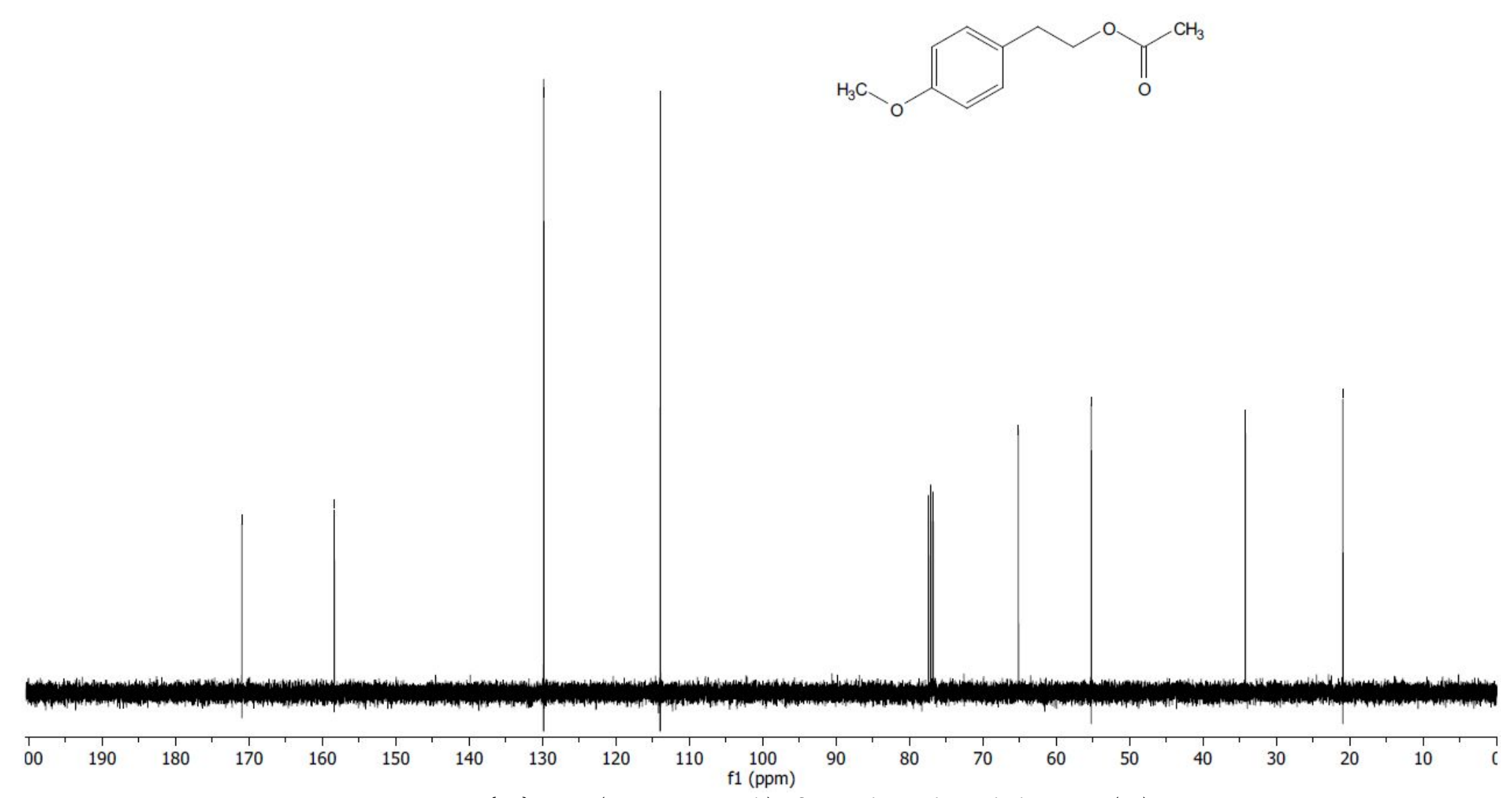

Fig S15. ${ }^{13} \mathrm{C}\left\{{ }^{1} \mathrm{H}\right\}$ NMR (100 MHz, $\mathrm{CDCl}_{3}$ ) of 4-methoxyphenethyl acetate (3c) 

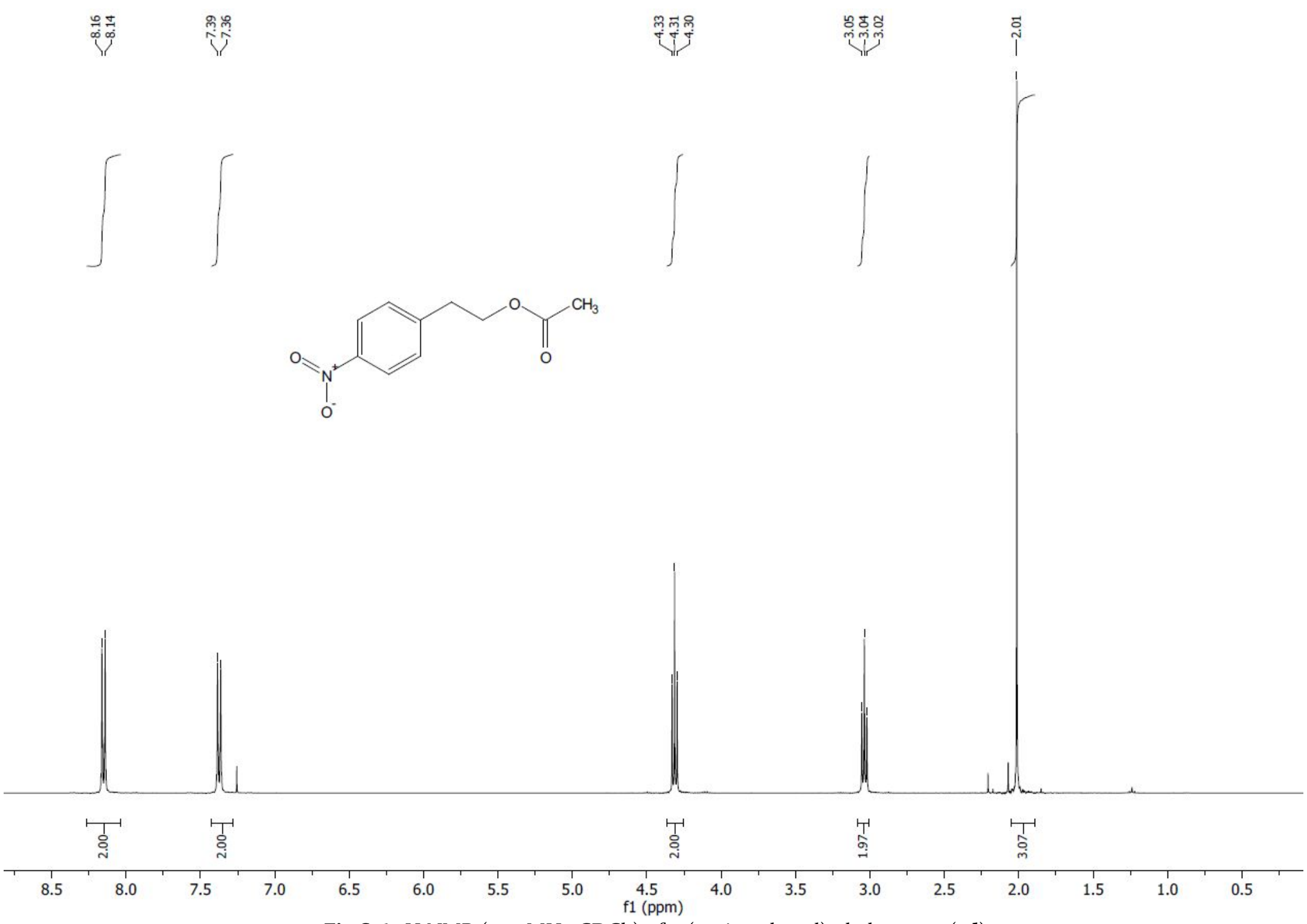

Fig S16. ${ }^{1} \mathrm{H}$ NMR (400 $\mathrm{MHz}, \mathrm{CDCl}_{3}$ ) of 2-(4-nitrophenyl)ethyl acetate (3d) 


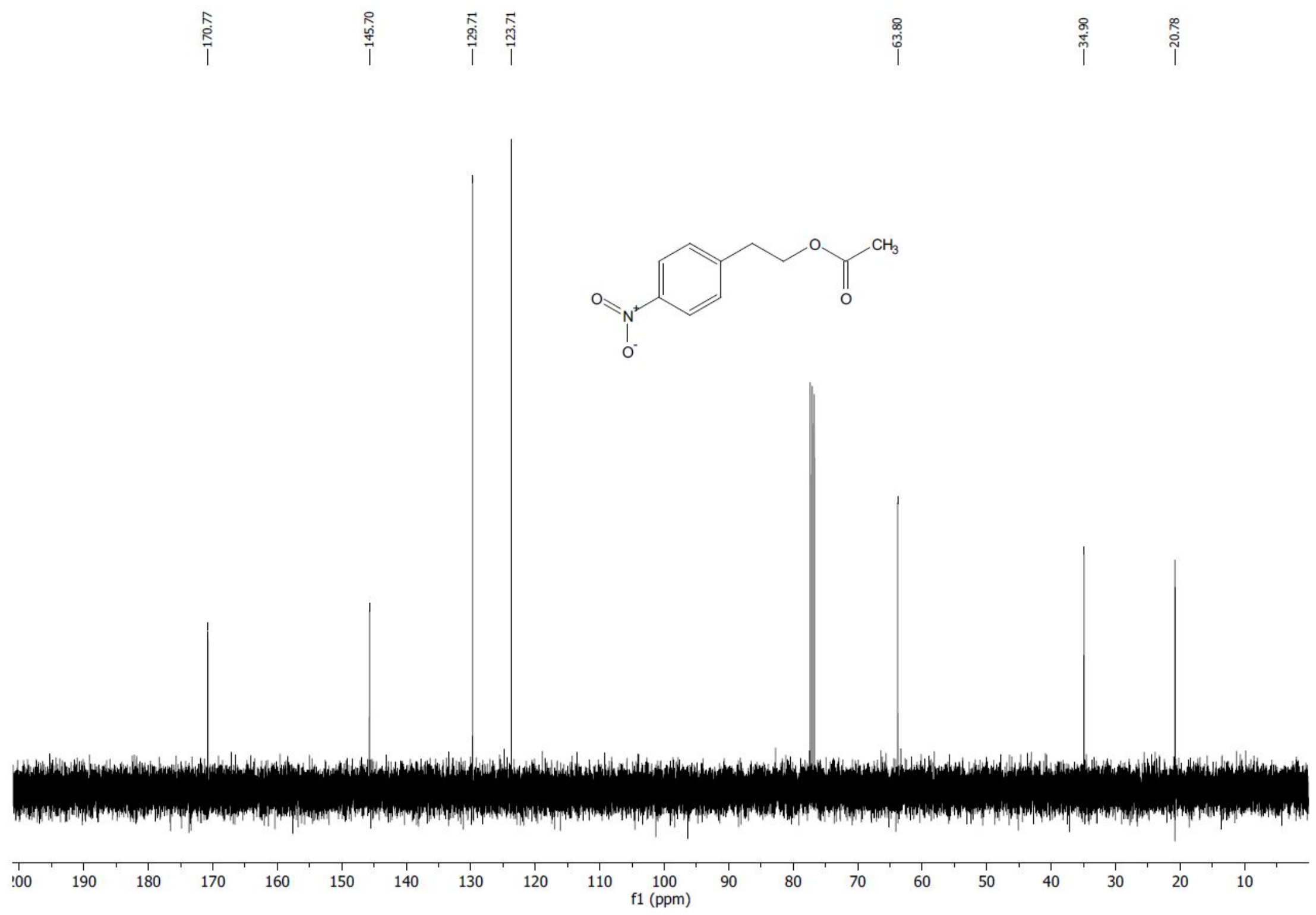

Fig S17. ${ }^{13} C\left\{{ }^{1} \mathrm{H}\right\}$ NMR (100 MHz, $\left.\mathrm{CDCl}_{3}\right)$ of 2-(4-nitrophenyl)ethyl acetate (3d) 

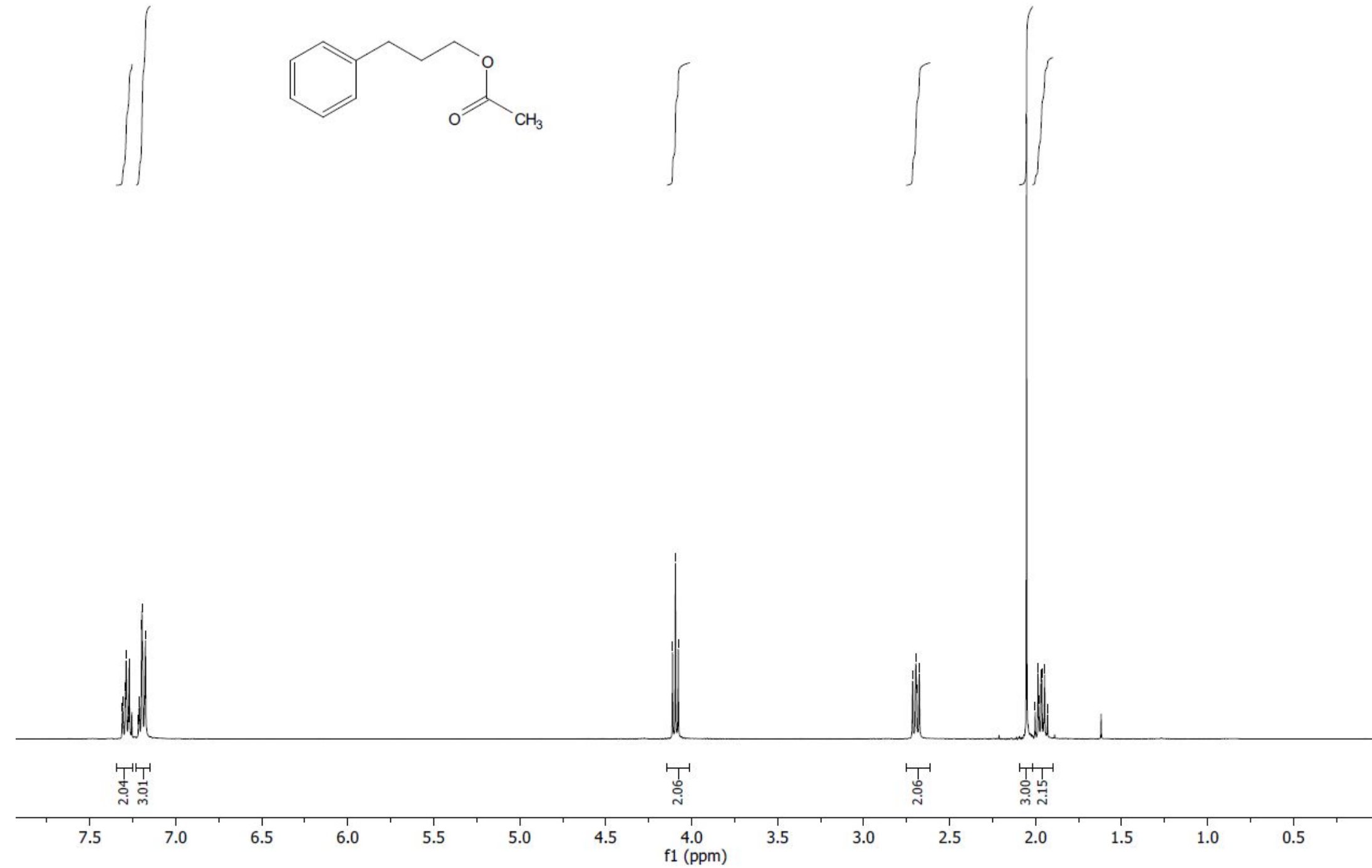

Fig S18. ${ }^{1} \mathrm{H} \mathrm{NMR}\left(400 \mathrm{MHz}, \mathrm{CDCl}_{3}\right.$ ) of 3-phenylpropyl acetate (3e) 


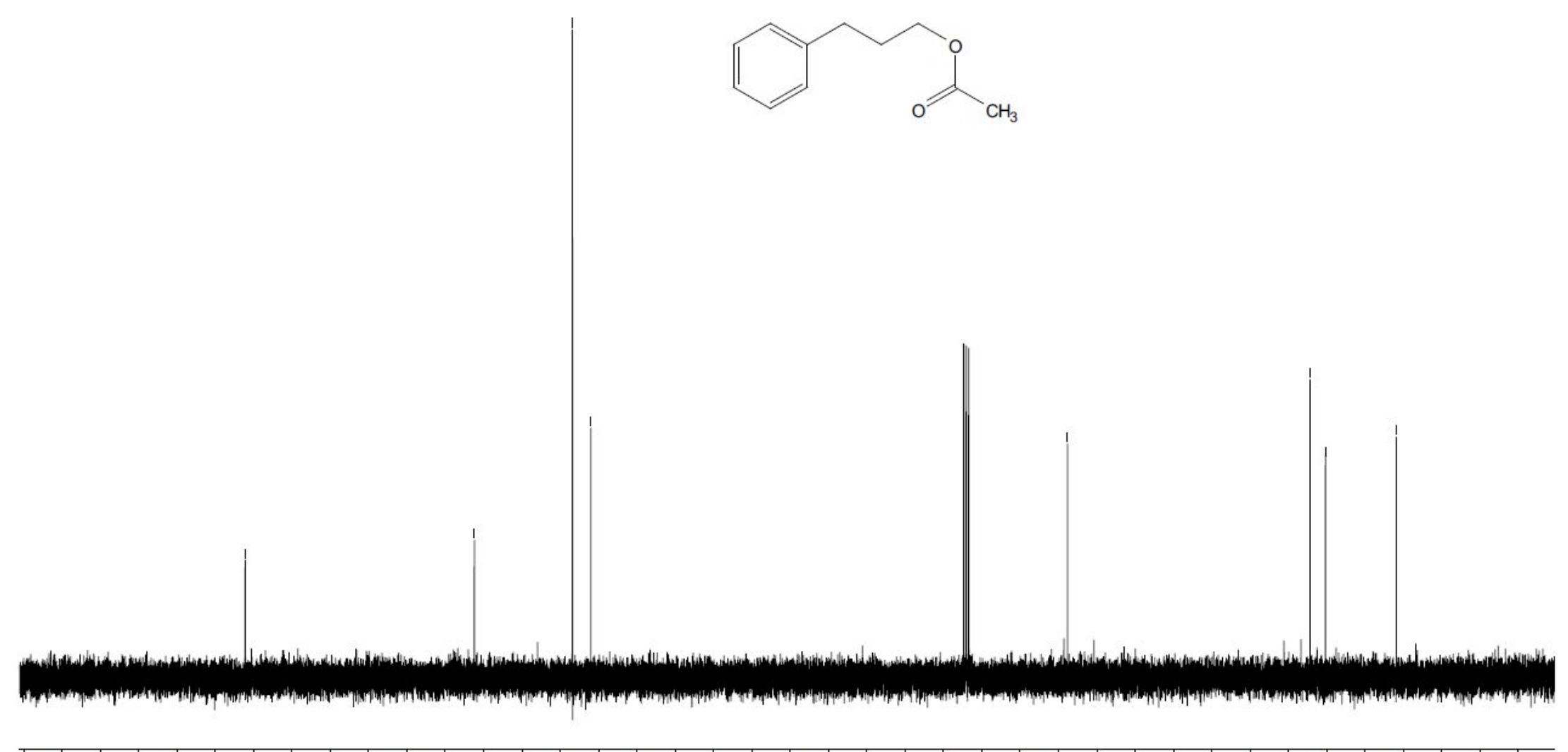

Fig S19. ${ }^{13} \mathrm{C}\left\{{ }^{1} \mathrm{H}\right\}$ NMR (100 $\mathrm{MHz}, \mathrm{CDCl}_{3}$ ) of 3-phenylpropyl acetate (3e) 


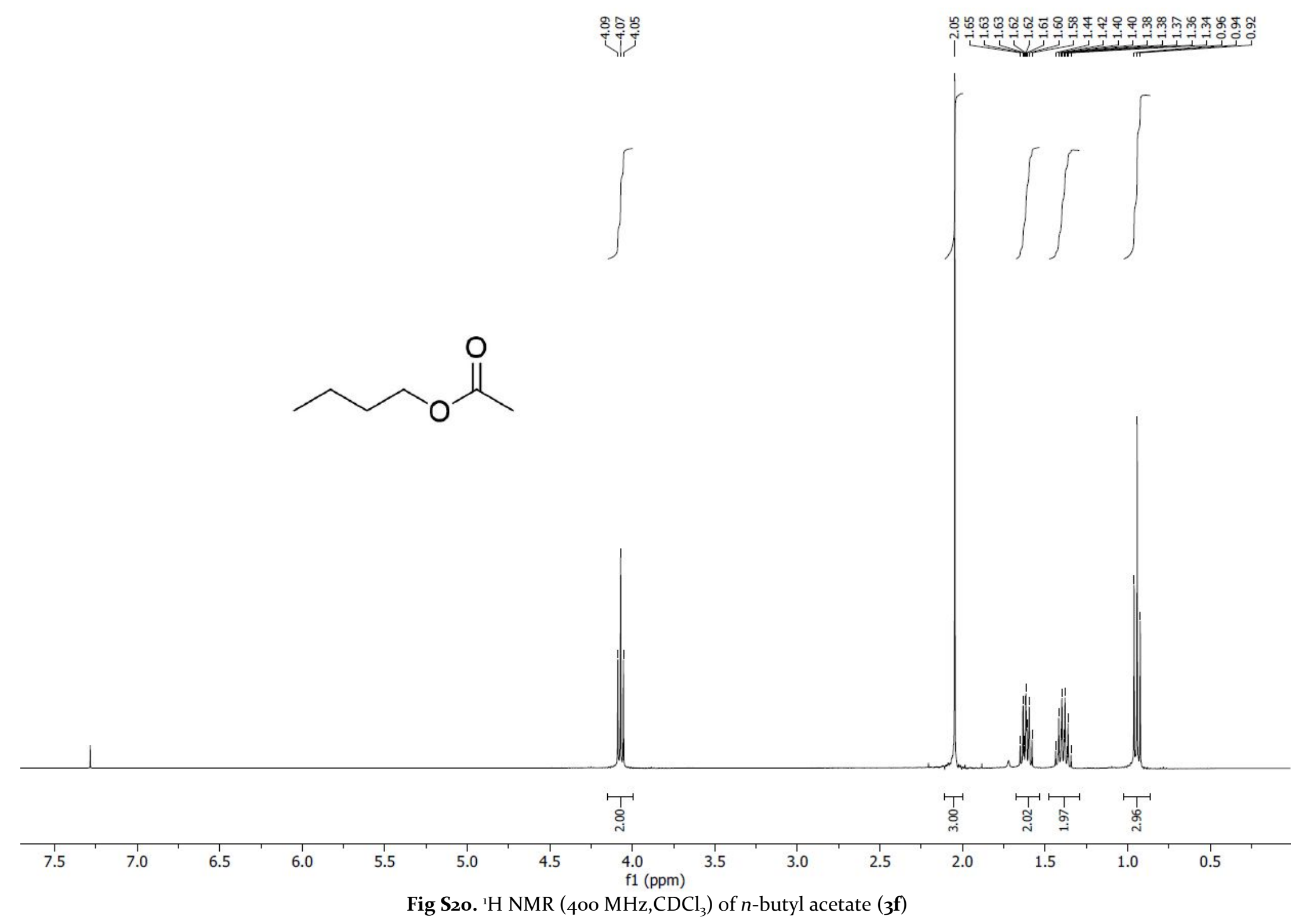




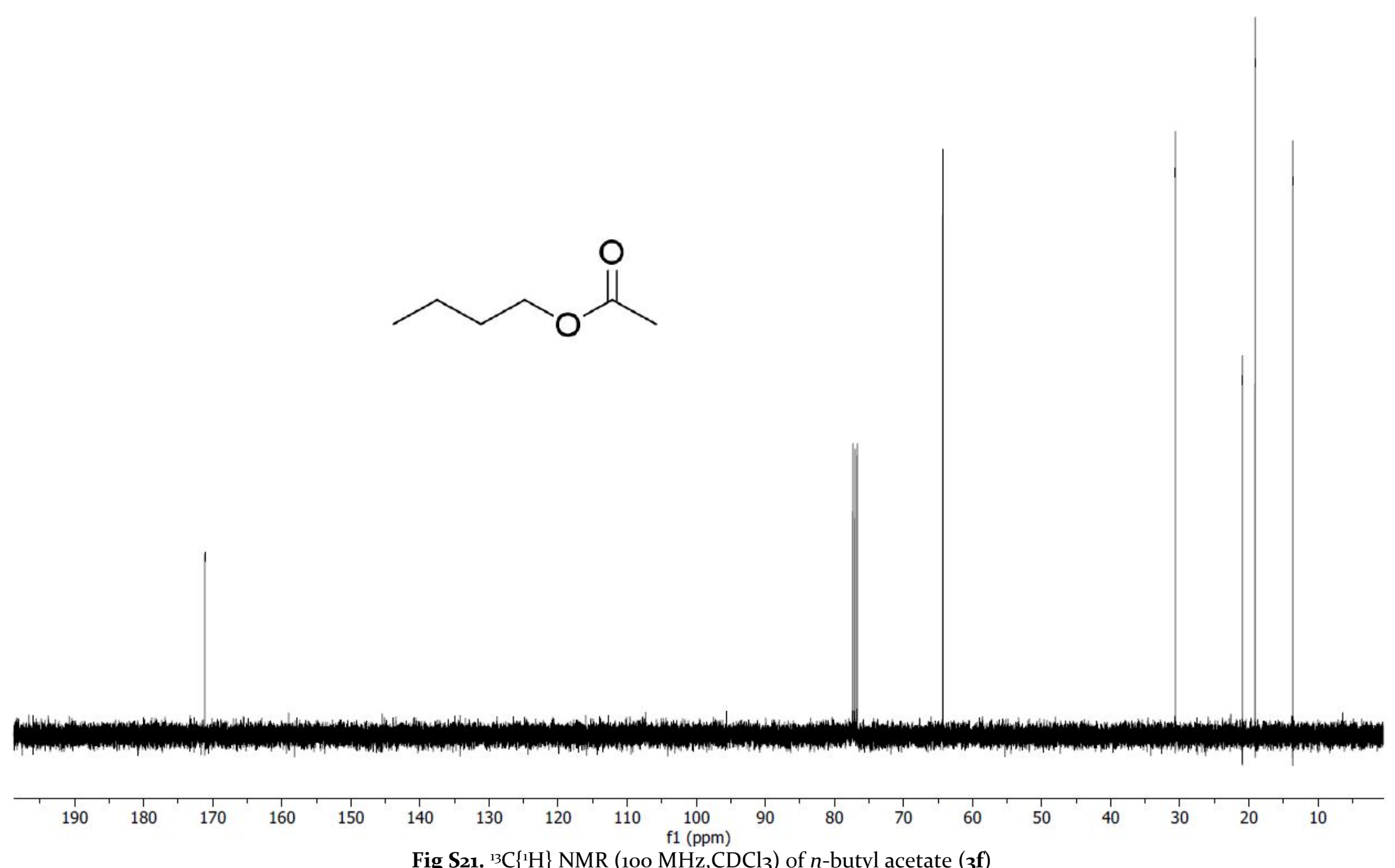

Fig S21. ${ }^{13}{ }^{1}\{\mathrm{H}\}$ NMR (100 $\left.\mathrm{MHz}, \mathrm{CDCl}_{3}\right)$ of $n$-butyl acetate (3f) 


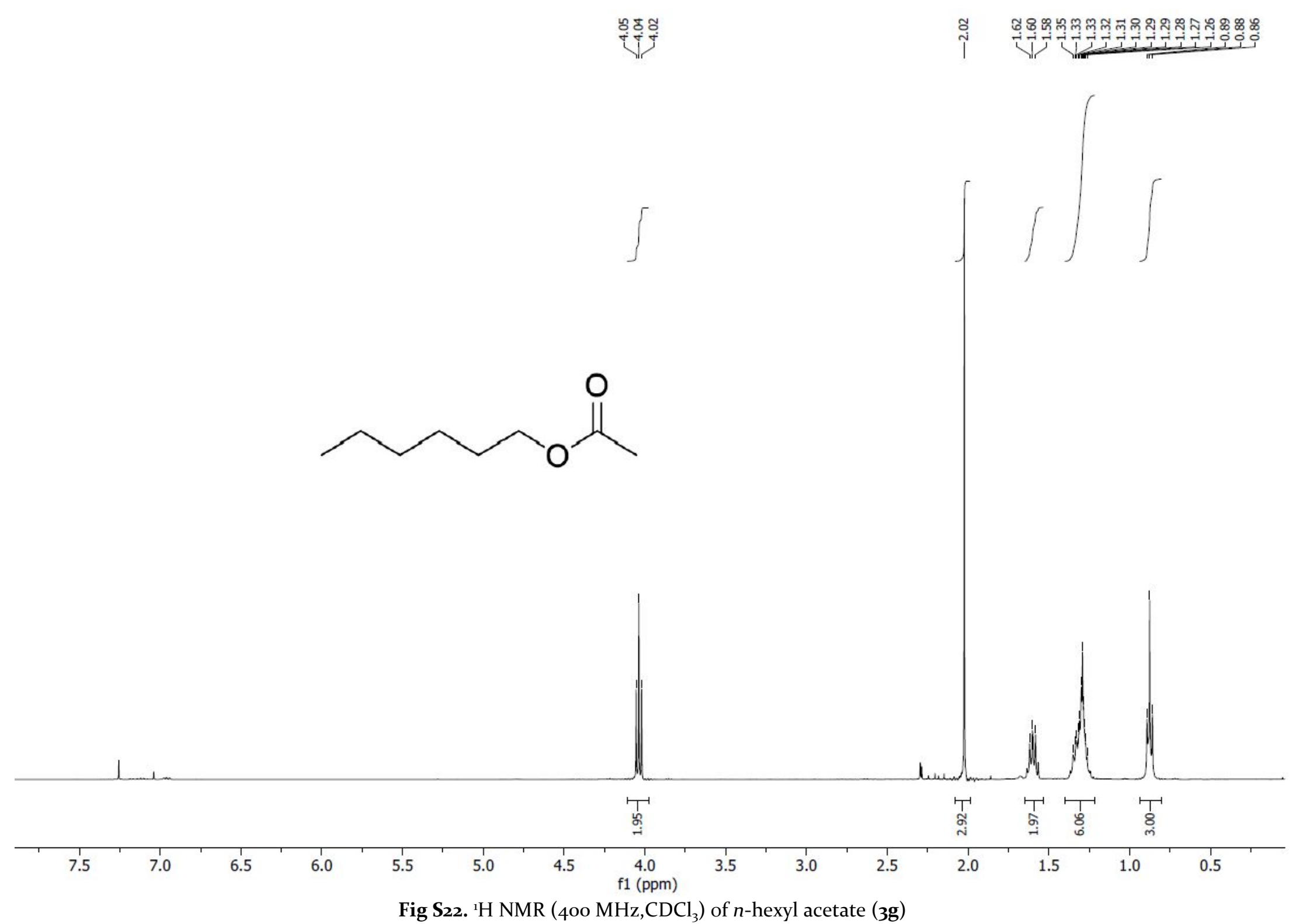




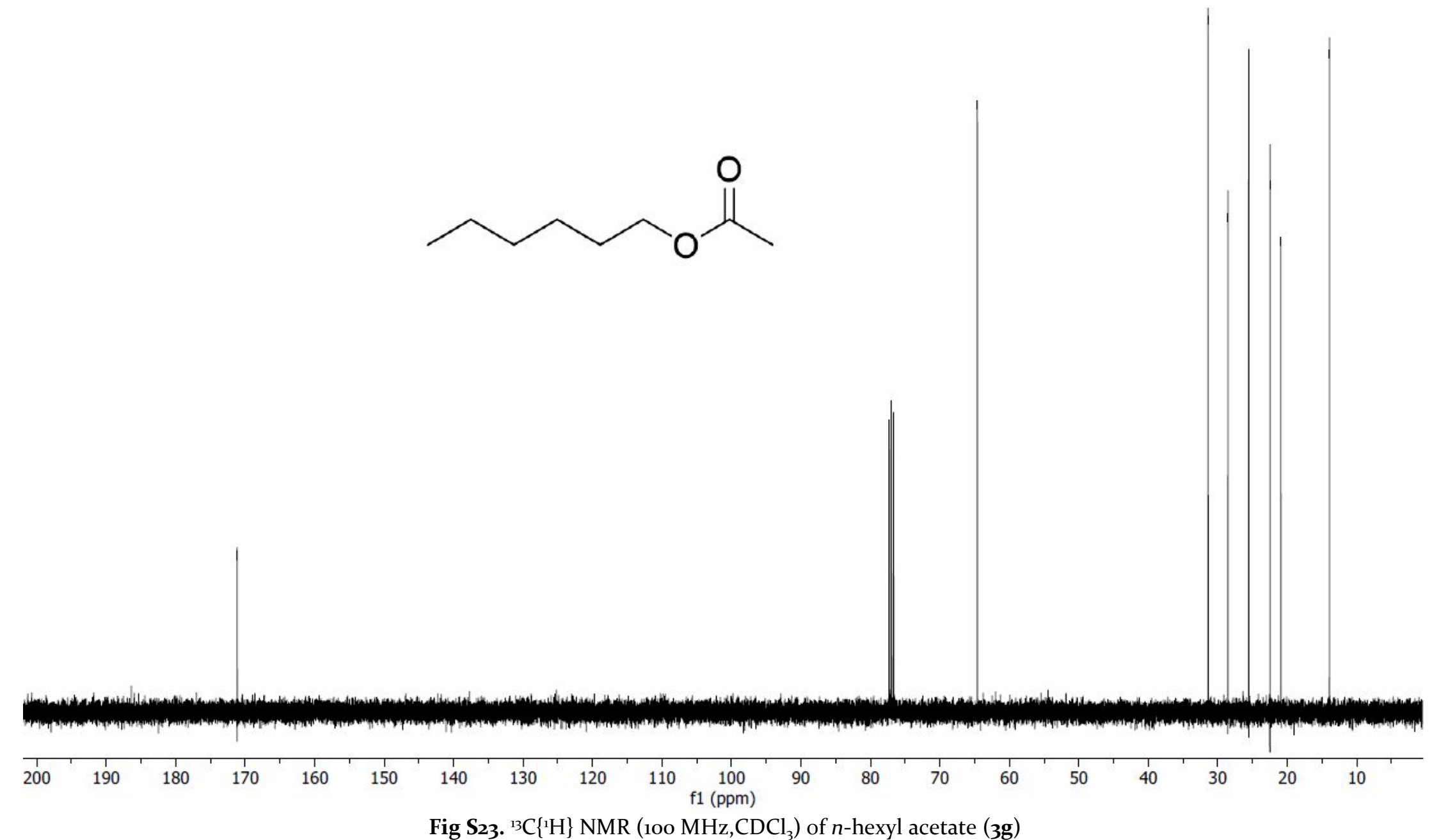



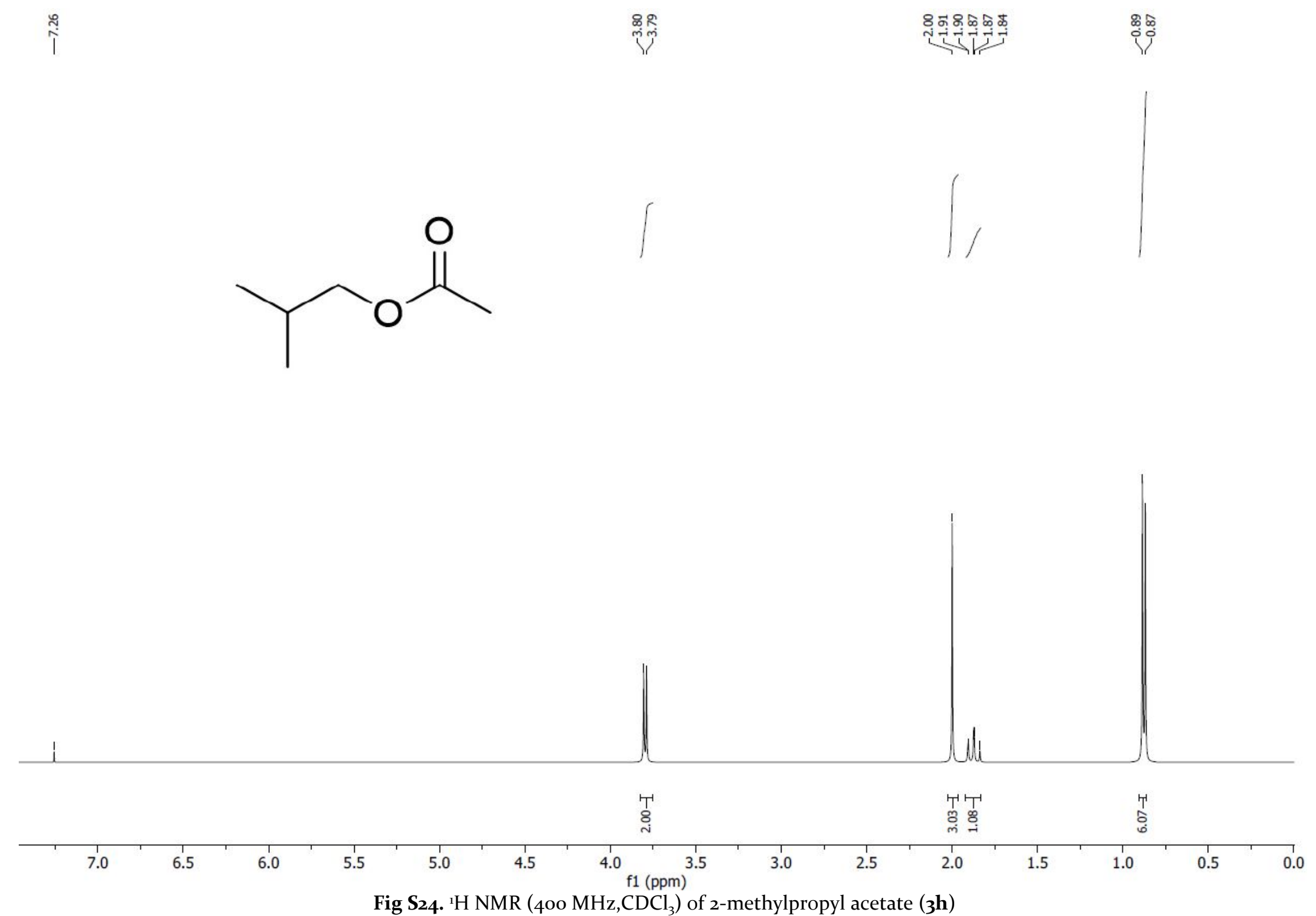


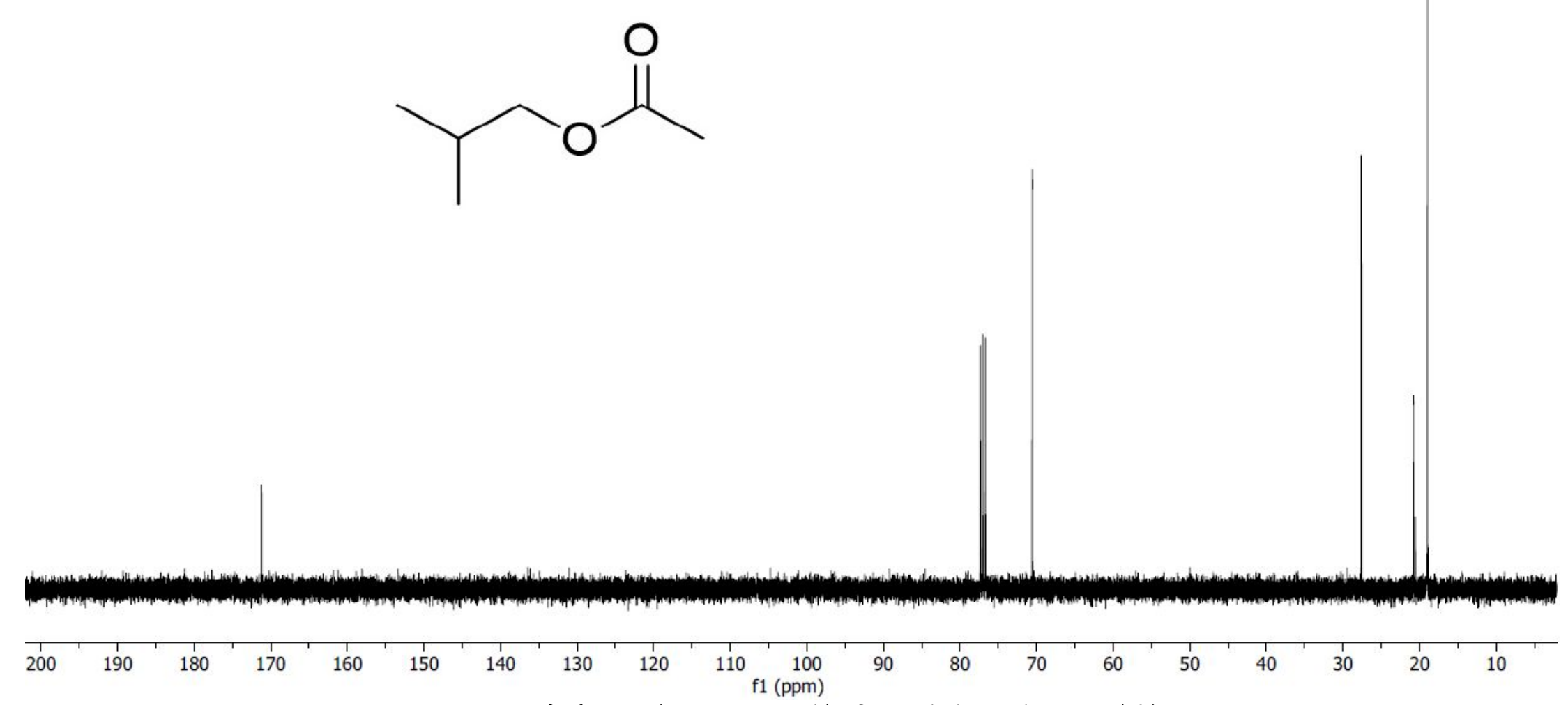

Fig S25. ${ }^{13} \mathrm{C}\left\{{ }^{1} \mathrm{H}\right\}$ NMR (100 MHz, $\left.\mathrm{CDCl}_{3}\right)$ of 2-methylpropyl acetate (3h) 


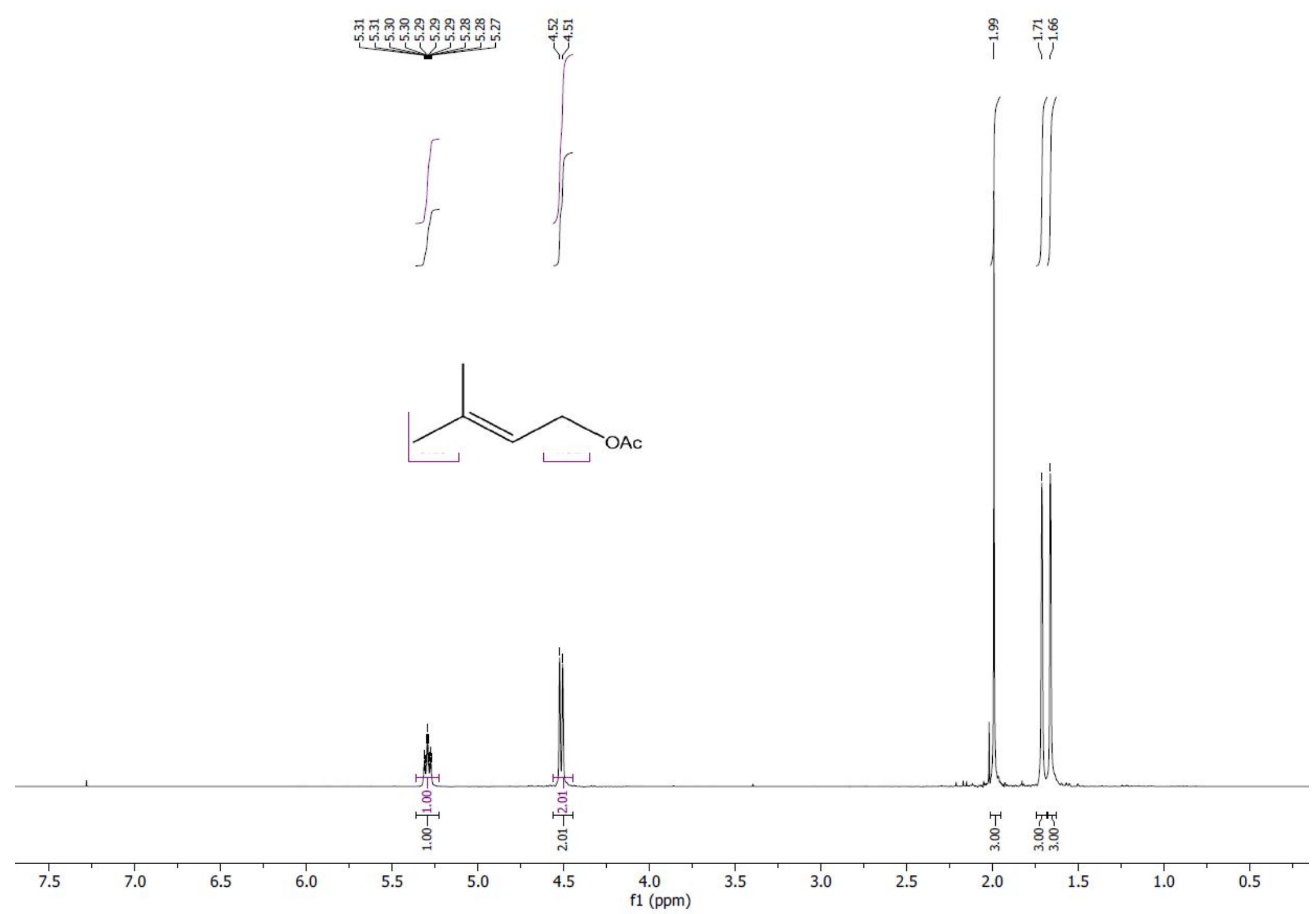

Fig S26. ${ }^{1} \mathrm{H}$ NMR (40o $\mathrm{MHz}, \mathrm{CDCl}_{3}$ ) of 3-methylbut-2-enyl acetate (3i) 


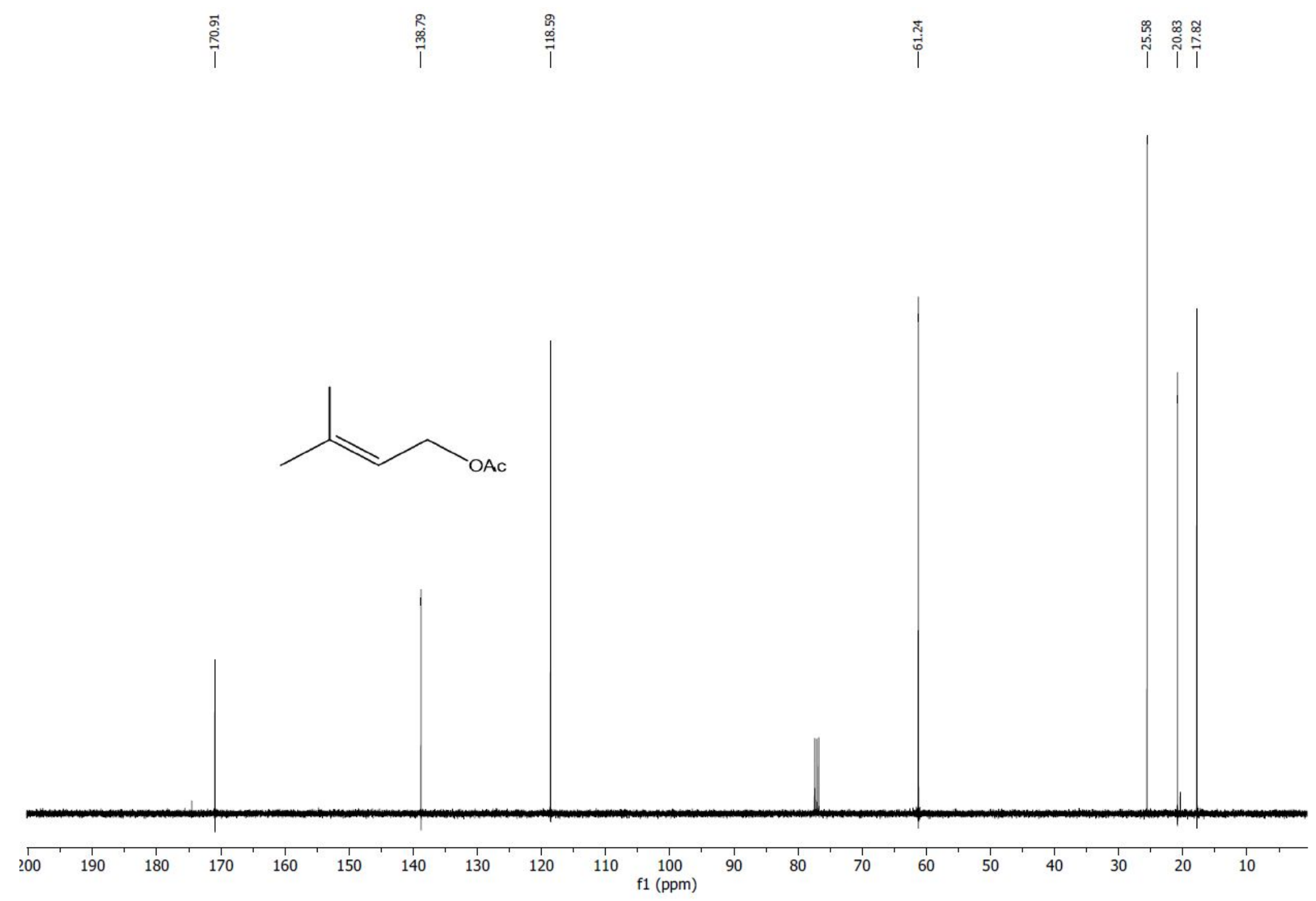

Fig S27. ${ }^{13} \mathrm{C}\left\{{ }^{1} \mathrm{H}\right\}$ NMR (10o $\mathrm{MHz}, \mathrm{CDCl}_{3}$ ) of 3-methylbut-2-enyl acetate (3i) 


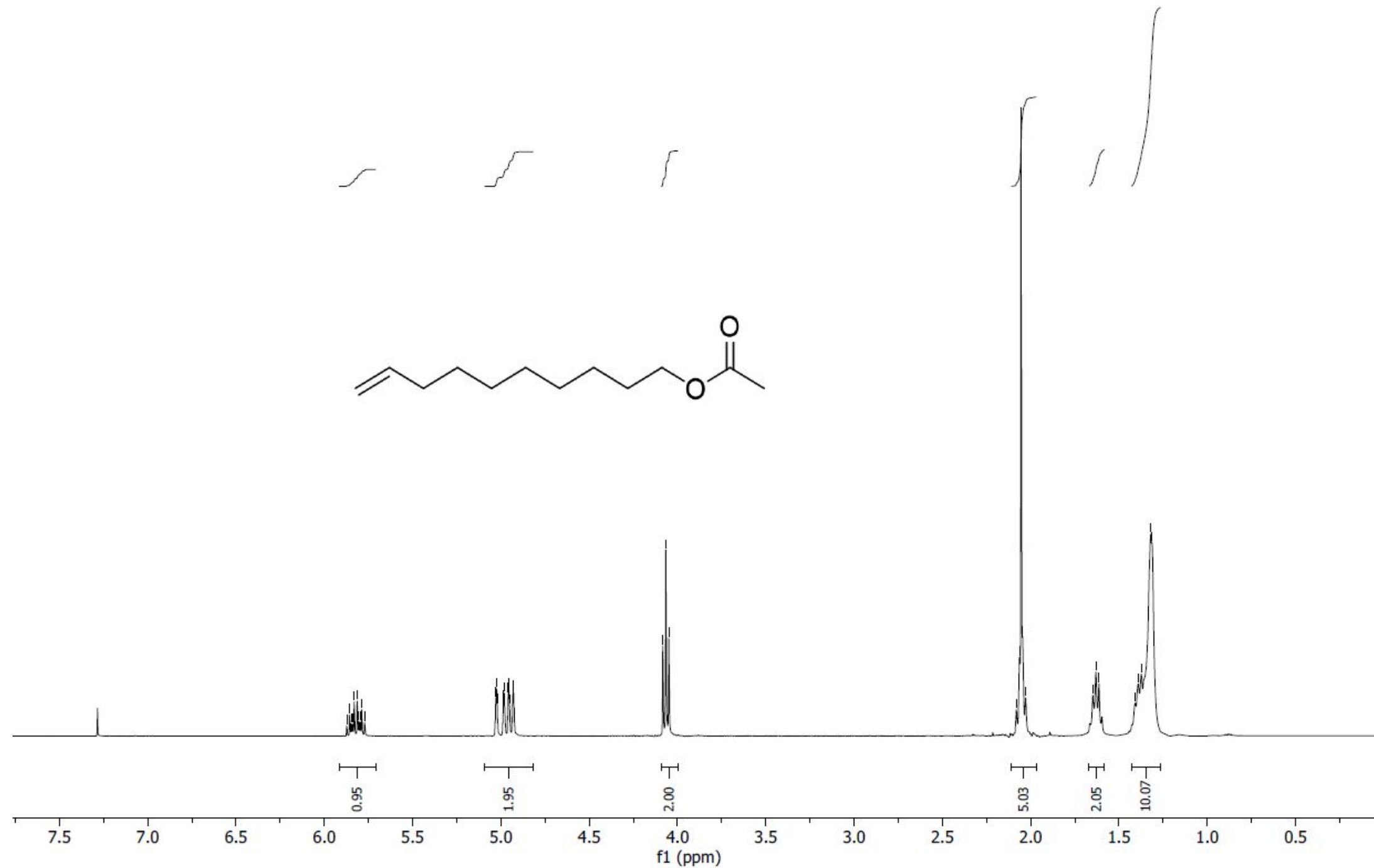

Fig S28. ${ }^{1} \mathrm{H}$ NMR (400 $\mathrm{MHz}, \mathrm{CDCl}_{3}$ ) of 9-decen-1-yl acetate (3j) 


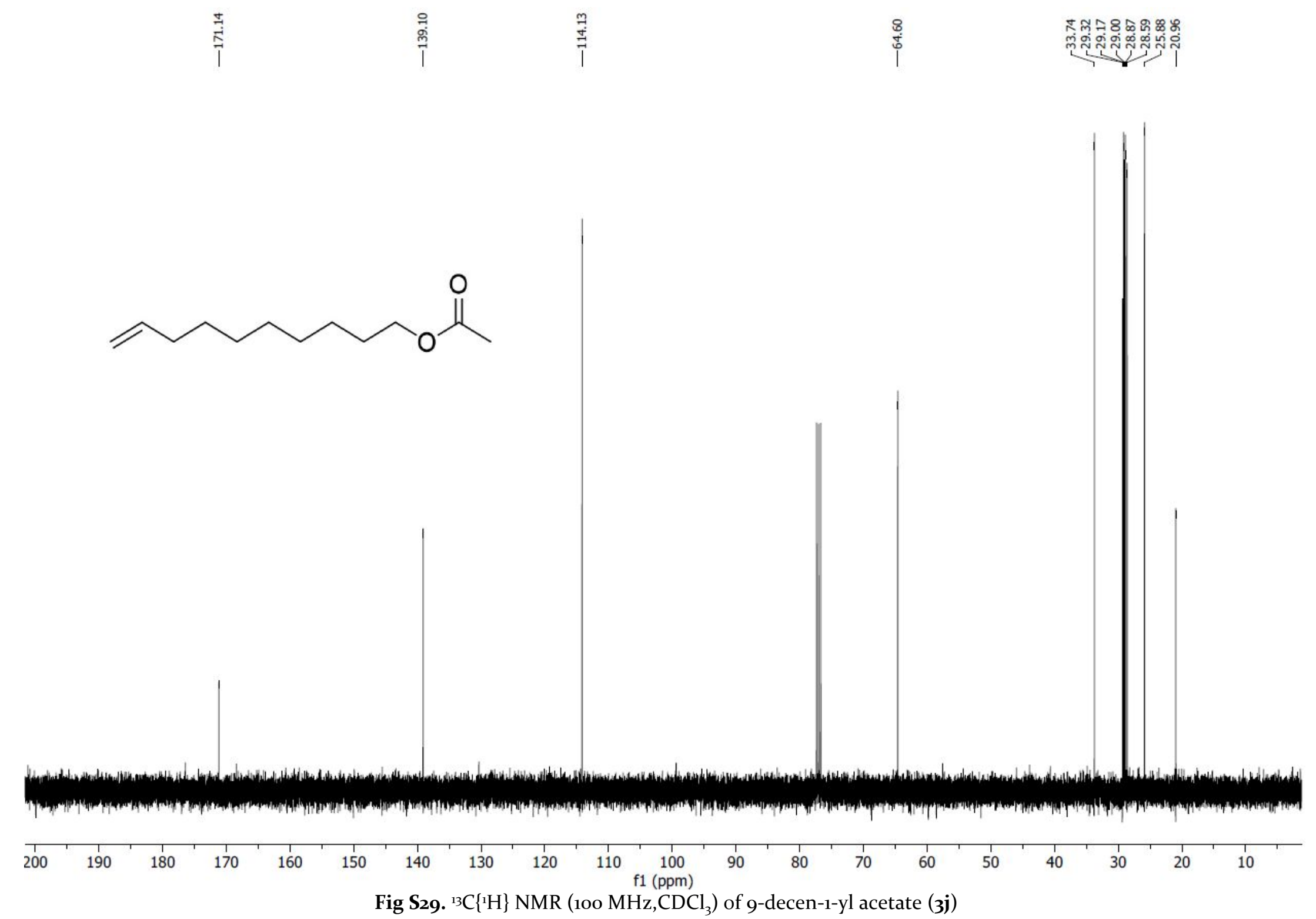




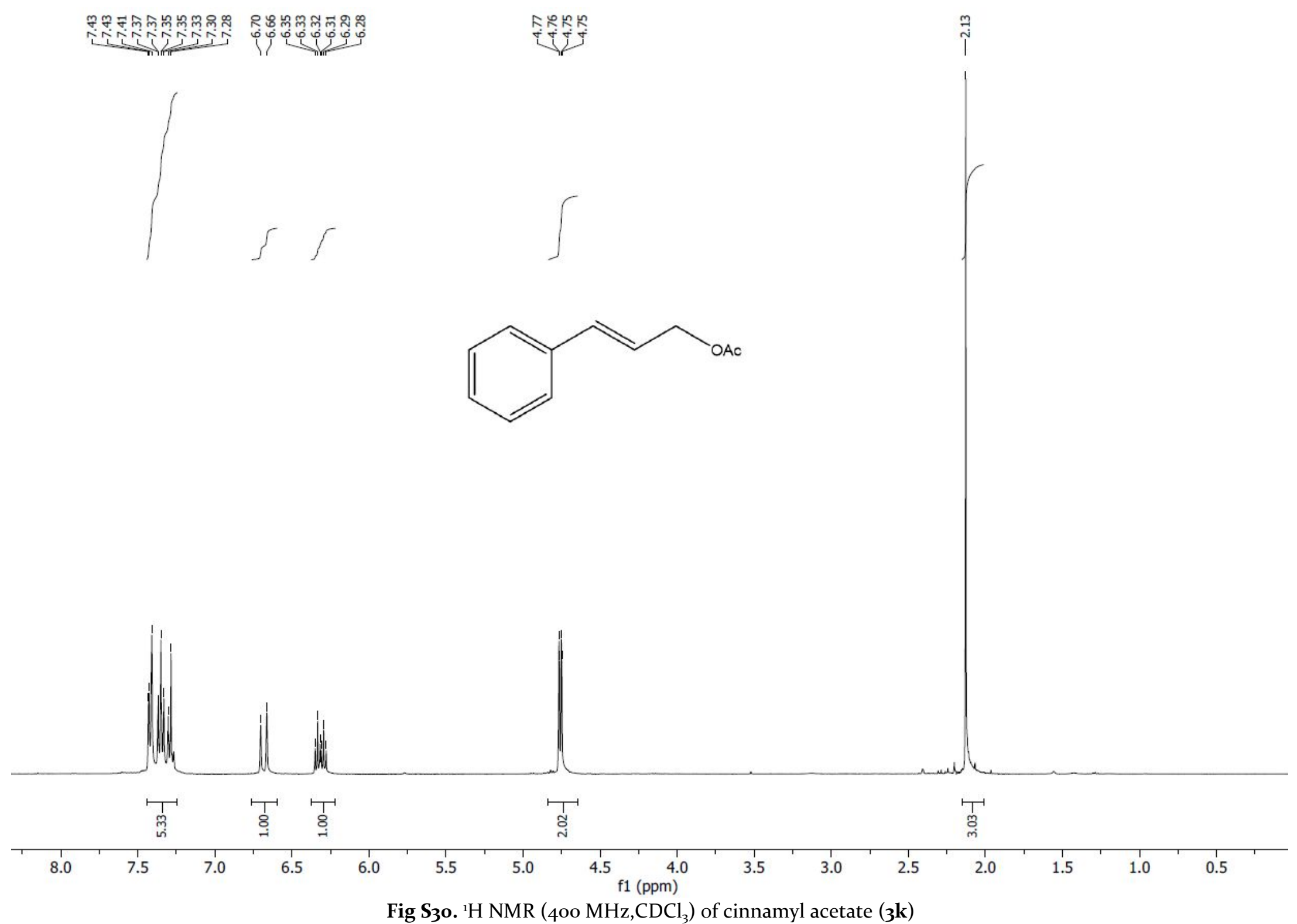




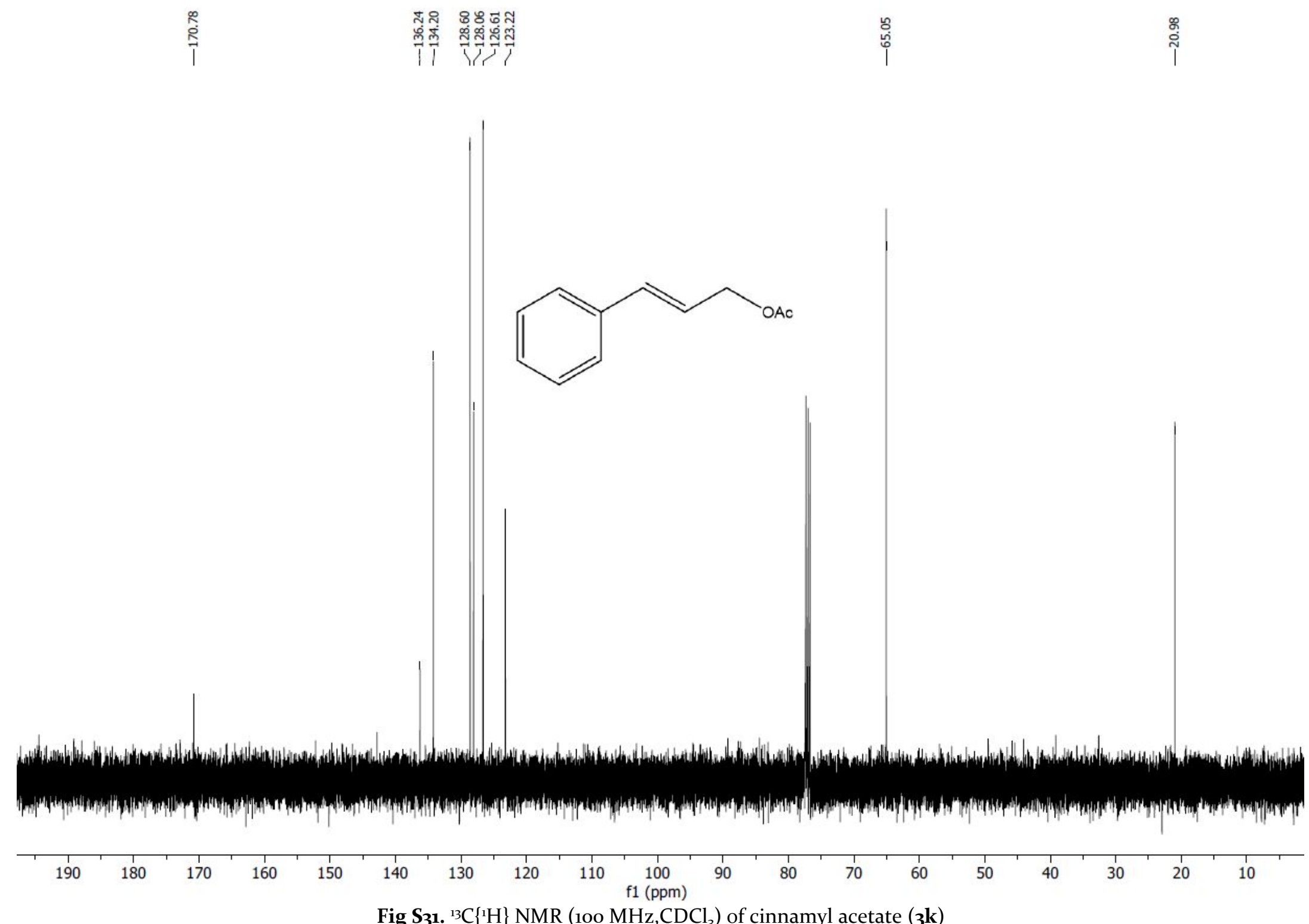



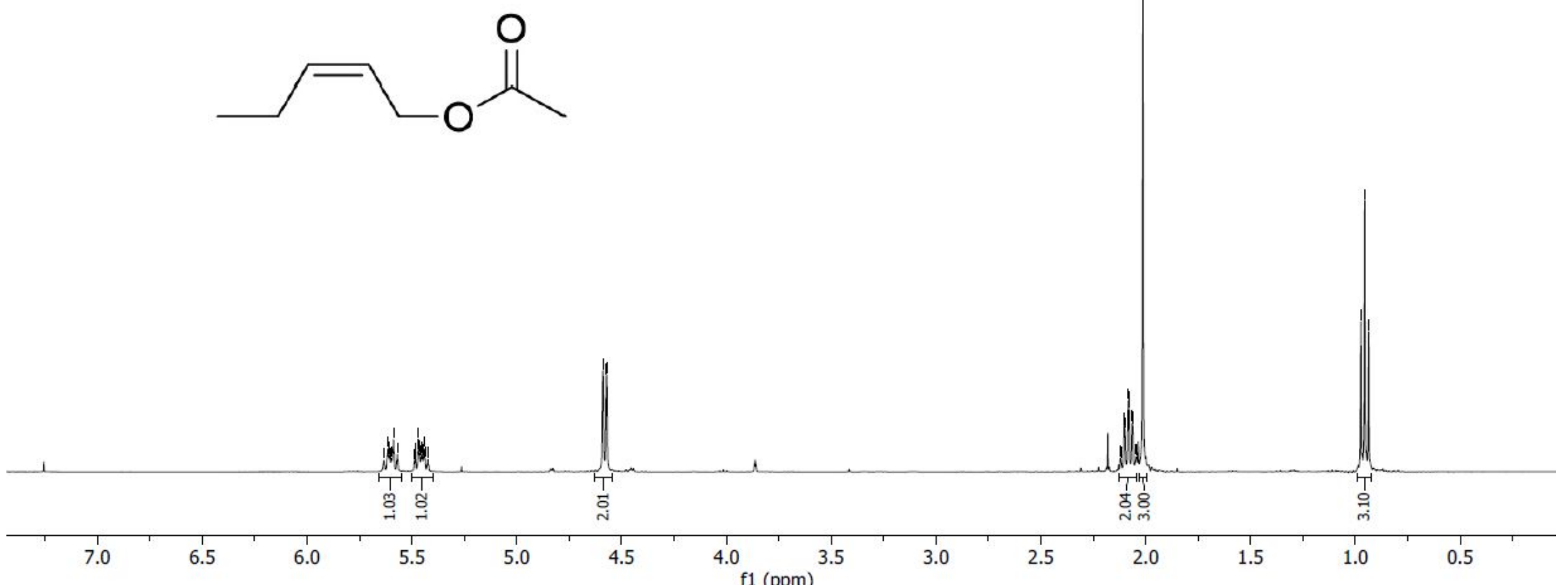

Fig S32. ${ }^{1} \mathrm{H}$ NMR (40o MHz, $\mathrm{CDCl}_{3}$ ) of (2Z)-pent-2-en-1-yl acetate (3l) 


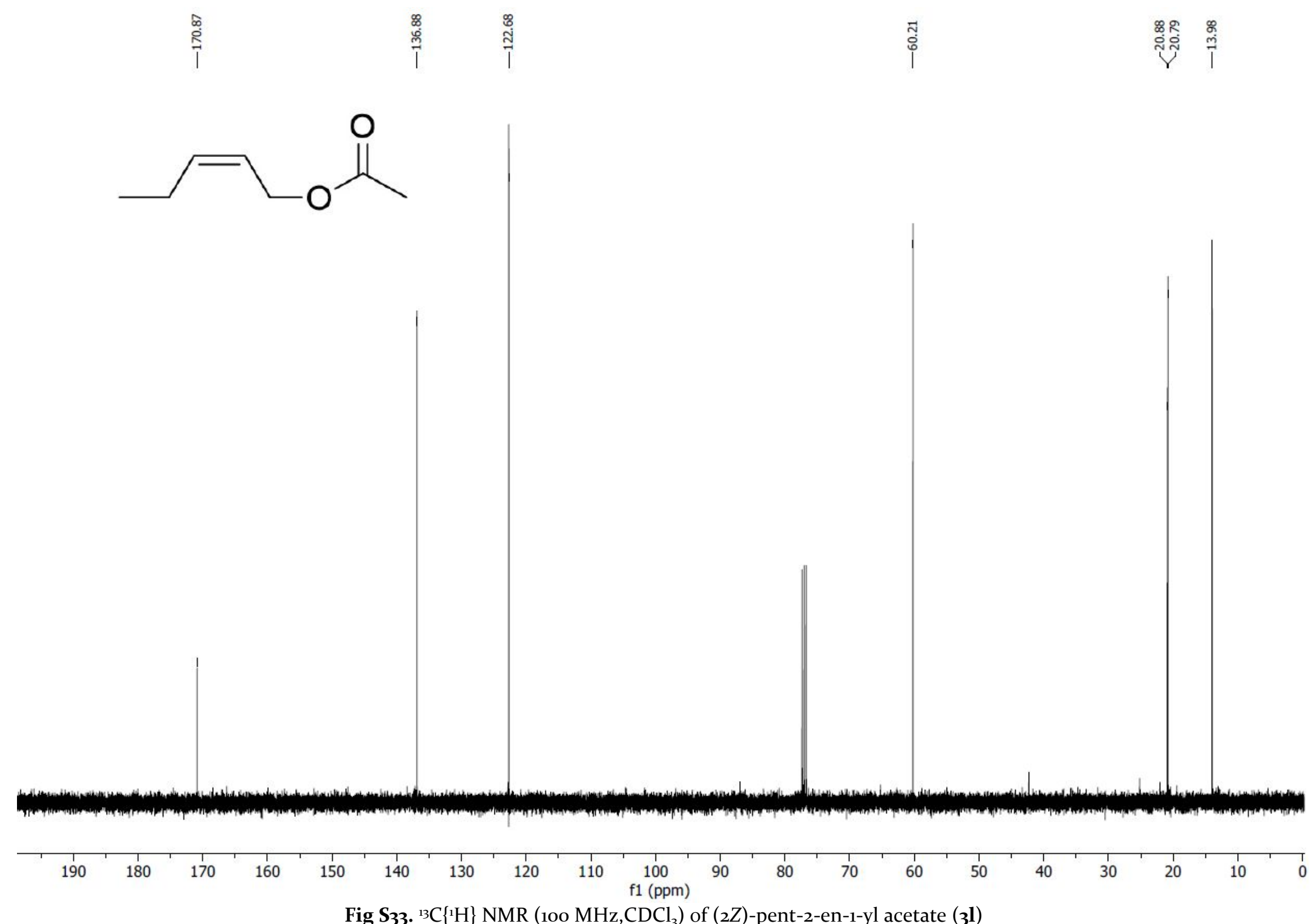

Fig S33. ${ }^{13}{ }^{1}\left\{{ }^{1} \mathrm{H}\right\}$ NMR (100 $\left.\mathrm{MHz}, \mathrm{CDCl}_{3}\right)$ of $(2 Z)$-pent-2-en-1-yl acetate $(3 \mathbf{l})$ 


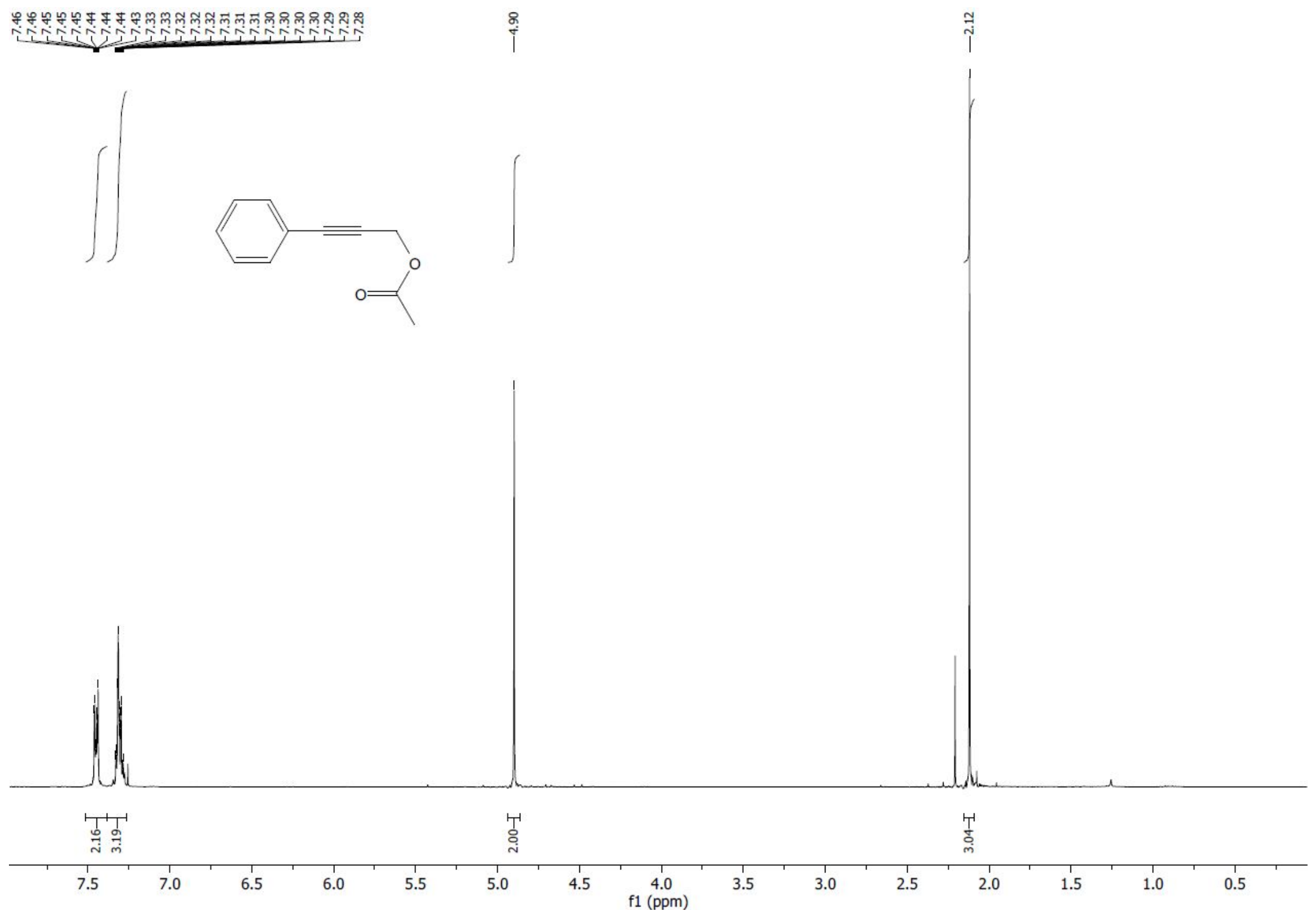

Fig S34. ${ }^{1} \mathrm{H}$ NMR (40o MHz, $\mathrm{CDCl}_{3}$ ) of 3-phenylprop-2-ynyl acetate (3m) 


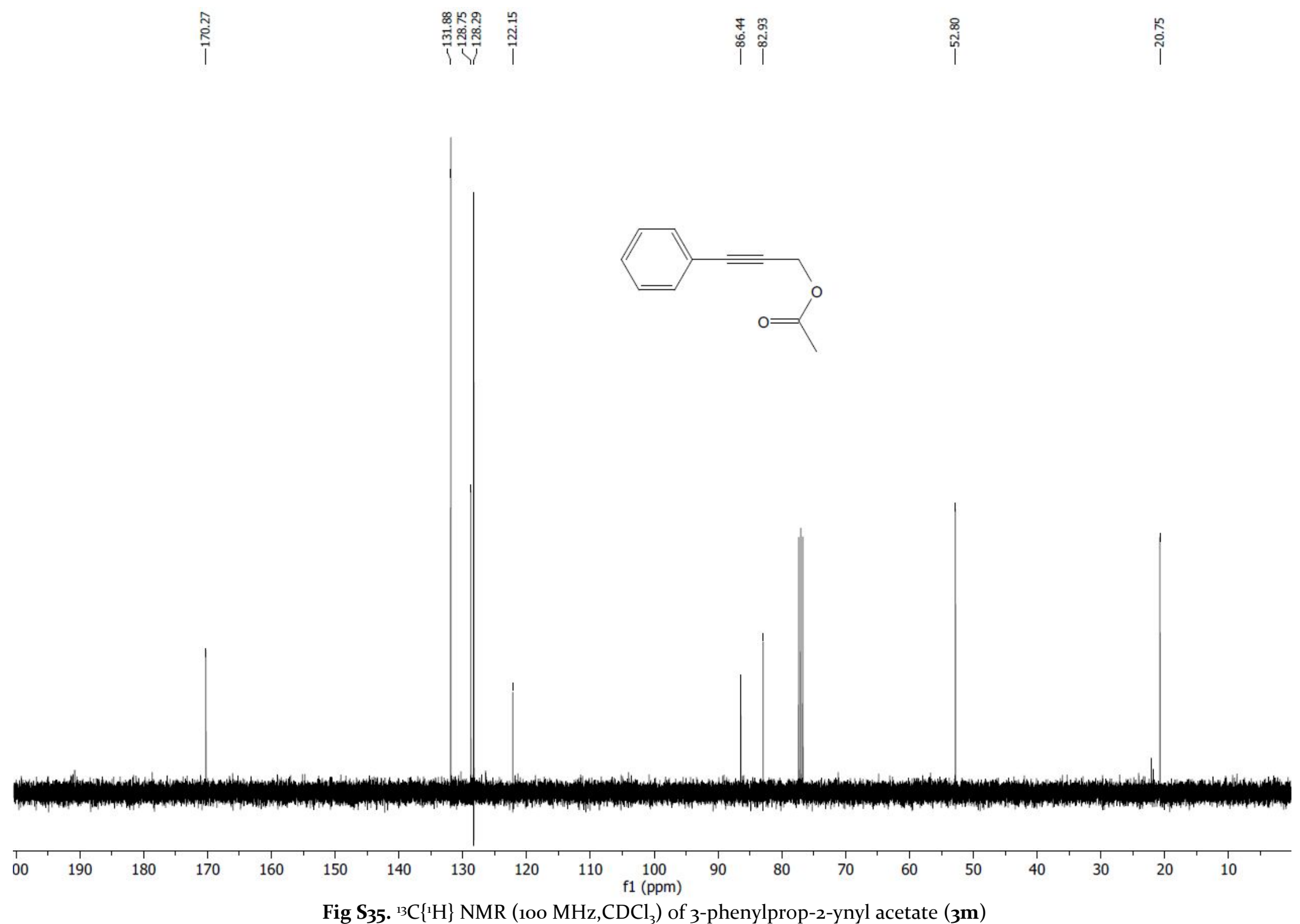




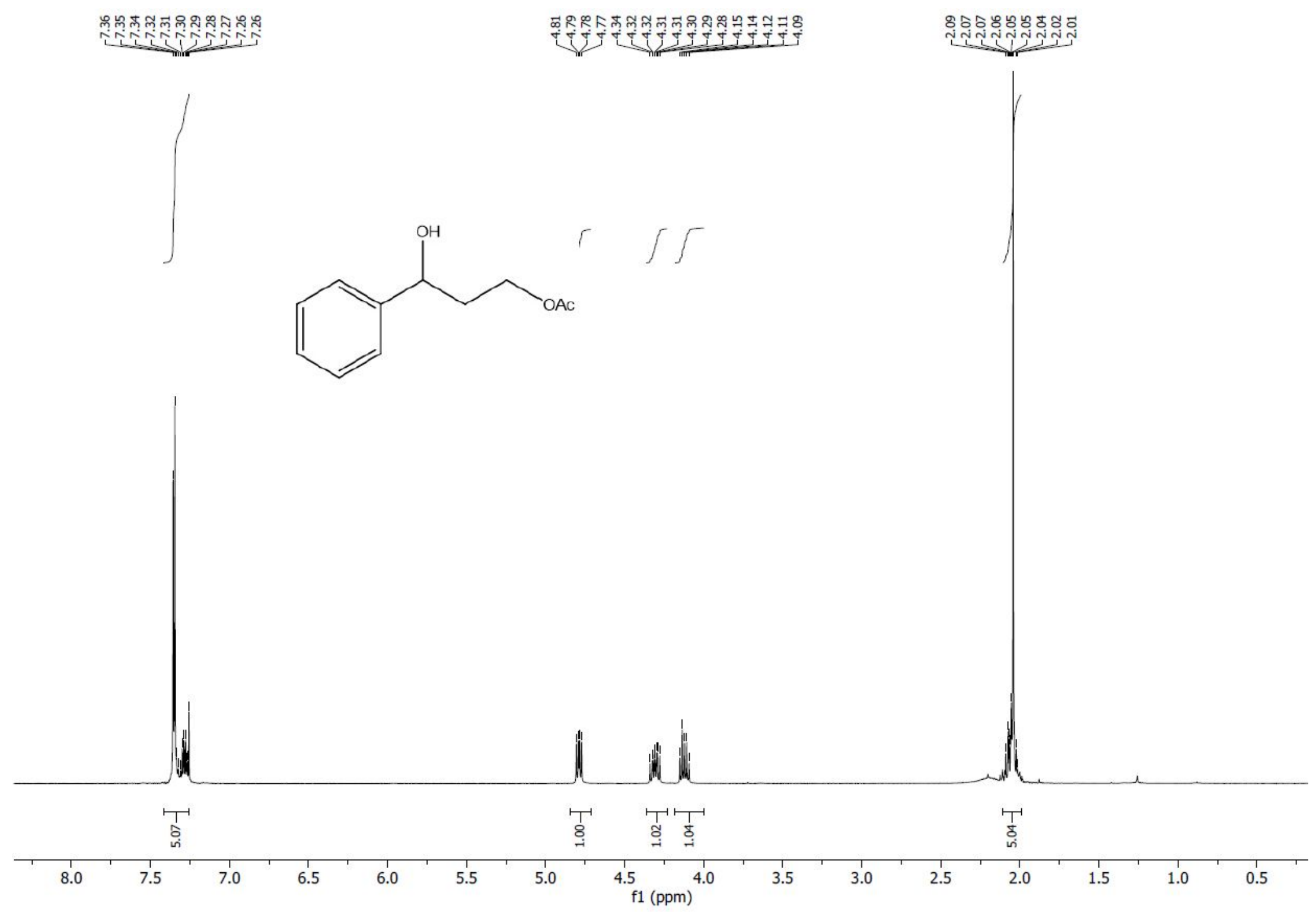

Fig S36. ${ }^{1} \mathrm{H}$ NMR (40o $\mathrm{MHz}, \mathrm{CDCl}_{3}$ ) of 3-acetoxy-1-phenyl-propan-1-ol (3n) 


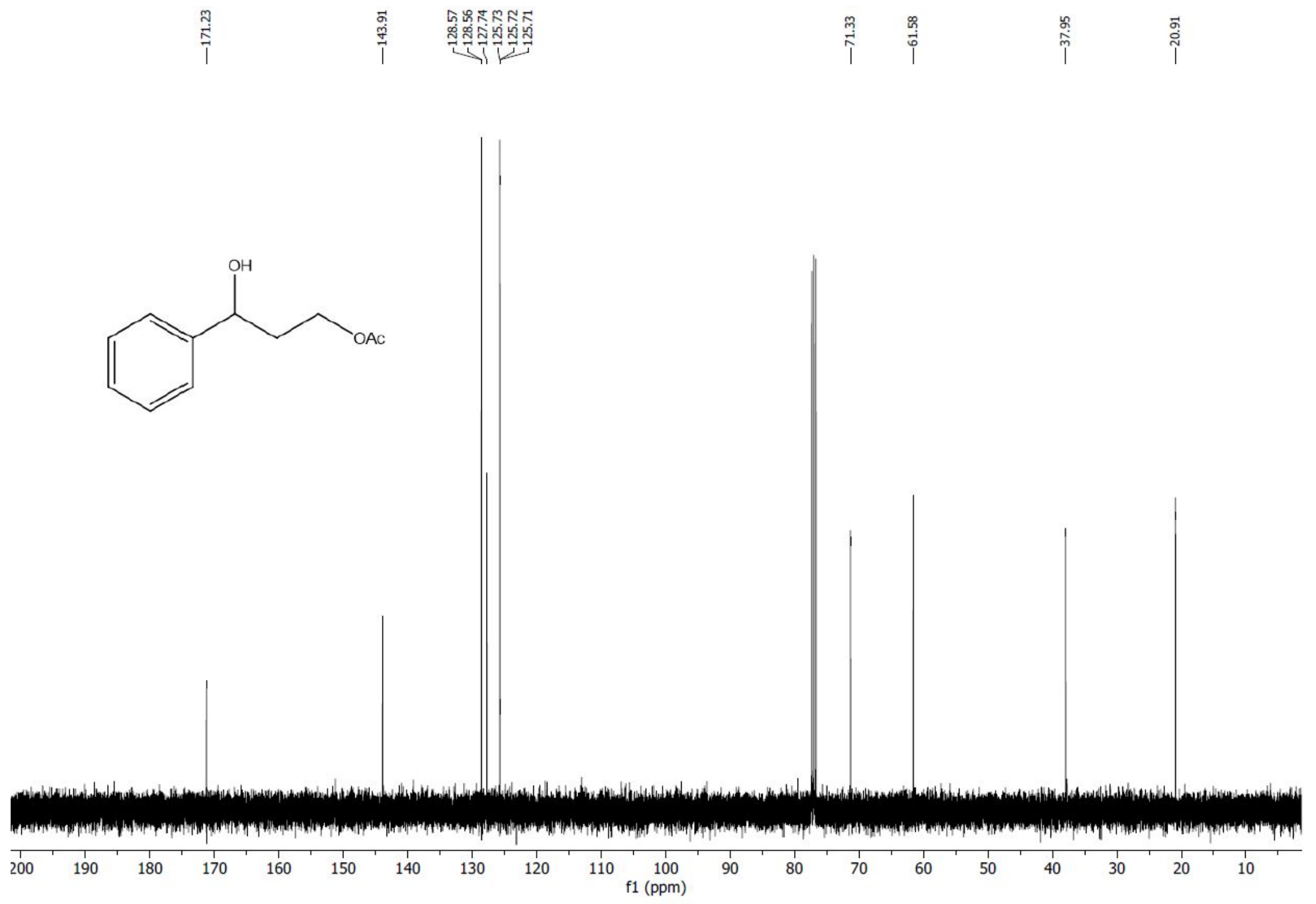

Fig S37. $\left.{ }^{13} C_{\{1}{ }^{1} \mathrm{H}\right\}$ NMR (10o MHz,CDCl ) of 3-acetoxy-1-phenyl-propan-1-ol (3n) 


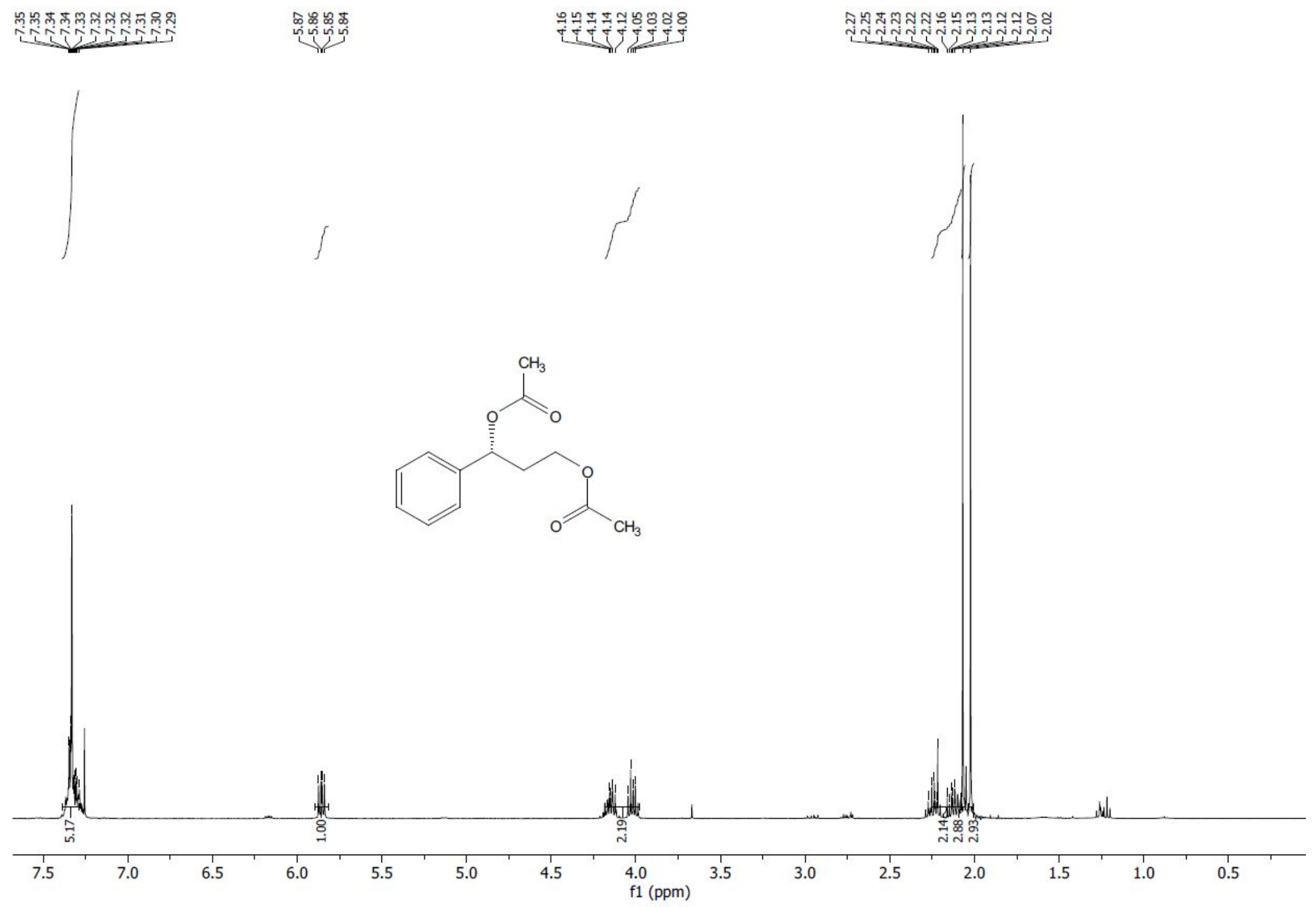

Fig S38. ${ }^{1} \mathrm{H}$ NMR (40o MHz, $\left.\mathrm{CDCl}_{3}\right)$ of $(R)$-1-phenylpropane-1,3-diyl diacetate $((R)$-3o) 

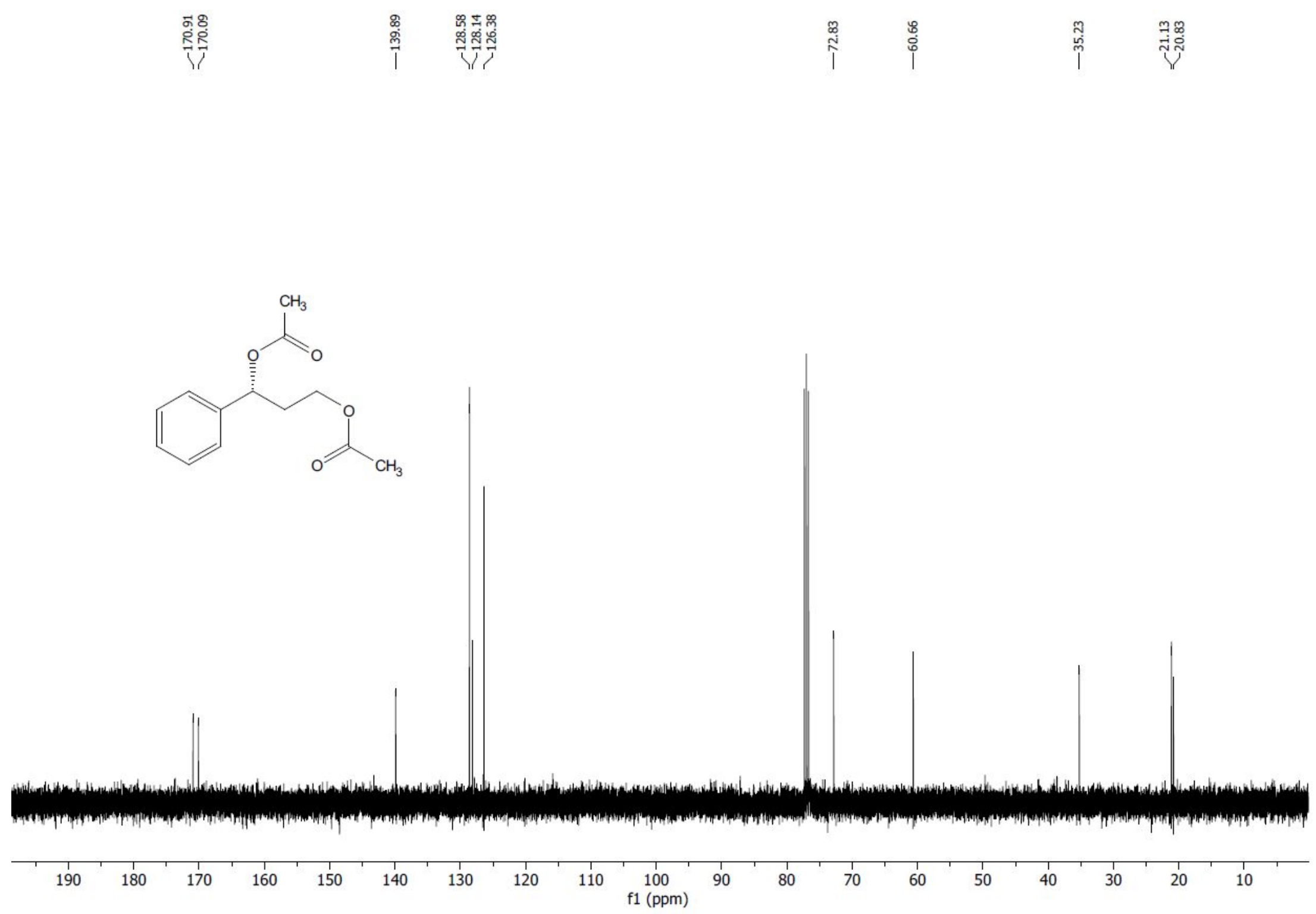

Fig S39. ${ }^{13} \mathrm{C}\{1 \mathrm{H}\}$ NMR (100 MHz, $\left.\mathrm{CDCl}_{3}\right)$ of $(R)$-1-phenylpropane-1,3-diyl diacetate $((R)-\mathbf{3 0})$ 


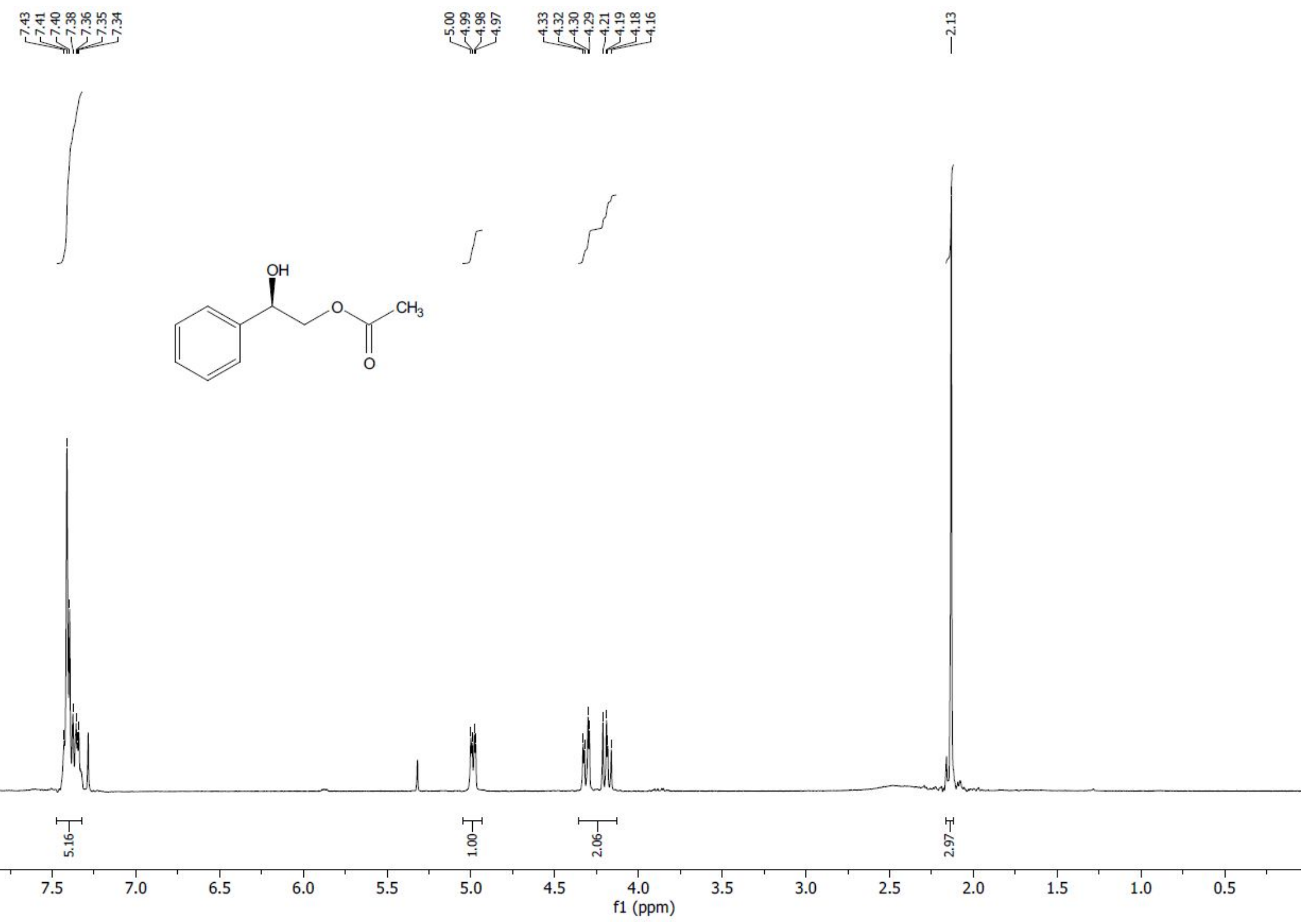

Fig S4o. ${ }^{1} \mathrm{H}$ NMR (40o $\left.\mathrm{MHz}, \mathrm{CDCl}_{3}\right)$ of $(R)$-2-hydroxy-2-phenylethyl acetate $((R)$-3p) 


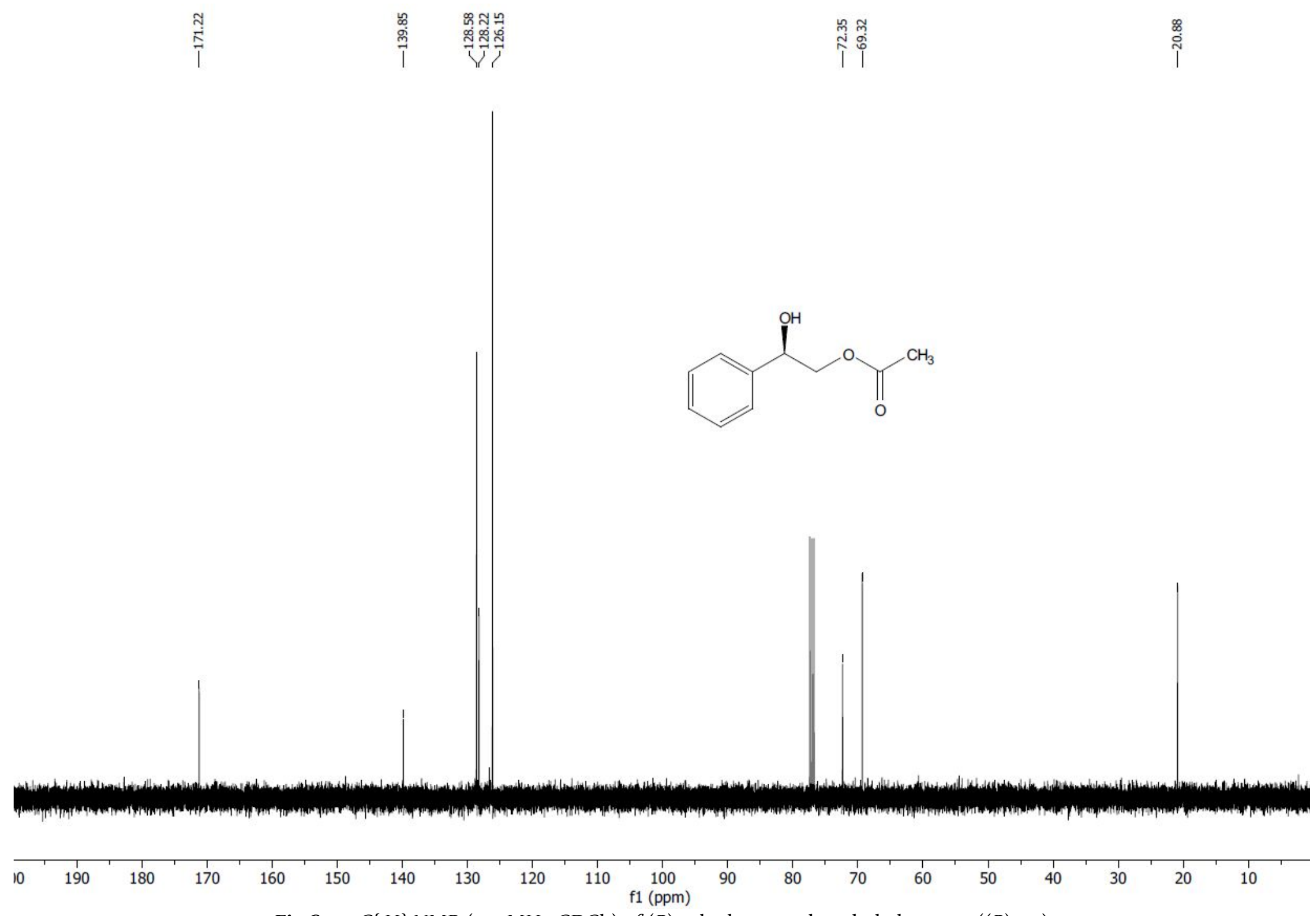

Fig S41. ${ }^{13} C\left\{{ }^{1} \mathrm{H}\right\}$ NMR (10o $\left.\mathrm{MHz}, \mathrm{CDCl}_{3}\right)$ of $(R)$-2-hydroxy-2-phenylethyl acetate $((R)$-3p) 


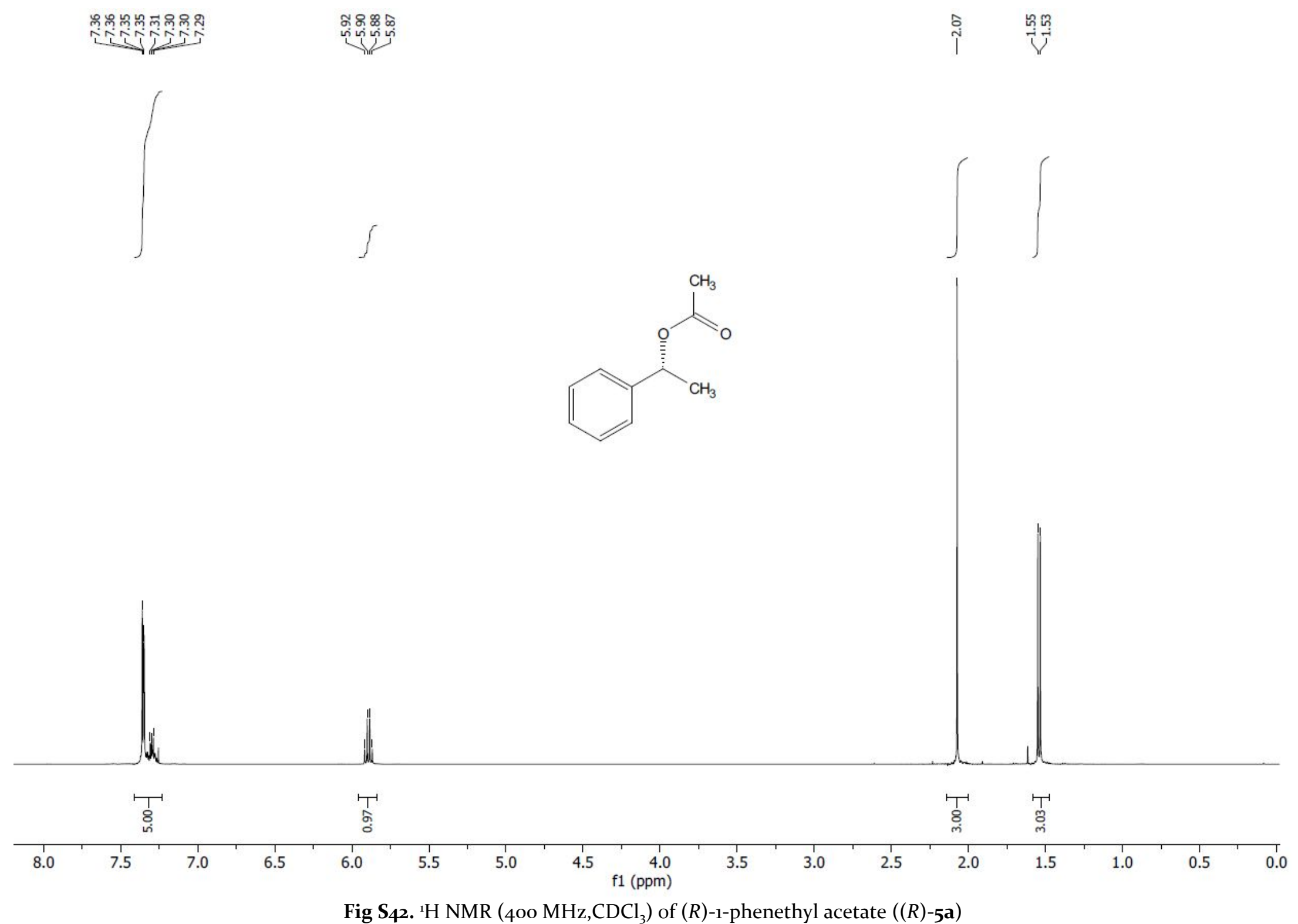

Fig S42. ${ }^{1} \mathrm{H}$ NMR (40o MHz, $\left.\mathrm{CDCl}_{3}\right)$ of $(R)-1$-phenethyl acetate $((R)-\mathbf{5 a})$ 


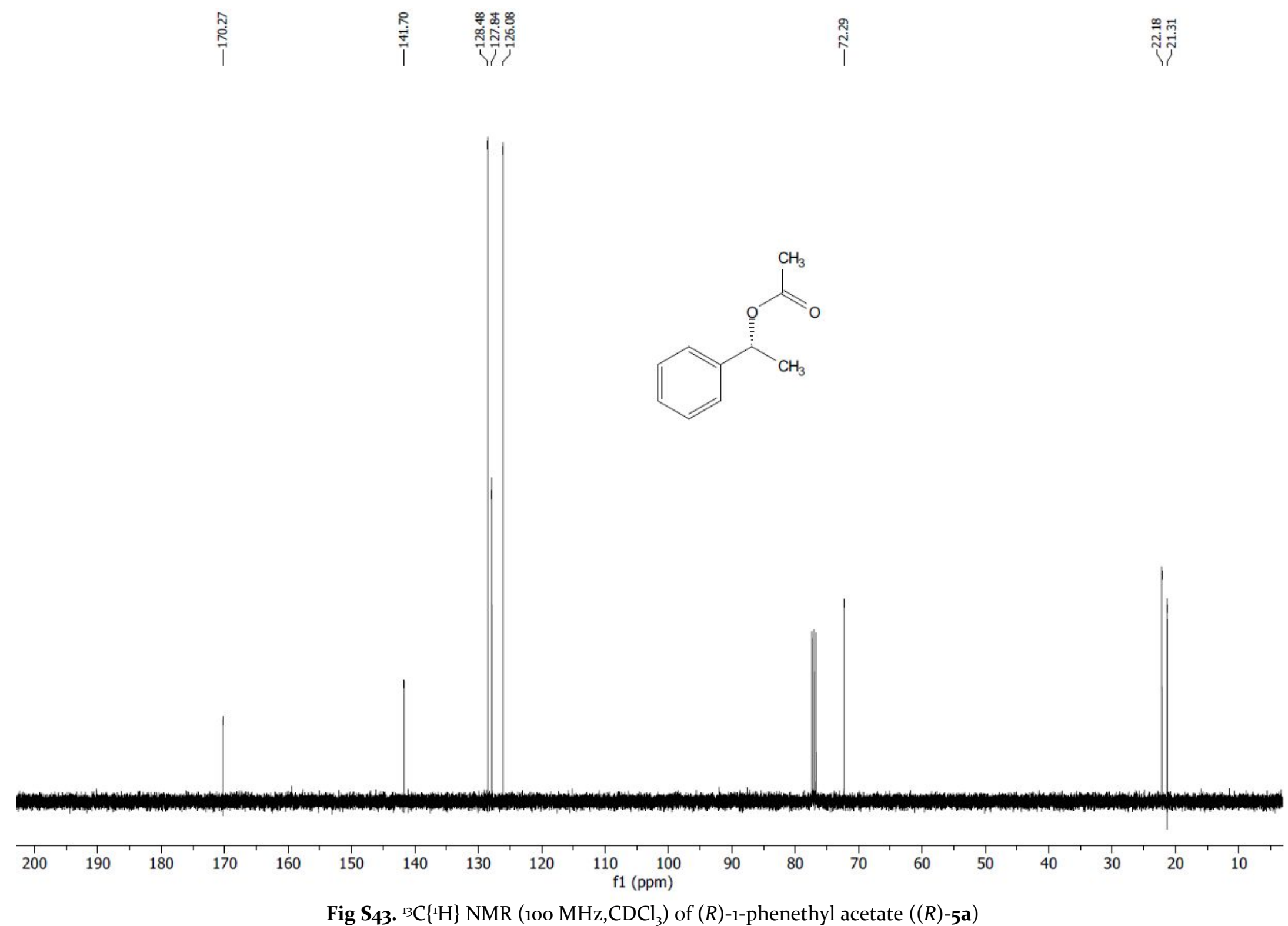




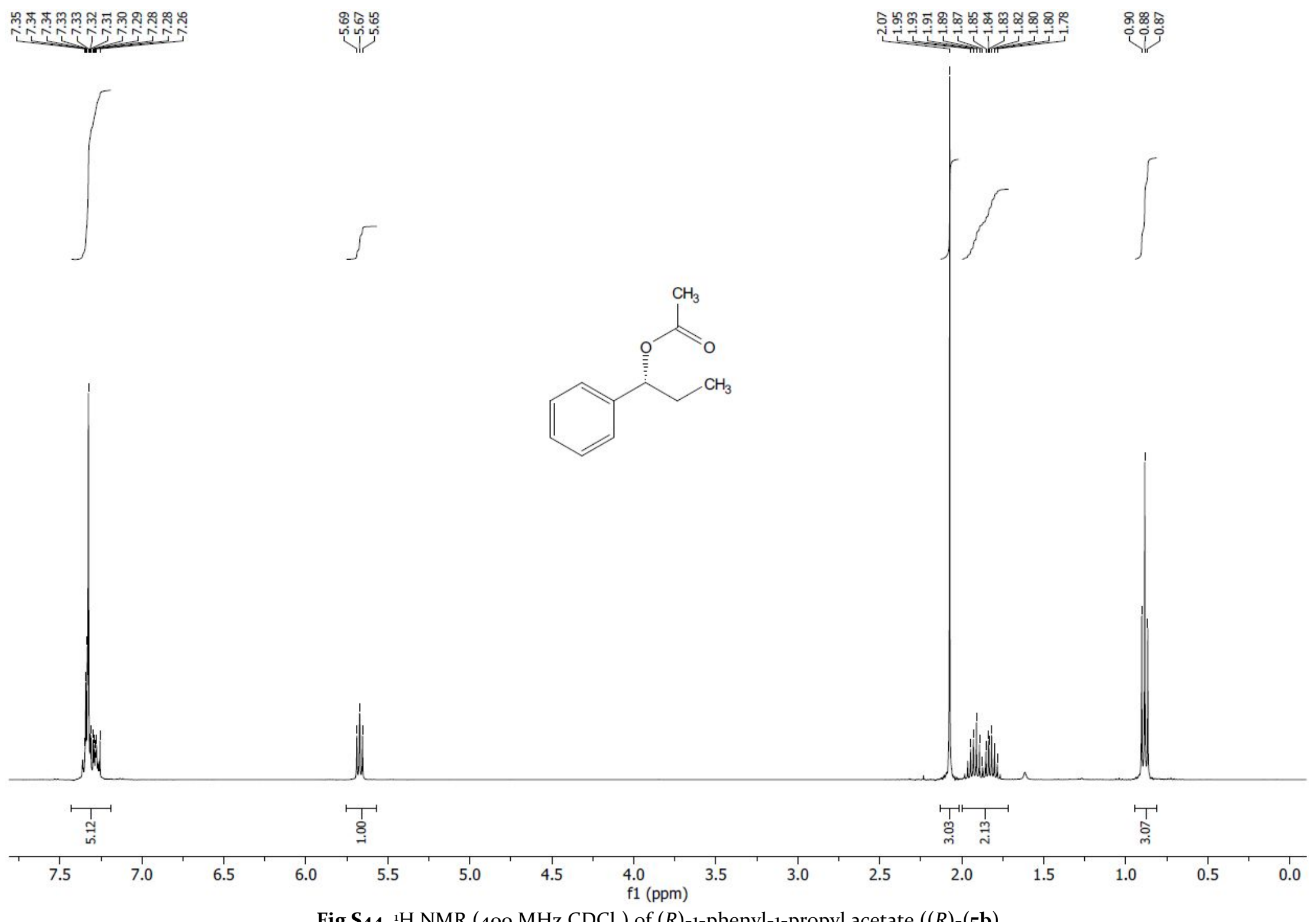

Fig S44. ${ }^{1} \mathrm{H}$ NMR (40o MHz,CDCl$\left.{ }_{3}\right)$ of $(R)$-1-phenyl-1-propyl acetate $((R)-(\mathbf{5} \mathbf{b})$ 


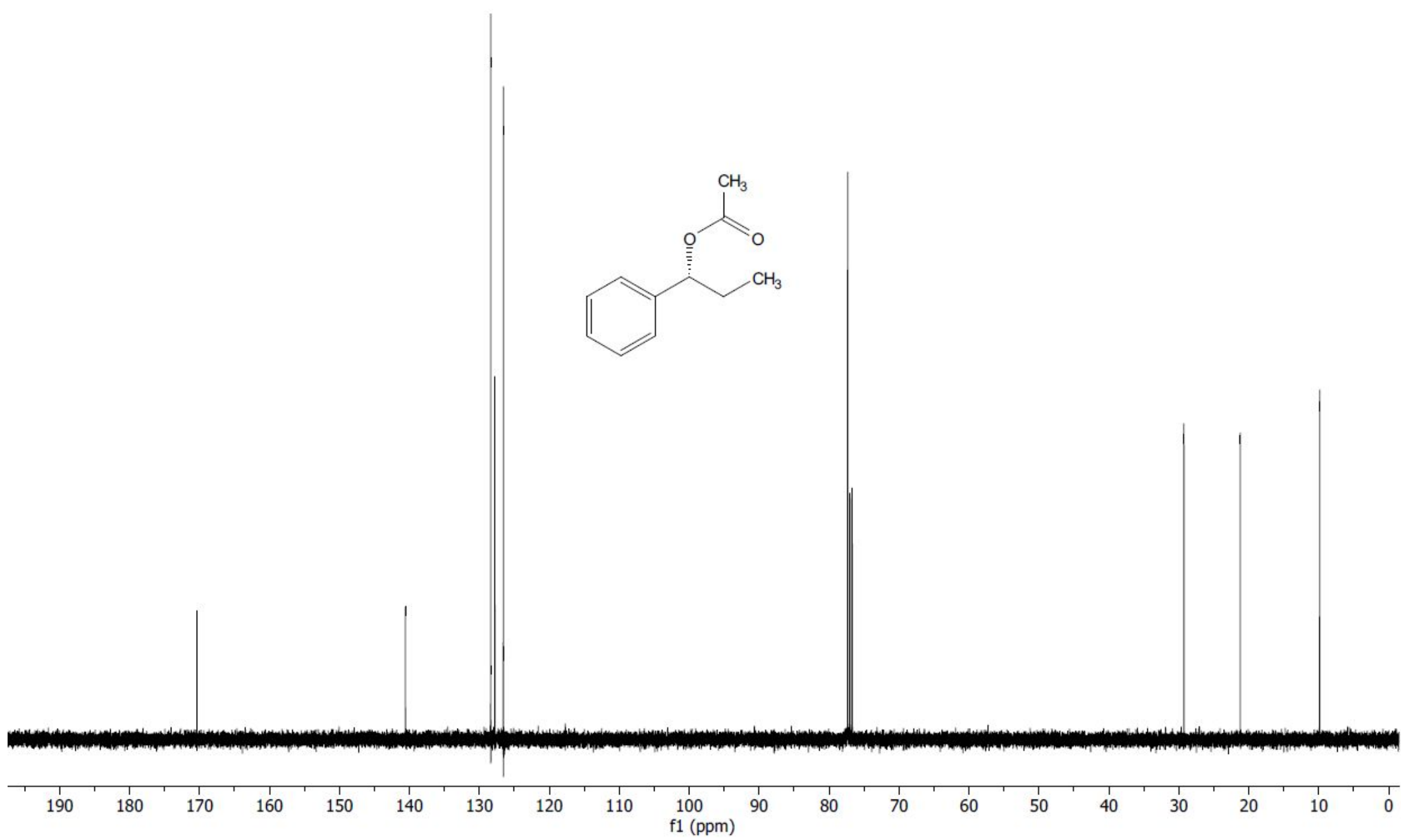

Fig S45. ${ }^{13} C\{1 \mathrm{H}\}$ NMR (100 $\left.\mathrm{MHz}, \mathrm{CDCl}_{3}\right)$ of $(R)-1$-phenyl-1-propyl acetate $((R)-(5 \mathbf{b})$ 


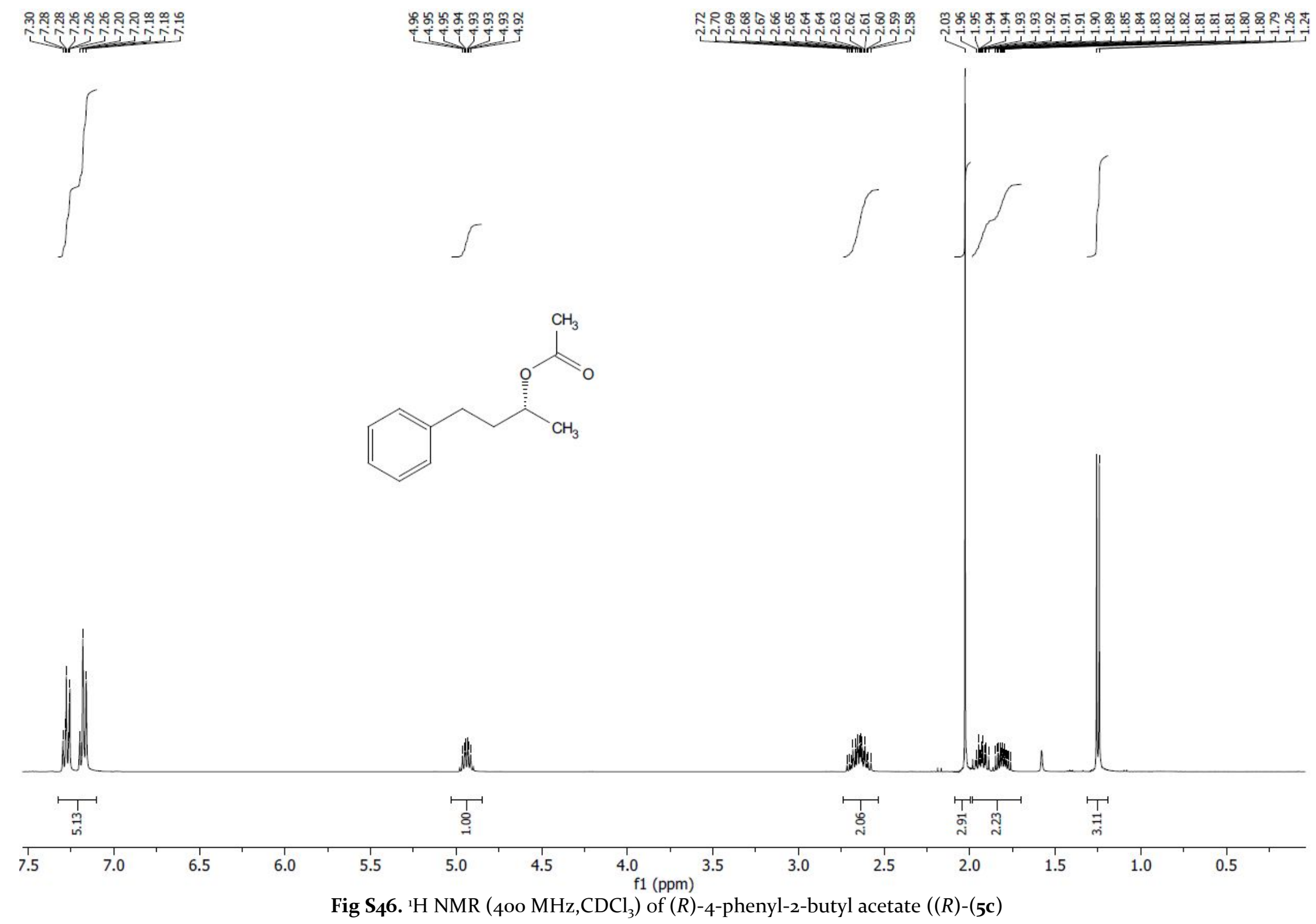




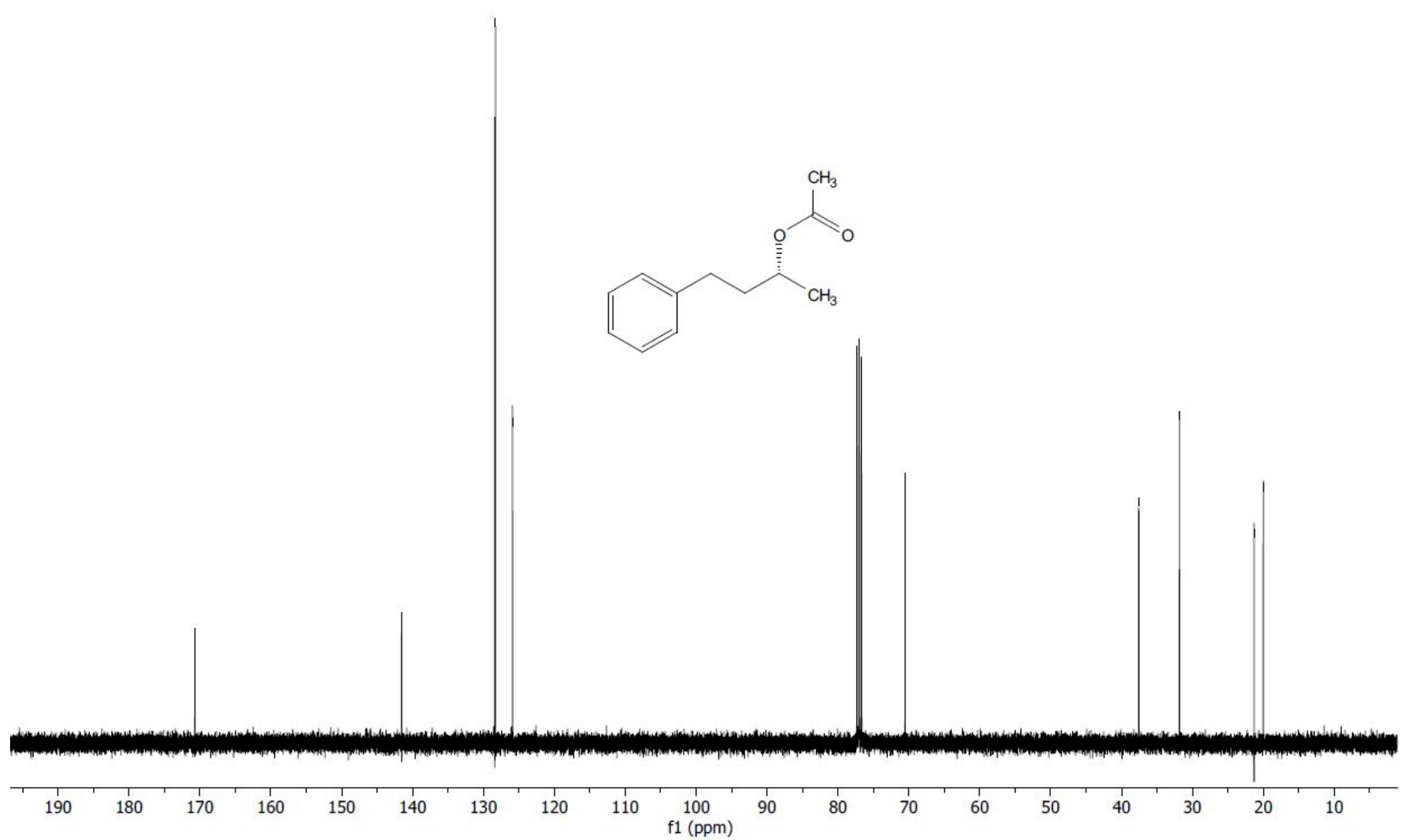

Fig S47. $\left.{ }^{3} \mathrm{C}^{1}{ }^{1} \mathrm{H}\right\}$ NMR $\left(100 \mathrm{MHz}, \mathrm{CDCl}_{3}\right)$ of $(R)$-4-phenyl-2-butyl acetate $\left((R)-{ }_{5} \mathbf{C}\right)$ 


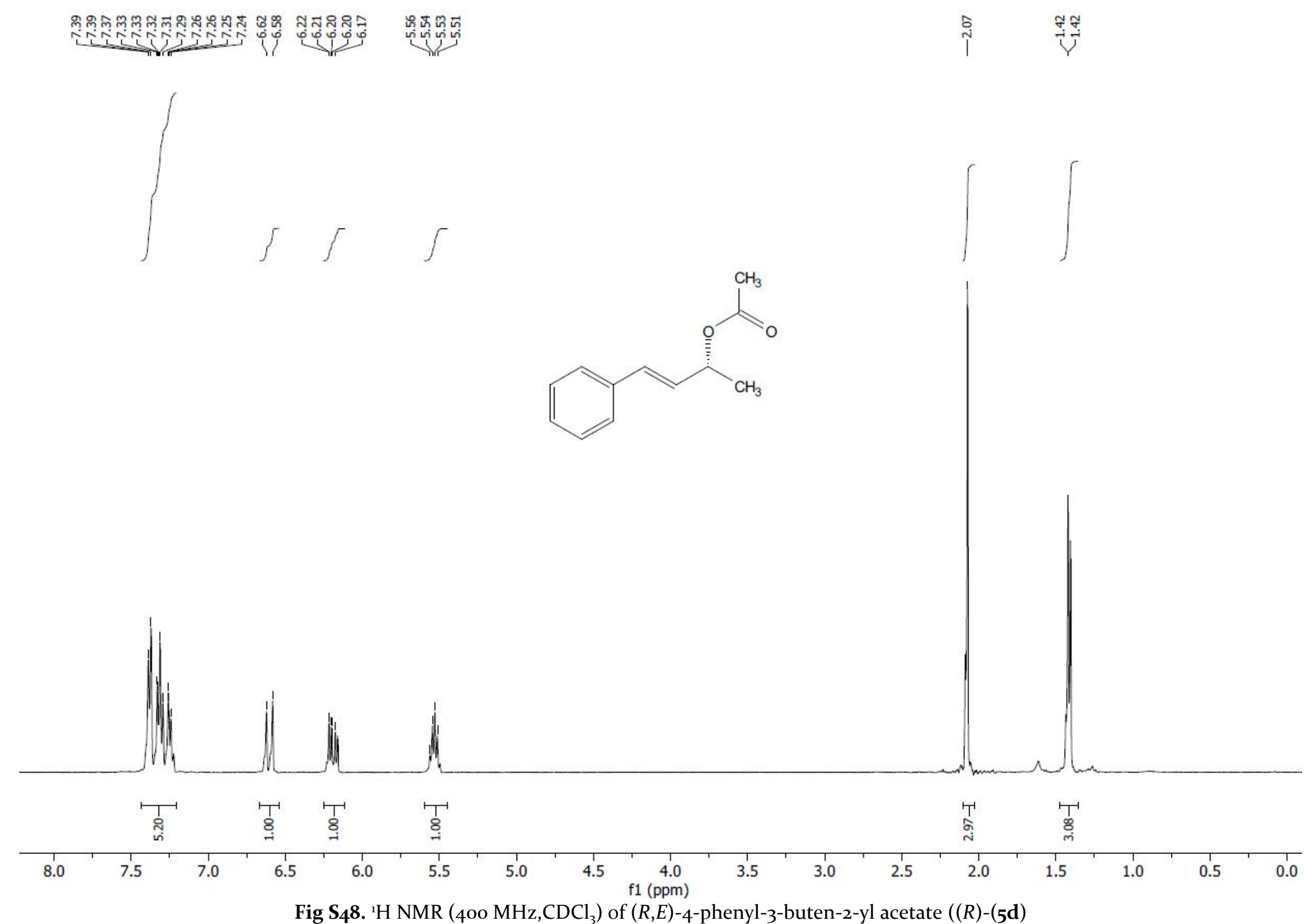




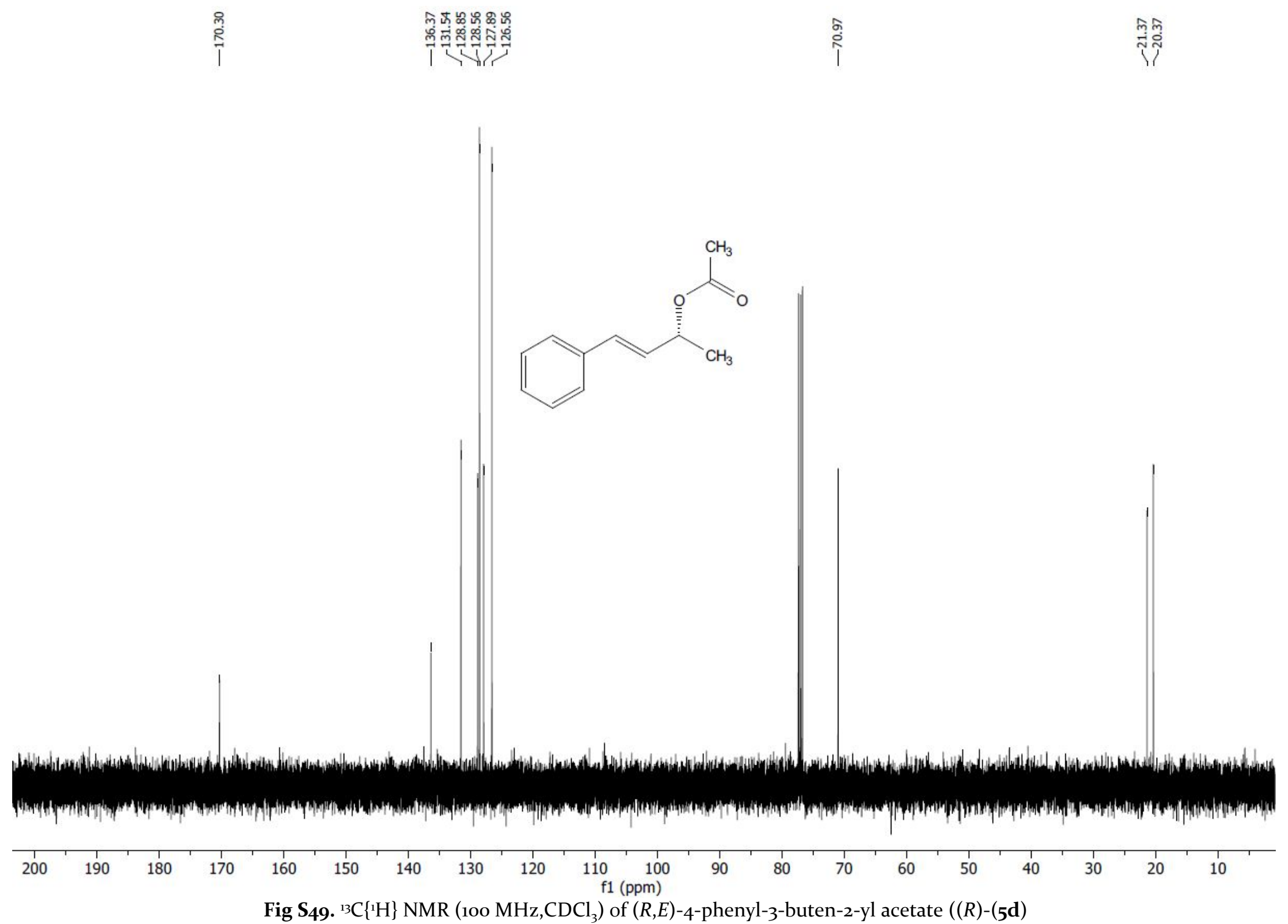




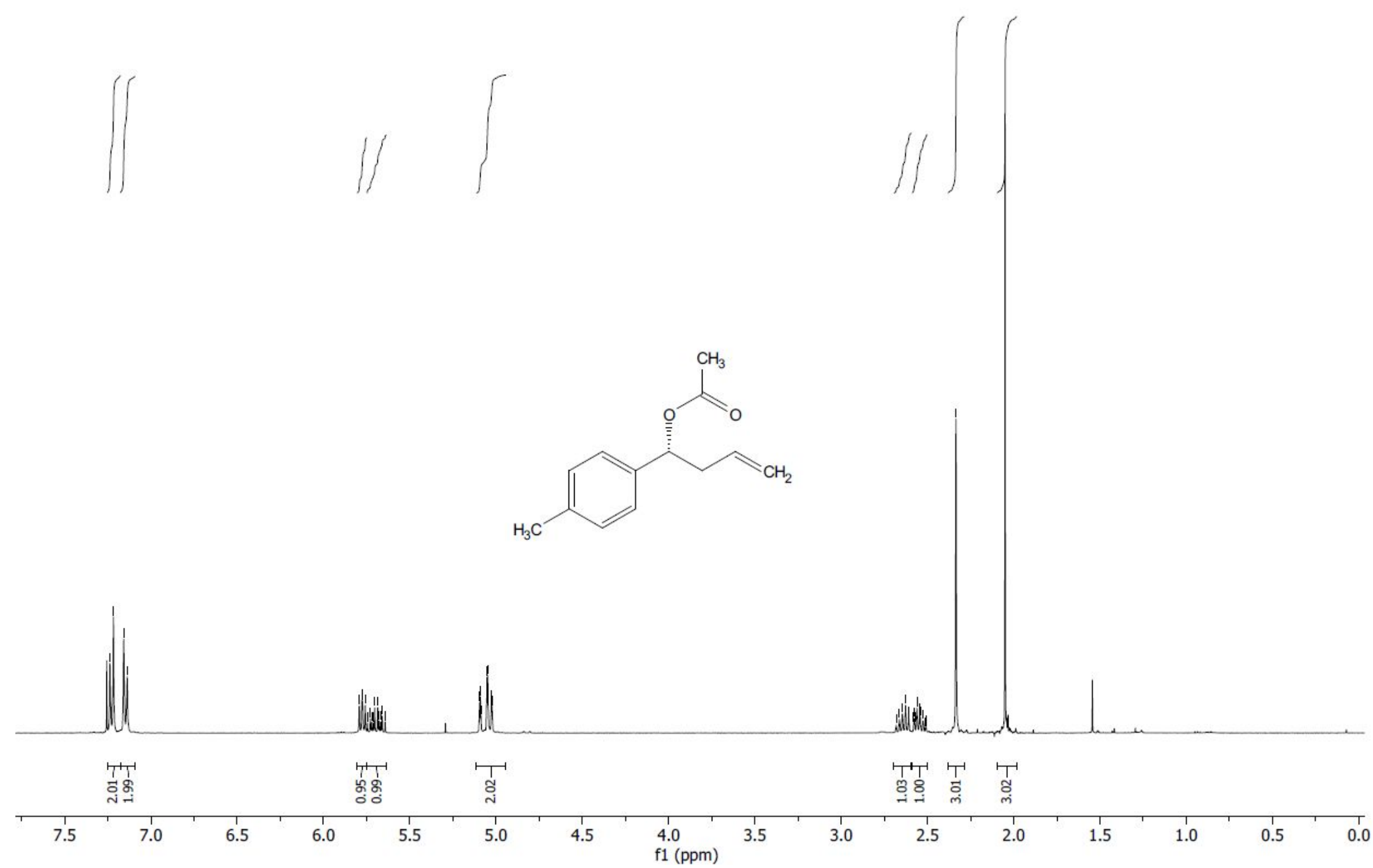

Fig S5o. $^{1} \mathrm{H}$ NMR $\left(400 \mathrm{MHz}, \mathrm{CDCl}_{3}\right)$ of $(R)$-1-p-tolyl-but-3-enyl acetate $\left((R)-{ }_{5} \mathbf{e}\right)$ 


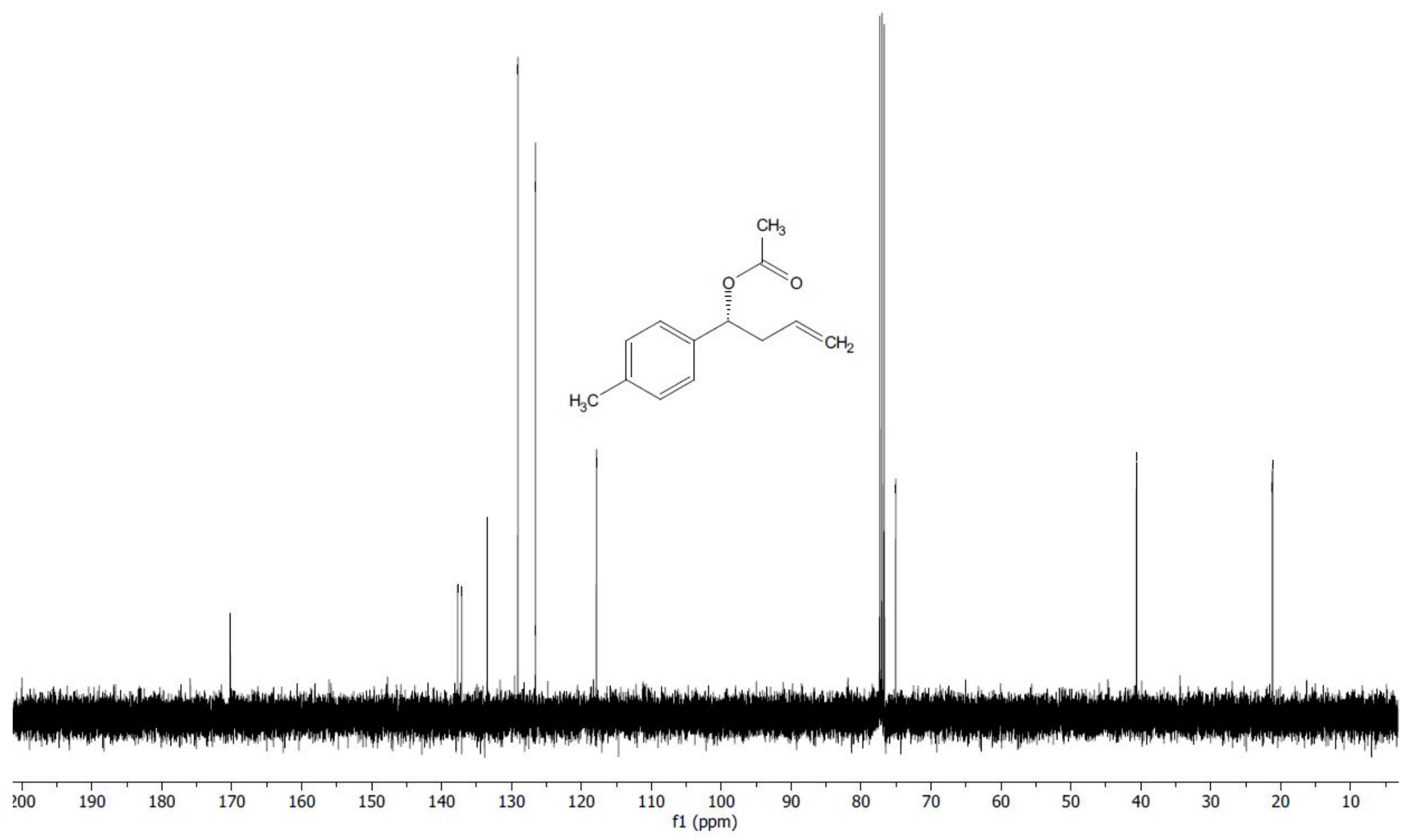

Fig $\mathrm{S}_{51} .{ }^{13} \mathrm{C}\left\{{ }^{1} \mathrm{H}\right\}$ NMR (100 MHz,CDCl 3$)$ of $(R)$-1-p-tolyl-but-3-enyl acetate $((R)-(\mathbf{5 e})$ 
4. GC and HPLC traces

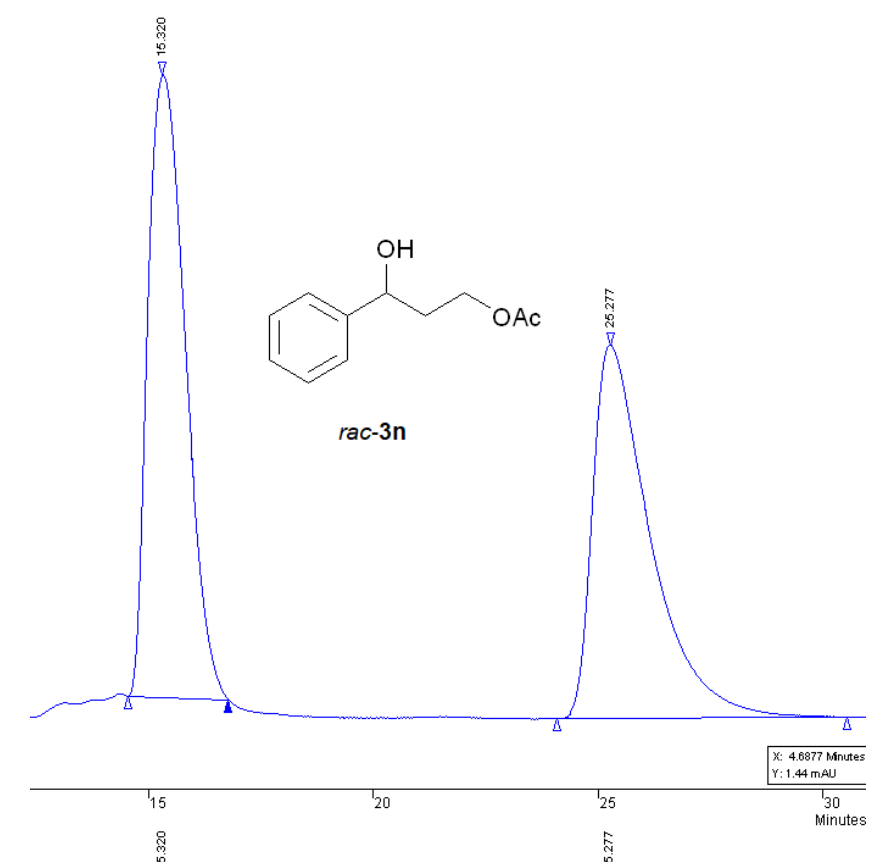

Fig S52. HPLC trace of rac-3-acetoxy-1-phenyl-propan-1-ol (3n). 


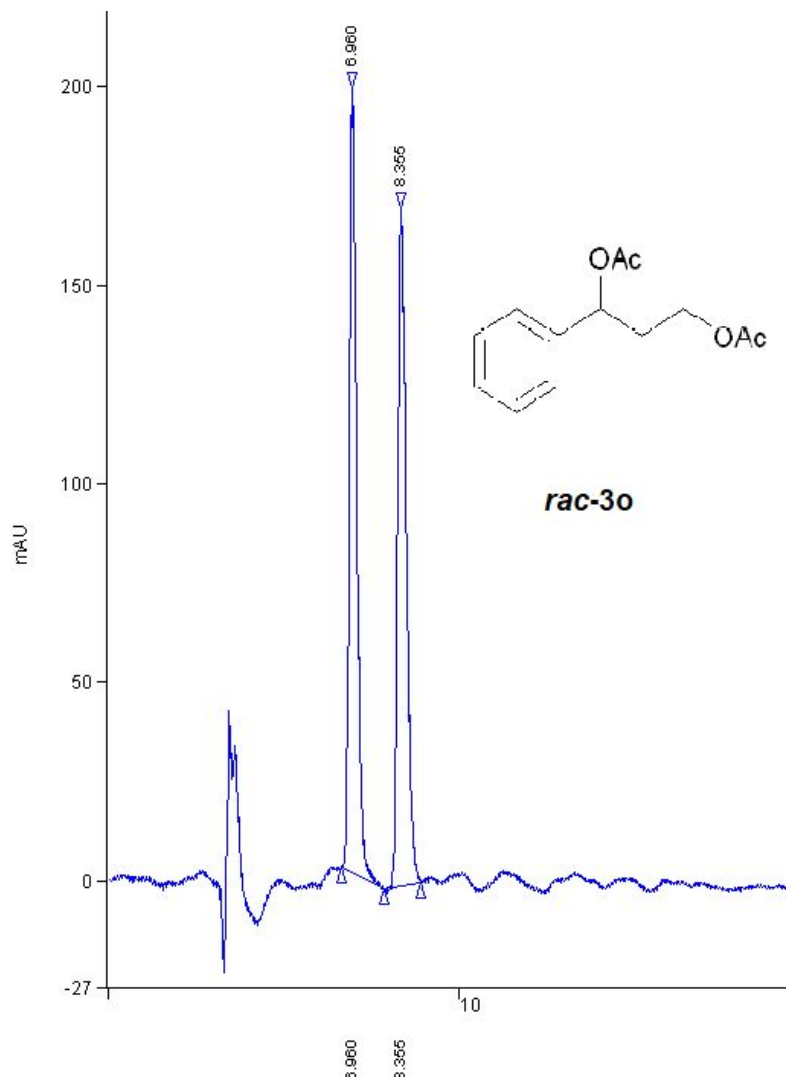

Fig S53. HPLC trace of rac-1-phenylpropane-1,3-diyl diacetate (30) 


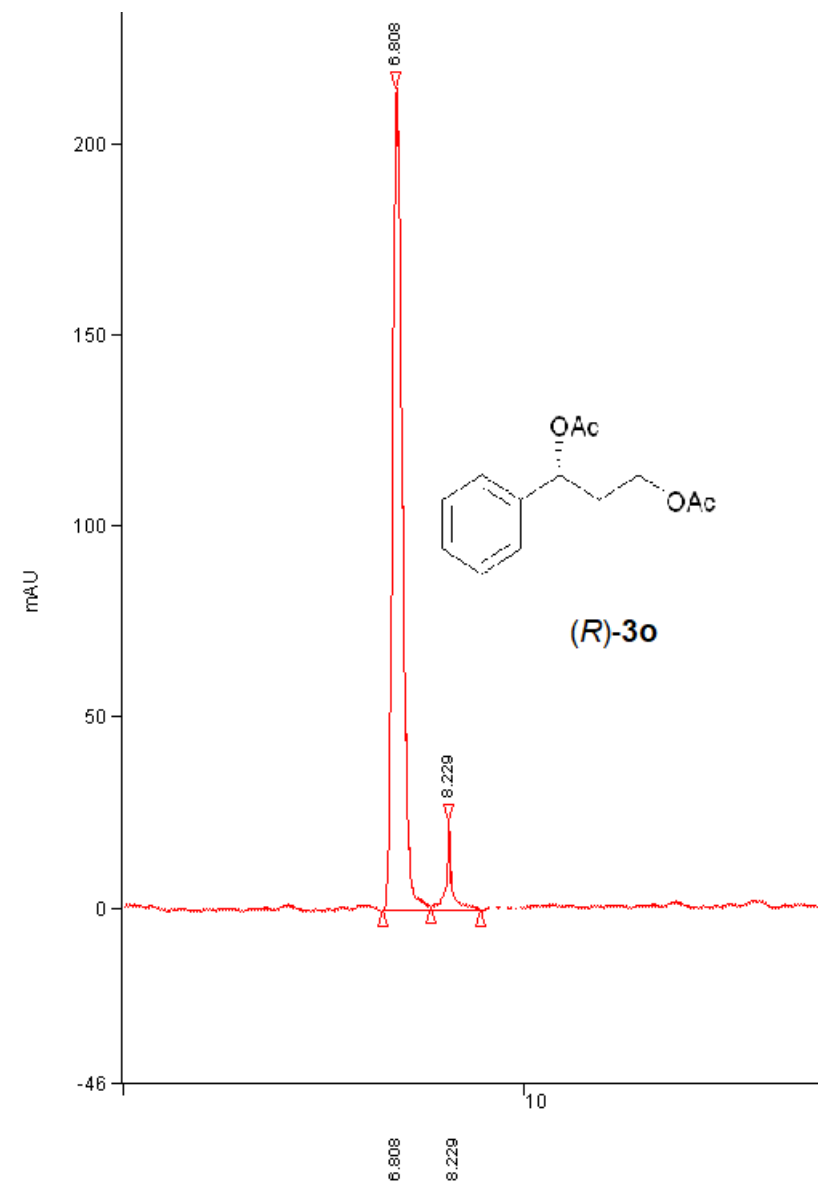

Fig S54. HPLC trace of $(R)$-1-phenylpropane-1,3-diyl diacetate $((R)$-(30) 


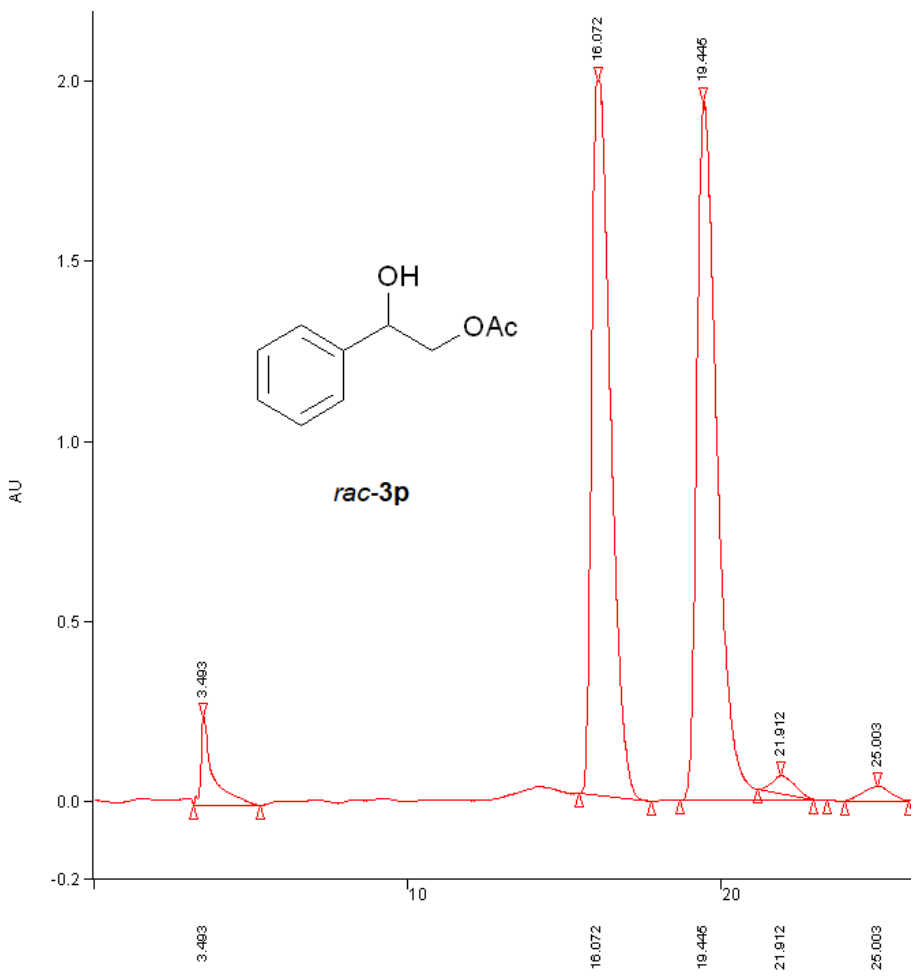

Fig S55. HPLC trace of rac-2-hydroxy-2-phenylethyl acetate (3p) 


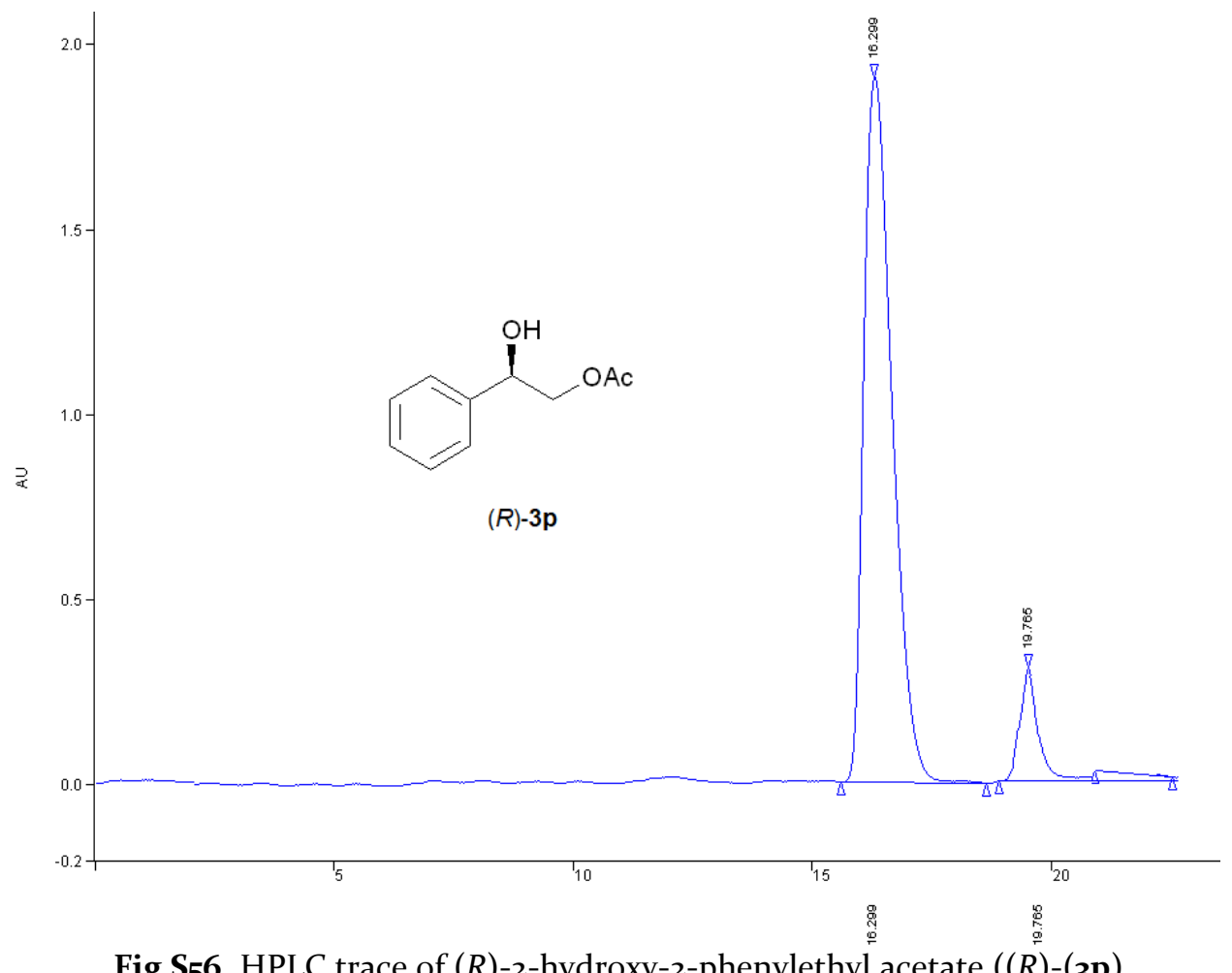

Fig S56. HPLC trace of $(R)$-2-hydroxy-2-phenylethyl acetate $((R)$-(3p)

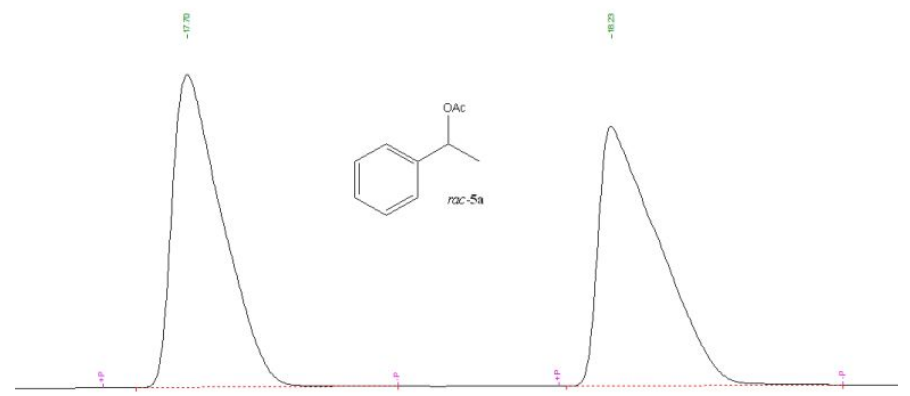

Fig S57. GC trace of rac-1-phenethyl acetate (5a) 


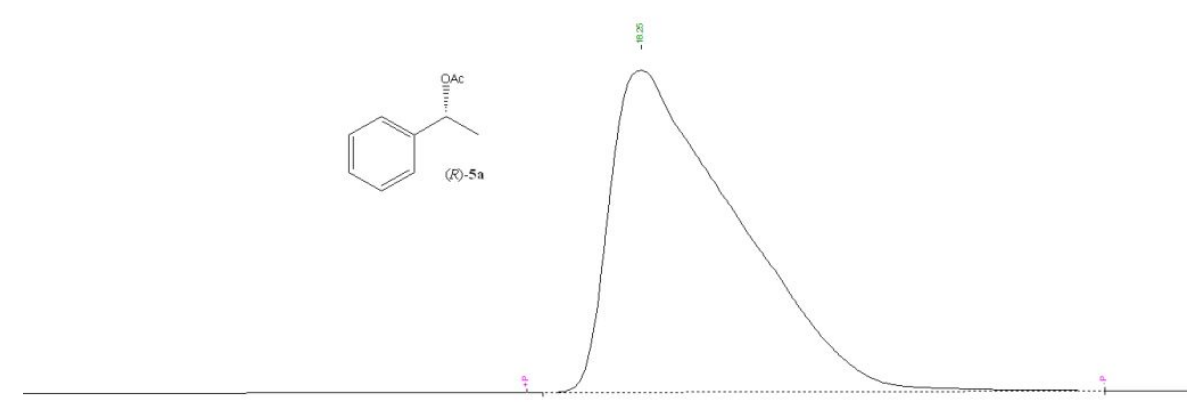

Fig S58. GC trace of $(R)$-1-phenethyl acetate $((R)$-5a $)$

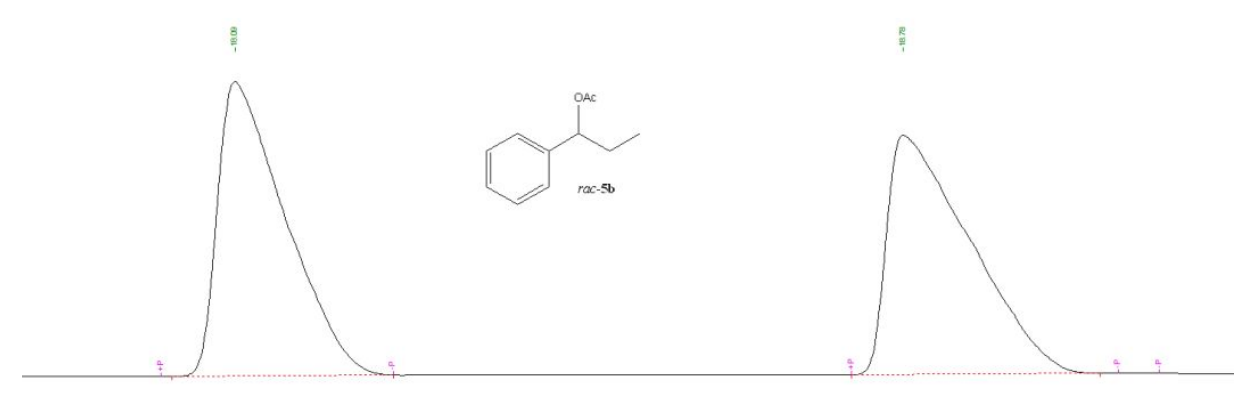

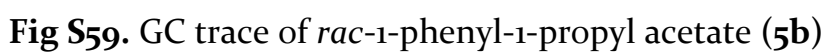

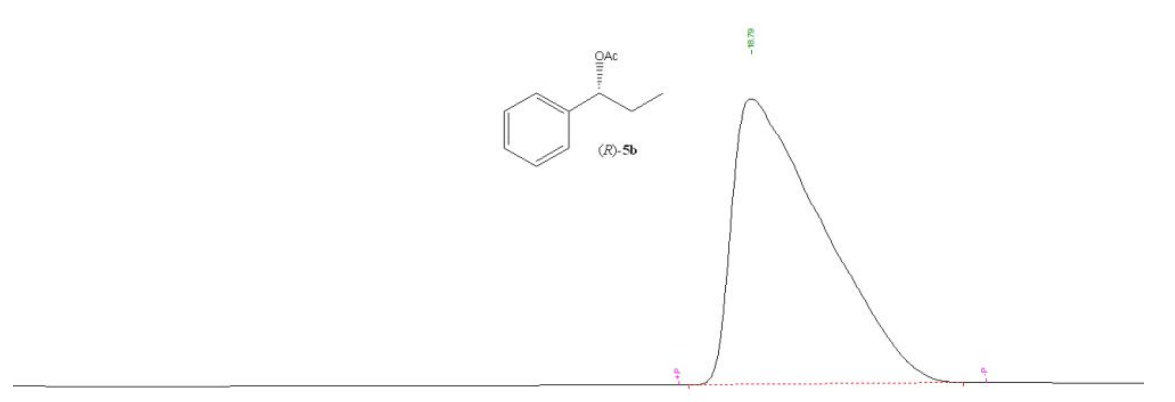

Fig S6o. GC trace of $(R)$-1-phenyl-1-propyl acetate $((R)-5 \mathbf{b})$ 


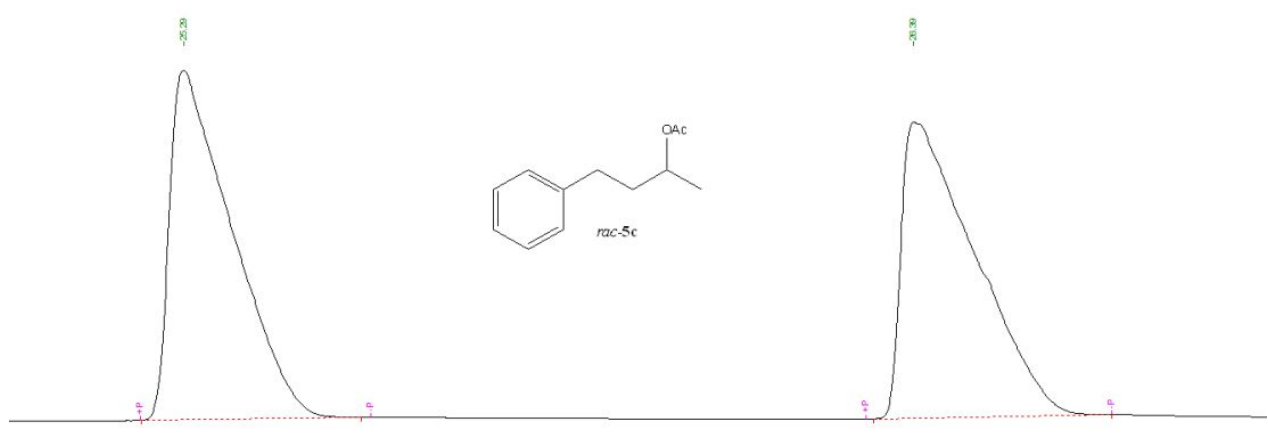

Fig S61. GC trace of rac-4-phenyl-2-butyl acetate (5c)

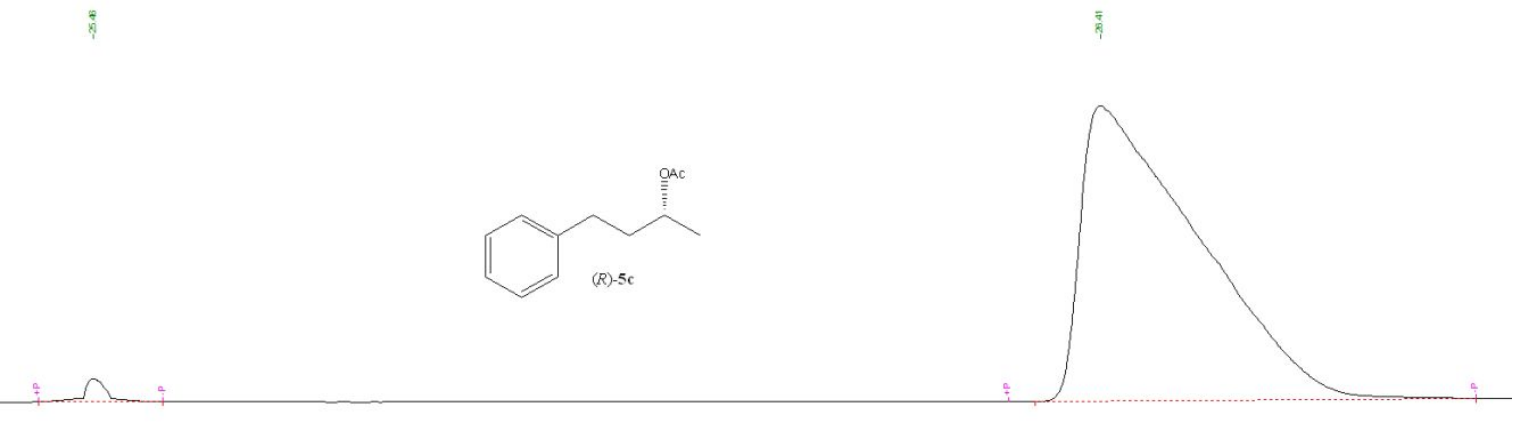

Fig S62. GC trace of $(R)$-4-phenyl-2-butyl acetate $((R)-5 \mathbf{C})$ 


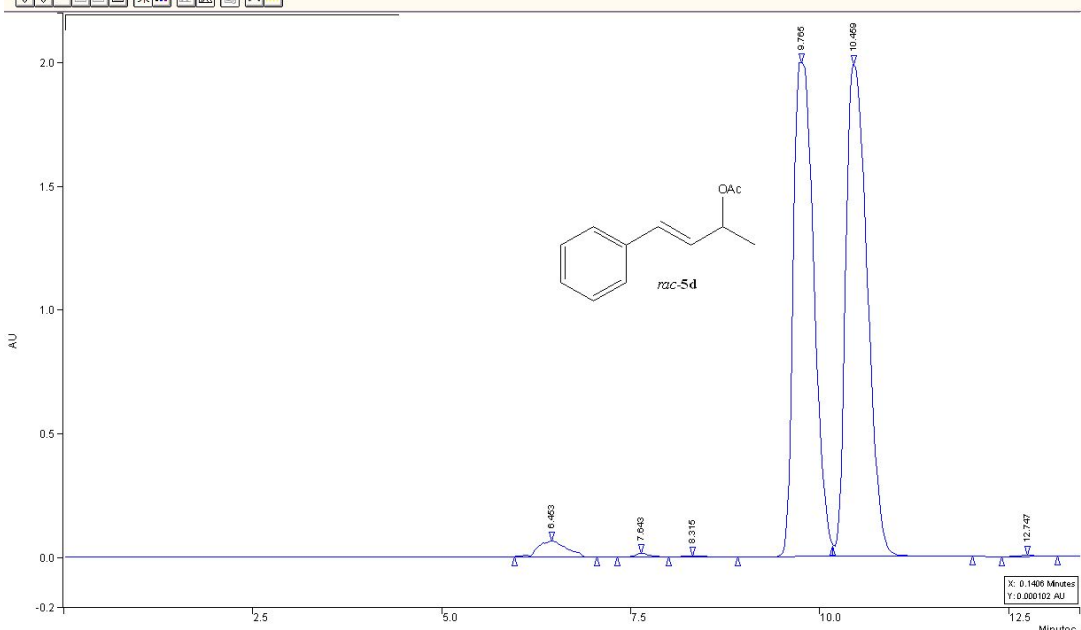

Fig S63. HPLC trace of (rac,E)-4-phenyl-3-buten-2-yl acetate (rac,E)-(5d)

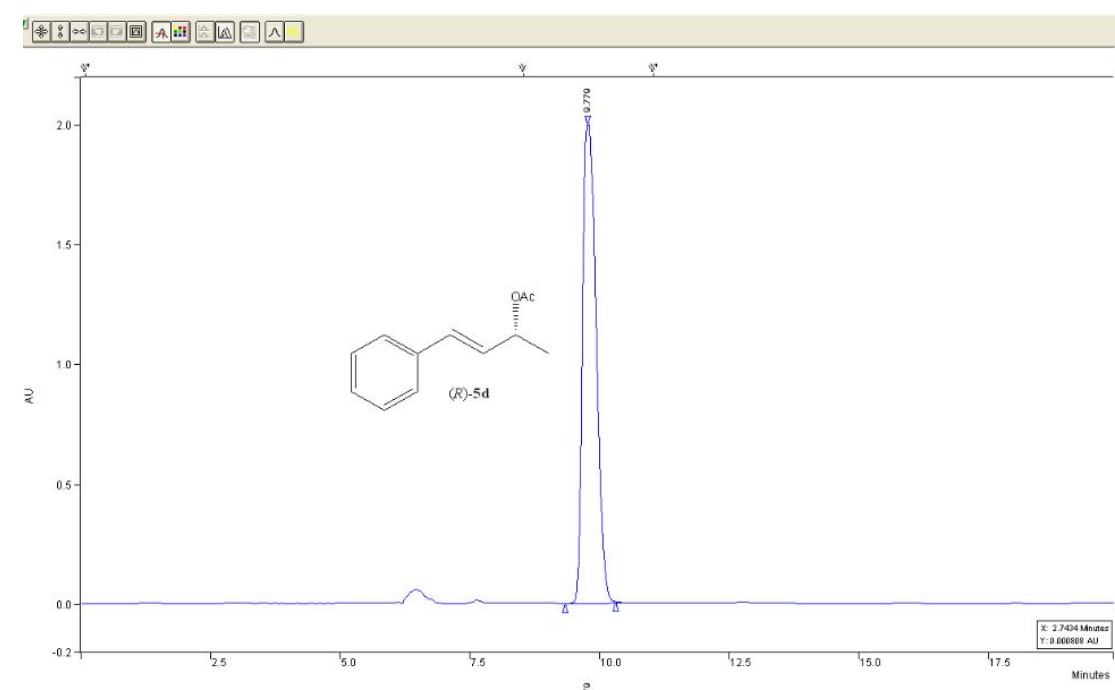

Fig S64. HPLC trace of $(R, E)$-4-phenyl-3-buten-2-yl acetate $((R, E)-5 \mathbf{d})$ 


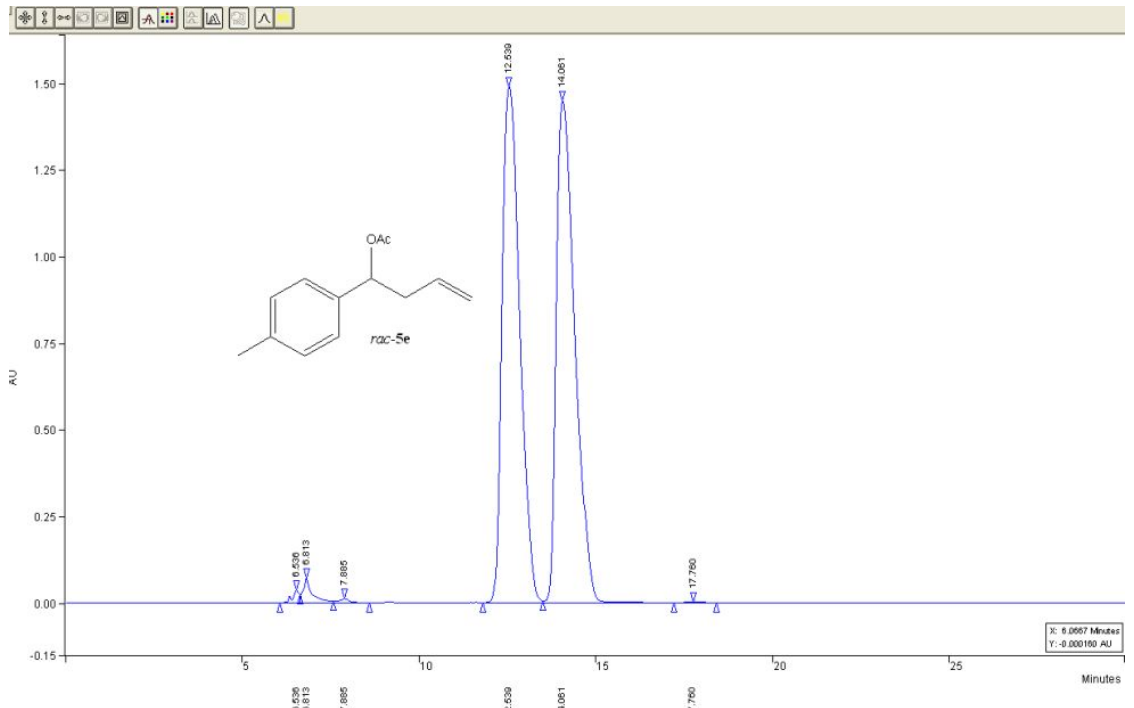

Fig S65. HPLC trace of ( $r a c)$-1-p-tolyl-but-3-enyl acetate (5e)

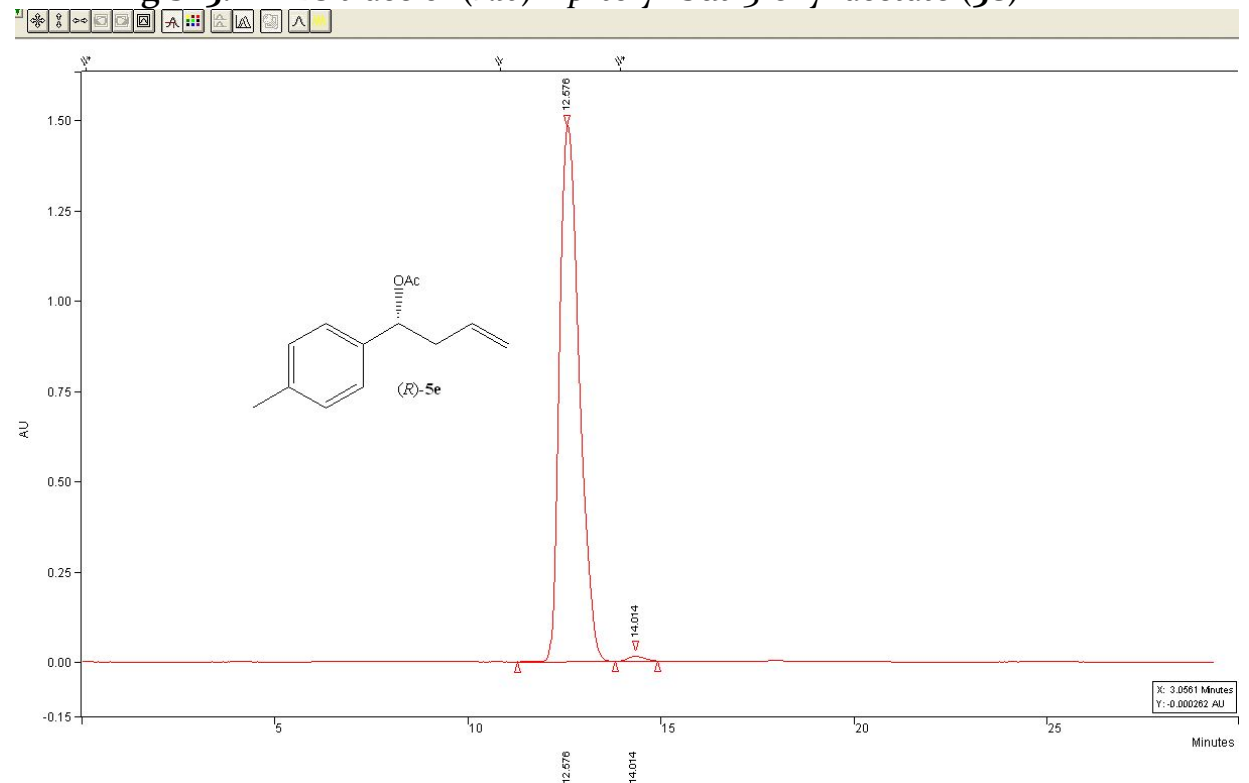

Fig S66. HPLC trace of $(R)$-1-p-tolyl-but-3-enyl acetate $((R)-5 \mathbf{e})$ 